\title{
ON CHARACTERISTICS AND DYNAMICS OF WATER-ROCK GLACIER INTERACTIONS IN MOUNTAIN AREAS (WESTERN ITALIAN ALPS)
}

by

Nicola Colombo

A thesis submitted to the Doctoral School of Sciences and Innovative Technologies and the Faculty of Graduate and Postdoctoral Affairs in partial fulfilment of the requirements for the degree of

\author{
Doctor of Philosophy \\ in \\ Earth Sciences and Geography \\ University of Turin, Turin, Italy \\ Carleton University, Ottawa (Ontario), Canada
}

(C) 2017

Nicola Colombo 


\section{University of Turin}

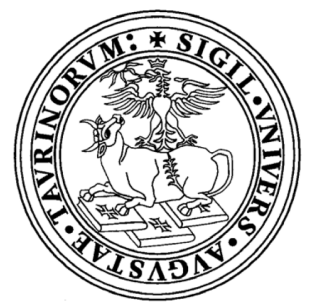

Doctoral School of Sciences and Innovative Technologies

Doctorate in Earth Sciences

(XXIX Cycle)

\section{ON CHARACTERISTICS AND DYNAMICS OF WATER-ROCK GLACIER INTERACTIONS IN MOUNTAIN AREAS (WESTERN ITALIAN ALPS)}

Candidate: Nicola Colombo

Tutors: Simona Fratianni, Marco Giardino, Michele Freppaz, Stephan Gruber

Ph.D. Coordinator: Prof. Anna Maria Ferrero

Years: 2014-2017

Scientific disciplinary sector: GEO/04 


\section{Abstract}

Permafrost degradation affects hydrochemistry of surface waters. In particular, evidence of modifications in water quality has been collected in mountain headwaters impacted by rock-glacier thawing. Rock glaciers are slowly flowing mixtures of debris and ice-rich permafrost, and can represent a reservoir of water. Melting ice inside them has been reported to affect surface water hydrochemistry, in some cases causing ecological damages. Investigating the mechanisms for this, however, requires understanding how, where and when rock glaciers and water bodies interact. Moreover, it is necessary to understand how atmospheric forcing can affect the export of physicochemical fluxes from rock glaciers. Different hypotheses have been proposed to explain the main driving weather-climate processes, nevertheless, they are still unclear.

With these goals, hydrology and structural setting of a rock glacier-pond system located in the NW Italian Alps were elucidated using waterborne geophysics (ground penetrating radar, electrical resistivity tomography and selfpotential) and heat tracing. An integrated study of atmospheric parameters (air temperature, snow cover duration, rainfall) and physicochemical characteristics of water (water temperature as a proxy of rock-glacier discharge, stable water isotopes, major ions and trace elements) was also performed in the pond on a high-resolution temporal basis (weekly) for two consecutive ice-free seasons.

The advancing movement of the investigated rock glacier has progressively filled the valley depression, creating a dam that could have modified the level of impounded water. A subsurface hydrological window connecting the rock glacier 
to the pond was also detected, where an inflow of cold underground waters from the rock glacier was observed. Here, greater water contribution from the rock glacier occurred following intense precipitation events during the ice-free season. An outflowing mechanism of the pond is hypothesised and might be associated with the presence of a subsurface seepage.

An intra-seasonal behaviour of solute export from the rock glacier into the pond was found, with increasing solute export associated with higher rock-glacier hydrological contributions. The key finding was the rainfall (after snowmelt depletion) as primary driver of solute export from the rock glacier during the thawing season after warm atmospheric periods, with the flushing of solutes stored in the rock glacier. 


\section{Contributions}

In this thesis, several collaborators helped in carrying out field and laboratory activities, and data elaboration.

Franco Salerno and Gaetano Viviano (CNR - National Research Council, IRSA - Water Research Institute) provided guidelines and helped with hydrological analyses.

Luigi Sambuelli (Polytechnic University of Turin, Department of Environment, Land and Infrastructure Engineering), Cesare Comina and Chiara Colombero (University of Turin, Department of Earth Sciences) performed the acquisition and processing of geophysical data.

Livia Vittori Antisari (University of Bologna, Department of Agricultural Sciences) carried out lacustrine sediment laboratory analyses.

Maria Martin (University of Turin, Department of Agricultural, Forest and Food Sciences) and Mery Malandrino (University of Turin, Department of Chemistry) supervised and helped with water physicochemical analyses.

Mark Williams (University of Colorado, Department of Geography) and Andrea Magnani (University of Turin, Department of Agricultural, Forest and Food Sciences) performed stable water isotopic analyses.

Danilo Godone (CNR-IRPI (National Research Council - Research Institute for Geo-Hydrological Protection) helped with the assessment of snow duration and field surveys.

Simona Fratianni, Marco Giardino (University of Turin, Department of Earth

Sciences), Michele Freppaz (University of Turin, Department of Agricultural, 
Forest and Food Sciences) and Stephan Gruber (Carleton University, Department of Geography and Environmental Studies) supervised and helped with the framework of the thesis. 


\section{Acknowledgments}

I would like to thank Emanuele Pintaldi, Diego Franco, Ilaria Mania, Elisa Giaccone, Elena Serra, Davide Viglietti, Marco Prati, Marco Bacenetti, Cristina Viani, Gioachino Roberti and Holly Hughes for their help in data acquisition, field work activities and laboratory analyses.

I am also grateful for the support given by Luigi Perotti (Department of Earth Sciences, University of Turin, Italy), Michele D'Amico, Roberta Gorra and Daniel Said Pullicino (Department of Agricultural, Forest and Food Sciences, University of Turin, Italy), Lino Judica and Adriana Bovio (Territorial Laboratory of Environmental Education, University of Turin, Italy), Ernesto Colombo, Lorena Bulla, Carina Schuh and Renée Leduc.

Finally, I give special thanks to the family Beck-Peccoz, Consorzio di Miglioramento Fondiario di Gressoney (Aosta) and MonteRosa-ski. 


\section{Table of contents}

Abstract I

Contributions III

Acknowledgments $\quad \mathrm{V}$

List of Tables $\quad$ XI

List of illustrations $\quad$ XII

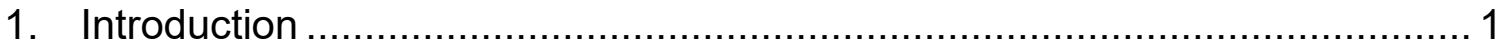

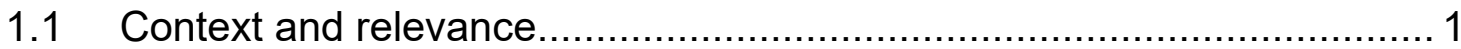

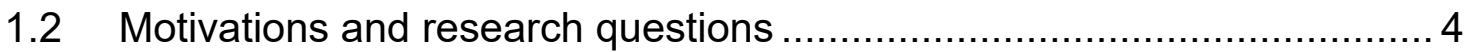

1.2.1 Hydrology and structural setting of a rock-glacier pond .................4

1.2.2 Atmospheric forcing of physicochemical fluxes from a rock glacier .. 6

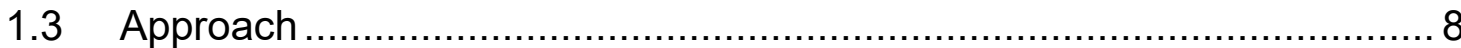

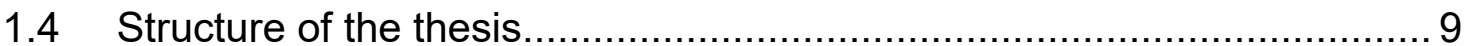

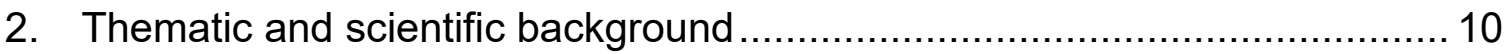

2.1 Permafrost, mountain permafrost and rock glaciers ....................... 10

2.1.1 Permafrost and mountain permafrost: definition and main

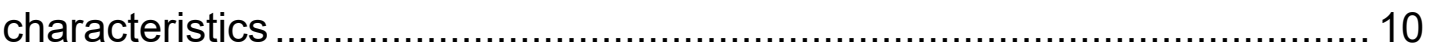

2.1.2 Rock glacier: definition and main characteristics .................... 13 
2.1.3 Rock-glacier hydrology at the landform scale

2.1.4 Rock-glacier hydrology at the catchment scale.

2.2 Inorganic solute dynamics and driving mechanisms in different

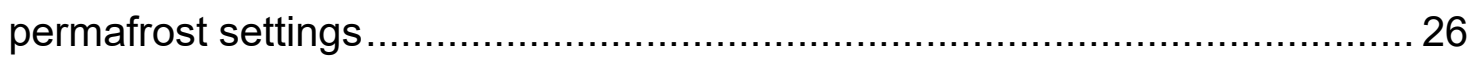

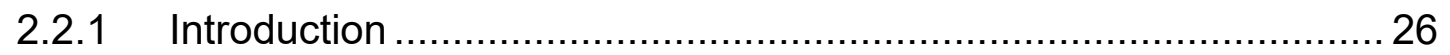

2.2.2 Geochemistry of near-surface permafrost and ground ice in high-

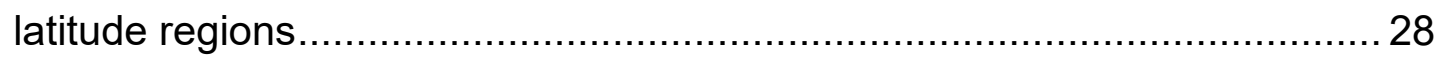

2.2.3 Geochemistry of rock glaciers ................................................. 42

2.3 Impacts of rock-glacier thawing on inorganic chemistry of surface fresh water 47

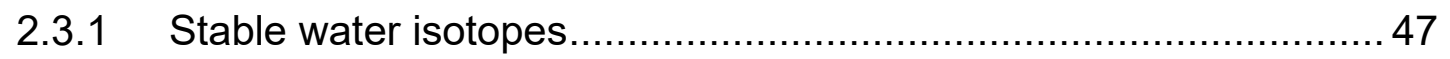

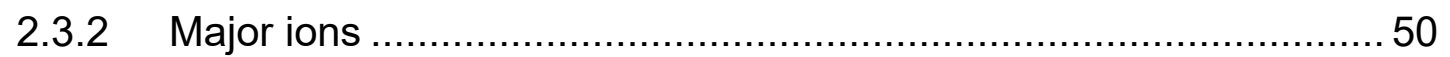

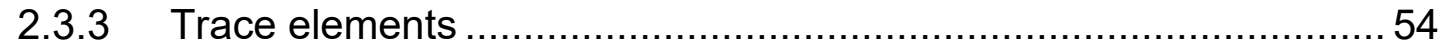

2.3.4 Driving processes for solute export........................................... 54

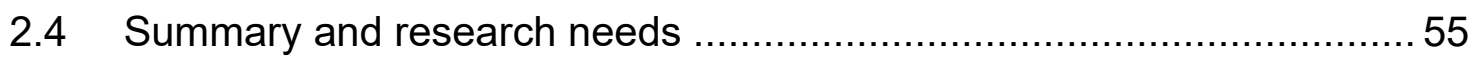

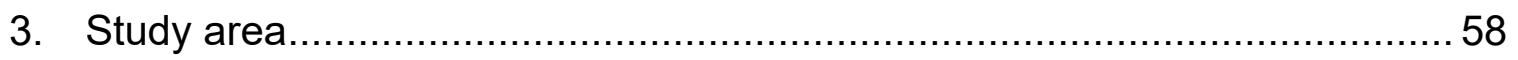

4. Methods: field measurements and laboratory analyses ............................64

4.1 Waterborne Ground Penetrating Radar (GPR) ............................... 64

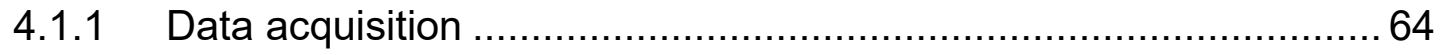

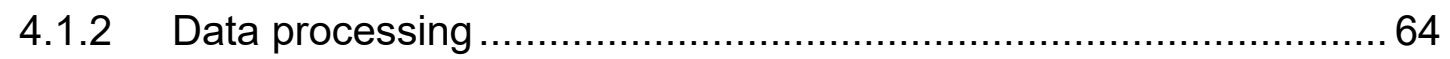


4.2 Waterborne Electrical Resistivity Tomography (ERT) and Self-Potential (SP) 67

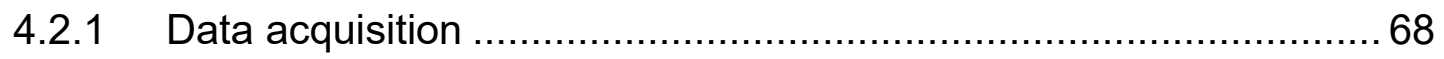

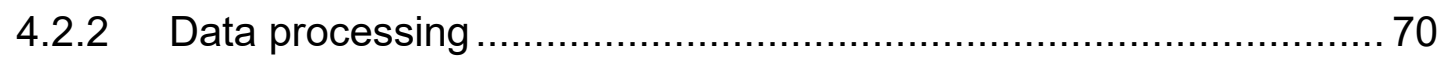

$4.3 \quad$ Lacustrine sediment properties ............................................... 71

4.3.1 Lacustrine sediment probing .................................................. 71

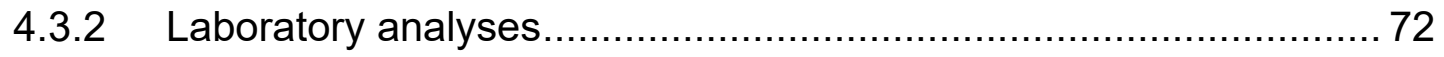

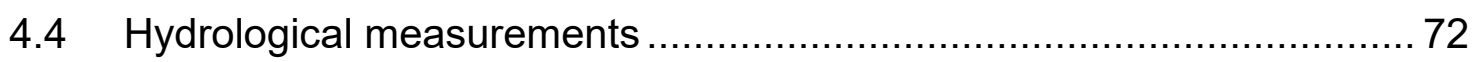

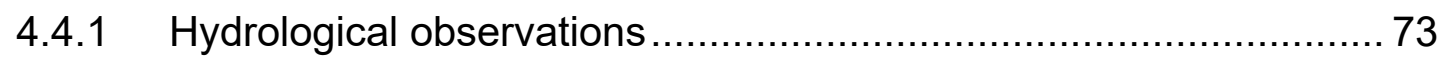

4.4.2 Water temperature and heat tracers .......................................... 74

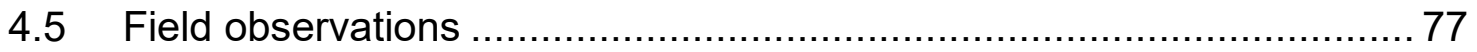

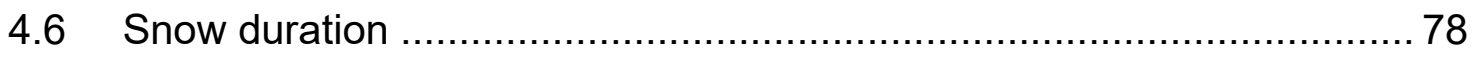

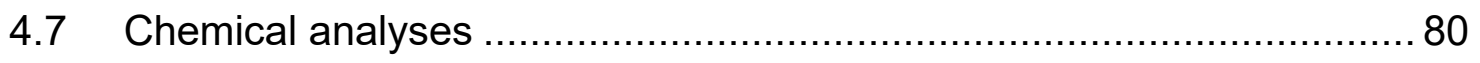

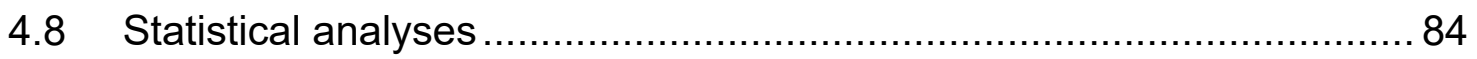

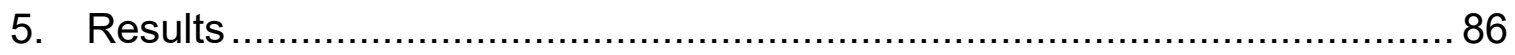

5.1 Hydrology and structural setting of the Col d'Olen Rock Glacier Pond.. 86

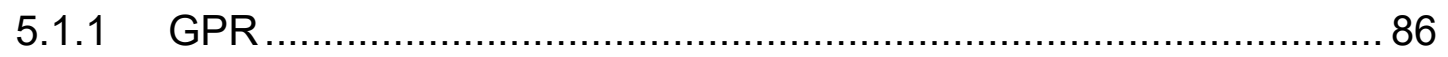

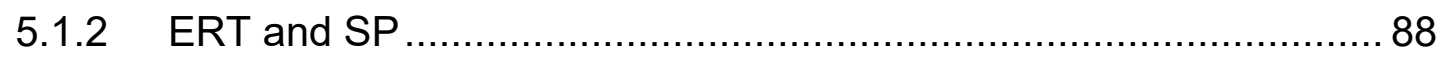

5.1.3 Lacustrine sediment properties ……....................................... 93

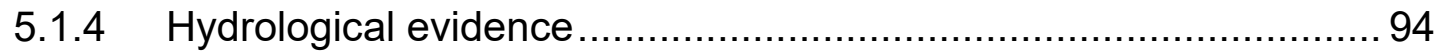


5.2 Atmospheric forcing of physicochemical fluxes from the Col d'Olen Rock Glacier. 99

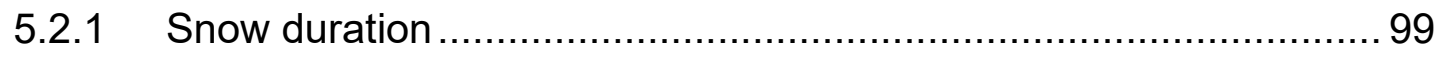

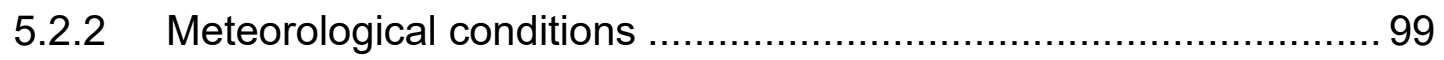

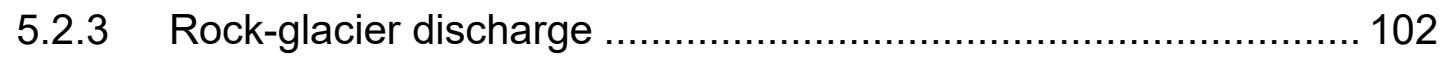

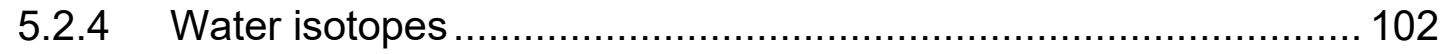

5.2.5 Water chemical composition .................................................... 104

5.2.6 Isotopic and geochemical relationships in the rock-glacier inflow area 108

6. Interpretation

6.1 Hydrology and structural setting of the Col d'Olen Rock Glacier Pond 112 6.1.1 Influence of rock-glacier geomorphological characteristics and structural setting in the evolution and potential subsurface outflowing dynamics of the pond

6.1.2 Subsurface hydrological connection between the rock glacier and the pond via intermittent inflow

6.2 Atmospheric forcing of physicochemical fluxes from the Col d'Olen Rock Glacier. 121

6.2.1 Export of solutes during rain events 122

7. Discussion 133

8. Conclusions and future research directions 


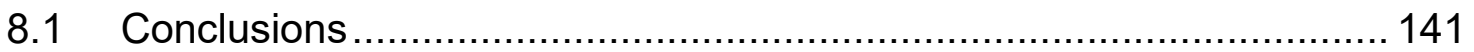

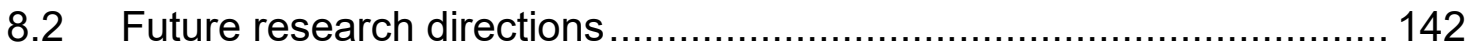

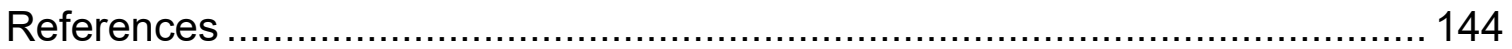

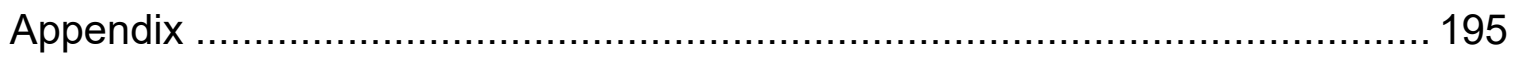




\section{List of tables}

3.1 Catchment, rock-glacier and pond morphometric

characteristics

5.1.1 Pond-water temperature profile

5.2.1 Isotopic measurements for the sampling sites

5.2.2 The $\delta^{2} \mathrm{H}-\delta^{18} \mathrm{O}$ relationship for the sampling sites

105

5.2.3 Solute concentrations in the sampling sites

106

5.2.4 Correlation matrix for measured variables of 20 sampling dates 


\section{List of illustrations}

2.1.1 Characteristic rock-glacier furrows and ridges at (a) Murtèl-Corvatsch (Swiss Alps) and (b) Gilpin Peak (Colorado, USA) 14

2.1.2 A hypothetical model of water flow through a rock glacier 21

2.1.3 Cascading system for a rock-glacier hydrological cycle 22

2.2.1 Excess ice content (a) and total soluble cation concentrations

(b) in active layer and near-surface permafrost at the Navy Road

site (Canada)

2.2.2 (a) Distribution of potassium in mineral layers close to the segregated ice lens in permafrost silt; (b) distribution of lead in the nature permafrost silt close to the ice lens

2.2.3 Vertical distribution of $\mathrm{SO}_{4}{ }^{2-}, \mathrm{Ca}^{2+}, \mathrm{Fe}, \mathrm{Mg}^{2+}, \mathrm{Na}^{+}$and $\mathrm{Al}$ within the active layer at Eagle Plains (Yukon Territory, Canada)

2.2.4 (a) $\delta^{18} \mathrm{O}$, deuterium excess (d) and total ion content (expressed as electrical conductivity, EC) across a horizontal transect in the massive ground ice body; (b) simplified model of slow closed-system freezing of an enclosed water body; (c) effects of radial freezing on bromine water and $\mathrm{KMnO}_{4}$ (potassium permanganate) solution

2.2.5 Geochemical profile of ice in a pingo in Tuktoyaktuk

Peninsula region (Canada)

2.2.6 Depth profile of the concentrations of $\mathrm{Na}^{+}$and $\mathrm{Cl}^{-}$in the glacier-derived ice-core section in the Foscagno Rock Glacier 
2.2.7 Vertical profile of conductivity in the core at the Lazaun

Rock Glacier, South Tirol (Italy)

2.3.1 Electrical conductivity, sulphate, calcium and magnesium concentrations in lake water of Rasass See and Schwarzsee ob Sölden lakes (1985-2005)

2.3.2 (a) Time series of nitrate in surface waters of the Green Lakes Valley, for 2003. (b) Time series of nitrate concentrations in the outflow of RG5 during the snow-free season from 1998 to 2004 . (c) Comparison of nitrate concentrations from the outflow of 7 rock glaciers and co-located surface waters

3.1 (a) Location of the study area in Italy. (b) Digital Terrain Model of the Valle d'Aosta Region and the location of the study area in the Region. (c) Elevation map of the Col d'Olen area. (d) Three-dimensional view of the rock glacier and the pond

4.1.1 (a) Tracks of the GPR surveys. (b) Pond bathymetry. (c) Fine sediment thickness.

4.2.1 ERT survey: (a) survey lines and (b) picture of the floating electrodes

4.6.1 Sensor regular grid

4.8.1 Model flow chart representing the applied methodological approach

5.1.1 GPR tracks in the pond: (a) $\operatorname{track} n^{\circ} 7,500 \mathrm{MHz}$; (b) track $n^{\circ} 6$, $200 \mathrm{MHz}$; (c) track $\mathrm{n}^{\circ} 2,500 \mathrm{MHz}$; (d) track $\mathrm{n}^{\circ} 11,200 \mathrm{MHz}$ 
5.1.2 Interpreted resistivity sections in the pond

5.1.3 3D fence diagram of the ERT inversions

5.1.4 (a) SP map of survey anomalies and (b) SP map superimposed to the $2000 \mathrm{Ohm} \bullet \mathrm{m}$ isosurface

5.1.5 Precipitation (as fresh snow and rain) and mean daily air temperature for 2014 (a) and 2015 (b). Pond relative water level during 2014 (c) and 2015 (d) (hydrometric observations)

5.1.6 Air and water temperatures during the investigated periods 2014 (a) and 2015 (b). Precipitation in 2014 (c) and 2015 (d). Rock glacier contribution at RG3 in 2014 (e) and 2015 (f)

5.2.1 Data series for the ice-free seasons 2014 (left) and 2015 (right). Snow height (HS) and percentage of catchment covered by snow from Landsat data (a-b). Mean daily liquid precipitation, fresh snow, air temperature, and water temperature at RG1, RG2 and RG3 (c-d).

Relative rock-glacier contribution in the pond (e-f). $d_{\text {excess }}$ values at RG1, RG2 and RG3 (g-h). EC values (i-l). SO ${ }_{4}{ }^{2-}$ concentration (m-n). $\mathrm{NO}_{3}{ }^{-}$concentration (o- $\left.p\right)$ 100

5.2.2 Data series for the ice-free seasons 2014 (left) and 2015 (right). $\mathrm{Mg}^{2+}$ concentration at RG1, RG2 and RG3 (a-b). $\mathrm{Ca}^{2+}$ concentration (c-d). Ni concentration (e-f). Mn concentration (g-h). Co concentration (i-I)

5.2.3 Summary of results: PCA among isotopes, $\mathrm{EC}$ and $\mathrm{pH}$, major ions and trace elements of 20 sampling dates 
6.1.1 (a1-a2) Simplified conceptual model of rock glacier-advance and progressive filling of the small valley depression. Deposit apron display on southern bedrock outcrop and associated potential modification of water level due to dam formation are also represented. (b) Hydrological dynamics of the rock glacier-pond system (profile representation - b) (planimetric representation - c).

(d) Increase in cold water export from the rock glacier after rainfall events at RG3 site

6.1.2 (a) Picture of the rock-glacier tongue flowing into the pond and deposit apron in the southern bedrock outcrop zone; (b) details of the deposit apron

6.1.3 (a) Large-scale structural evidence in the Col d'Olen area. (b)

Fine-scale structural evidence in the rock glacier area

6.2.1 Conceptual scheme of hypothesised internal structure of the rock glacier and main processes driving the export of physicochemical fluxes into the adjacent pond

Figure 1 (appendix) Snow melt-out date (MD) series 195 Figure 2 (appendix) $\delta^{2} \mathrm{H}-\delta^{18} \mathrm{O}$ relationship for the Local Meteoric Water Line (LMWL) and the 3 sampling points in the pond 196 Figure 3 (appendix) $\delta^{2} \mathrm{H}$ versus $\delta^{18} \mathrm{O}$ of LMWL (the regression line of the LMWL is reported) and sampling sites in the pond 


\section{Introduction}

\subsection{Context and relevance}

Permafrost is defined as ground (soil and/or rock, including ice and organic material, plus air/gas in unsaturated ground) that remains at or below $0{ }^{\circ} \mathrm{C}$ for at least two consecutive years (Muller, 1943). The global permafrost region (exposed land surface below which some permafrost can be expected) is estimated to be $22 \pm 3 \times 10^{6} \mathrm{~km}^{2}$, approximately $17 \%$ of the global land area (Gruber, 2012). Permafrost interacts with climate dynamics (Walter Anthony et al., 2006; Schuur et al., 2015), ecosystems (Jorgenson et al., 2001; Vonk et al., 2015) and human systems (Nelson et al., 2002; Harris et al., 2009).

The aggradation and degradation of permafrost usually occurs in association with a change of mean ground temperature due to microclimatic and climatic changes (Williams and Smith, 1989). Today, no doubt remains that the global average air temperature is dramatically increasing. Global warming over the past several decades is now large enough that regional climate change is emerging above the noise of natural variability (Hansen and Sato, 2016). Despite the small magnitude of warming relative to weather fluctuations, effects of the warming already have notable environmental, social and economic impacts. For this reason, the possible degradation of permafrost is seen as a major challenge in the current discussion of globally rising air temperature (IPCC, 2013).

Permafrost degradation has been reported to modify hydrochemical characteristics of surface fresh water across the world, such as in Arctic (e.g., Malone et al., 2013; Manasypov et al., 2014), sub-Arctic (e.g., Klaminder et al., 
2008; Giesler et al., 2014) and Antarctic (e.g., Harris et al., 2007; Gooseff et al., 2016) areas. Some studies also reported strong modifications in hydrochemistry of surface waters in mountain watersheds due to permafrost degradation in the Rocky Mountains (USA) (e.g., Mast et al., 2011) and European Alps (e.g., Thies et al., 2007).

Mountains occupy approximately one fourth of the global land surface areas. About $10 \%$ of the world's population depends directly on mountain resources for their livelihood and wellbeing and $40 \%$ depends indirectly on them for water, hydroelectricity and other ecosystem services (Zomer and Sharma, 2009). A large proportion of the global permafrost region is situated in mountain terrains, including densely populated areas such as the European Alps (Boeckli et al., 2012; Gruber, 2012). The global community recognised the importance of mountains at the United Nations Conference on Environment and Development (UNCED) in Rio de Janeiro in 1992. Mountains also represent unique areas for the detection of climatic change and the assessment of climate-related impacts (Nogués-Bravo et al., 2007) because of their particular vulnerability to the negative impacts of climate change, making them outstanding scientific field laboratories.

High-elevation lakes are a common feature of mountain environments and play an important role in the hydrological and chemical dynamics of mountain watersheds (e.g., Hauer et al., 1997; Catalan et al., 2006; Tolotti et al., 2009; Salerno et al., 2014). These lakes are also recognised as key freshwater reference sites for global scale processes, due to the common lack of direct 
human influence and because their physical, chemical, and biological properties respond rapidly to climate-related changes (Carpenter et al., 2007; Pham et al., 2008; Williamson et al., 2008; Adrian et al., 2009; Catalan et al., 2009; Mladenov et al., 2009; Lami et al., 2010). Usually, water bodies located in high mountain environments are characterised by small dimensions, and can be defined as ponds according to Hamerlík et al. (2014) (a threshold of $2 \times 10^{4} \mathrm{~m}^{2}$ exists between ponds and lakes). Their relatively low water volumes and high surface area to depth ratios make these features more fragile (Buraschi et al., 2005; Beniston, 2006). Finally, recent studies have demonstrated that ponds and lakes located in mountain permafrost areas have been affected by permafrost degradation, which modified their chemical status (llyashuk et al., 2014), especially in the context of climate change during the last decades (Thies et al., 2007).

Thus, the study of surface waters in mountain watersheds, especially highelevation ponds located in permafrost areas, is important due to their sensitivity to climate change (e.g., Beniston, 2006; Catalan et al., 2009; Hamerlík et al., 2014). Moreover, considering the recent modifications induced by climate change on high-elevation permafrost areas (e.g., Harris et al., 2009) and particularly on the physicochemistry of surface waters (e.g., Thies et al, 2007), they should be considered as key "field" laboratories for the study of climate change impacts on aquatic ecosystems. However, so far only a few studies exist that deal with permafrost dynamics and associated effects on the physicochemical 
characteristics of surface water in mountainous areas (e.g., Williams et al., 2006; Thies et al., 2007).

\subsection{Motivations and research questions}

\subsubsection{Hydrology and structural setting of a rock-glacier pond}

Active rock glaciers are widespread in mountain regions and contain ice-rich permafrost. They are slowly flowing mixtures of debris and ice which form by processes on a continuum from glacial to periglacial (for a review: Haeberli et al., 2006). Active rock glaciers can represent a reservoir of water (e.g., Corte, 1976; Azócar and Brenning, 2010; Millar et al., 2013) and can slowly release fresh water. Especially in arid areas and during low-flow conditions, they are likely to become increasingly important water sources under global-warming conditions (e.g., Brenning, 2005; Azócar and Brenning, 2010; Rangecroft et al., 2015). Their hydrological significance primarily relates to the long-term storage of frozen water, the seasonal storage and release of water, and the interaction with water flowing through or beneath them (Burger et al., 1999).

Rock glaciers, and lakes and ponds hydrologically connected with them can create specific ecosystems sensitive to climate change. Indeed, recent studies have pointed out an increase in electrical conductivity and metal concentrations in some lakes of the European Alps, ascribing these changes to solute release from active rock glaciers as a response to atmospheric warming (Thies et al., 2007; llyashuk et al., 2014). 
Hydrological studies on rock glaciers are rare (e.g., Krainer and Mostler, 2002; Berger et al., 2004; Krainer et al., 2007). Indeed, the hydrology of rock glaciers is complicated because of unknown flow paths, phase change and an irregular distribution of frozen material (e.g., Burger et al., 1999). Moreover, hydrological research on outflows of active rock glaciers is difficult, because most water often drains within the debris (Krainer and Mostler, 2002). The presence of multiple and often inaccessible springs can further increase uncertainties (Krainer et al., 2012) and where rock glaciers terminate in lakes or ponds, discharge is difficult to measure. Thus, how rock glaciers contribute to shaping high-elevation hydrological dynamics, specifically in affecting adjacent ponds, is barely known. Therefore, a better understanding of these periglacial hydrological systems and their links with impounded surface waters is required. The research question of this section is:

How do rock glacier geological and geomorphological characteristics influence hydrology of an adjacent pond?

A pond, in direct contact with a rock glacier, has been selected as a case study in the north-western Italian. In this context, waterborne geophysical methods can map hydrogeological information, correlating geophysical parameters to hydrological and geological properties through a non-invasive approach (e.g., Befus et al., 2012; Colombero et al., 2014). Moreover, the use of natural tracers such as heat (e.g., Schmidt et al., 2007; Constantz, 2008) can be 
helpful in discriminating among different water sources in impounded surface waters in remote and logistically difficult areas, without using invasive methods (Langston et al., 2013).

This thesis section provides new insights into the capability of a rock glacier to influence the evolution and hydrological behaviour of an adjacent pond both on temporal and spatial basis. Then, the application of waterborne geophysical techniques and their integration with non-invasive hydrological methods (heat tracers) in a high-elevation hydrological system are presented and evaluated.

\subsubsection{Atmospheric forcing of physicochemical fluxes from a rock glacier}

Active rock glaciers have been found to increase solute concentrations of Alpine mountain lakes (llyashuk et al., 2014) during recent decades (Thies et al., 2007). Seasonally, increased solute content has been reported in rock-glacier outflows from May to October (Krainer and Mostler, 2002; Williams et al., 2006; Krainer et al., 2007). Moreover, Thies et al. (2013) reported that outflows from rock glaciers can have high metal concentrations.

Generally, it is hypothesised that given the large mineral surface area in contact with ice within rock glaciers, the production of highly-concentrated chemical substances in these landforms is enhanced (Williams et al., 2006; Fegel et al., 2016), due to active chemical weathering (Ilyashuk et al., 2014). How this solute-rich water is released in response to seasonal or decadal changes in weather and climate is unclear. Thies et al. (2007) hypothesised atmospheric warming caused enhanced solute export via ice melt at depth, although the authors did not provide in-depth details about this process. Williams 
et al. (2006) hypothesised long-lasting snow cover reduces solute export by delaying subsurface melt, which is expected to release solutes, and by dilution of solute-rich water with snowmelt. Similarly, periods of summer rainfall correspond with lower solute contents (Krainer et al., 2007). By contrast, Thies et al. (2007) assumed rainfall to contribute to exporting solutes based on an intensification of water percolation in rock glaciers. In summary, warm periods correlate with increased solute export from rock glaciers. The responsible processes, however, are unknown and three hypotheses exist at present: (a) Warm periods cause increased subsurface melt, which releases solutes. (b) Dry periods reduce the input of meteoric water and thus reduce the dilution of rock-glacier outflow. (c) The percolation of meteoric water through the rock glacier exports solutes. Aiming to elucidate these processes, the research question is:

How is atmospheric forcing affecting the physicochemical fluxes from a rock glacier into an adjacent pond?

In this section of the thesis, the same rock-glacier pond located in the NW Italian Alps is considered, as in 1.2.1. Investigating a pond instead of a stream provides temporal integration of signals that might otherwise vary too quickly to be sampled adequately (Salerno et al., 2016). During the ice-free seasons 2014 and 2015, the rock-glacier pond was monitored weekly. Given its duration, this study is focused on weather rather than climate. The investigation of the connection between atmospheric forcing and solute export was performed by 
measuring the atmospheric variables (air temperature, rainfall, snowmelt) that were assume to exert control on the export of physicochemical fluxes from the rock glacier and the reaction of the pond (temperature, stable water isotopes, major ions and trace elements). Causal relationships between atmospheric forcing and pond response were investigated analysing the differences in measured variables among three sampling points in the pond (heterogeneous behaviour), considered representative of specific water sources.

\subsection{Approach}

Research related to the assessment of the relationships between hydrology and physicochemistry of impounded surface waters, and permafrost dynamics in high-elevation areas bears two main requirements: (i) multi-methodological and non-invasive approaches are required to overcome logistical difficulties and technical challenges, and to avoid human-induced modifications in the investigated pristine natural systems; (ii) high-temporal and -spatial resolution investigations are necessary in these remote areas to detect and quantify shorttime/fine-scale modifications induced by permafrost dynamics during the short ice-free seasons. Non-invasive in-situ field measurements, such as waterborne geophysics and natural heat tracers, and weekly sampling of waters for physicochemical laboratory analyses enable a diversity of challenges to be addressed. This thesis applies such approaches in order to investigate hydrological and physicochemical mechanisms linking surface waters and permafrost dynamics in mountain environment. 


\subsection{Structure of the thesis}

This thesis is organised in eight chapters: following the introduction in Chapter 1, Chapter 2 provides the thematic and scientific background necessary to understand the current state of research and the scientific problems that motivated the present work. The study area is described in Chapter 3. Methodological approaches of the thesis are described in Chapter 4, while Chapter 5 presents the results of the work. Interpretation and discussion of the results obtained are reported in Chapter 6 and 7, respectively. Chapter 8 provides the conclusions and suggests future research directions. Additional figures are reported in the appendix. 


\section{Thematic and scientific background}

\subsection{Permafrost, mountain permafrost and rock glaciers}

\subsubsection{Permafrost and mountain permafrost: definition and main characteristics}

Permafrost is defined as ground (soil and/or rock, including ice and organic material, plus air/gas in unsaturated ground) that remains at or below $0{ }^{\circ} \mathrm{C}$ for at least two consecutive years (Muller, 1943); this definition is based on temperature and not on the freeze-thaw state of water in the host medium (Woo, 2012). Permafrost can, but does not need to, contain water or ice. Most permafrost areas experience seasonal thaw, during which ground surface temperatures rise above $0{ }^{\circ} \mathrm{C}$. The layer of ground that thaws on a seasonal basis is called "active layer" (ACGR, 1988). Given its influence on energy exchange, hydrological processes, carbon budgets and natural hazards, permafrost has been identified as one of the key components of the global climate system (Harris et al., 2001; Gruber and Haeberli, 2007; Harris et al., 2009).

Permafrost regions can be divided into a continuous permafrost zone, where more than $90 \%$ of the surface area is underlain by permafrost, a discontinuous zone, of which $10 \%$ to $90 \%$ is underlain by permafrost, and a zone of isolated patches of permafrost, where permafrost occurs under less than $10 \%$ of the ground. The discontinuous zone is divided into extensive discontinuous permafrost $(90 \%$ to $50 \%)$ and sporadic discontinuous permafrost $(50 \%$ to $10 \%)$ (Heginbottom et al., 1995). The permafrost thickness is the distance between the 
permafrost table and the permafrost base (French, 2007). It is highly variable and generally ranges from $100-800 \mathrm{~m}$ in continuous permafrost, $25-100 \mathrm{~m}$ in discontinuous permafrost, and 10-50 m in sporadic permafrost (Anisimov and Reneva, 2006), with a maximum permafrost depth of $1,500 \mathrm{~m}$ measured in Yakutia (Russia), near the Arctic Circle (Devyatkin, 1993). In the European Alps, permafrost is 10 to several 100 m deep (Haeberli, 1992, Luethi and Funk, 2001, PERMOS, 2007), and the active layer is few meters thick (PERMOS, 2007).

The global permafrost region (exposed land surface below which some permafrost can be expected) is estimated to be $22 \pm 3 \times 10^{6} \mathrm{~km}^{2}$, approximately $17 \%$ of the global land area (Gruber, 2012). Zhang et al. (1999; 2003) estimated that permafrost region is nearly $25 \%$ of the land area of the Northern Hemisphere. Despite occupying only $0.36 \%\left(49,800 \mathrm{~km}^{2}\right)$ of the Antarctic region, permafrost is estimated to be virtually present beneath all ice-free terrain, except at the lowest elevations of the maritime Antarctic and sub-Antarctic islands (Vieira et al., 2010). Although mainly discontinuous or patchy, permafrost is also widespread in mountain ranges such as the European Alps (e.g., Boeckli et al., 2012), the Hindu Kush Himalaya (e.g., Gruber et al., 2017), and the Andes (e.g., Brenning, 2005).

Mountain permafrost is simply defined as permafrost in mountain areas and it can be situated at low or at high latitudes, in the Arctic or Antarctica. Mountain permafrost is a phenomenon that is governed by different factors and processes at and below the Earth's surface, that operate at three scale domains (Gruber, 2005): "Climate", "Topography" and "Ground". Climate is the governing factor 
determining air temperature, solar radiation and precipitation patterns at the continental scale (e.g., whole mountain chain). Climatic conditions are then further modified by topography, which plays a major role at regional scale (areas covering several square kilometres), determining the amount of solar radiation through geometric effects, differences in air temperature, and snow redistribution by avalanches and wind. At the local scale (e.g., zones of tens of square metres), ground material properties, air or water movement, ice presence, and snow cover distribution have an important influence on the total energy and mass exchange in the ground (e.g., Fuchs et al., 1978; Goodrich, 1982; Harris and Pedersen, 1998; Gruber and Hoelzle, 2008). The distinction between these scales and processes is not sharply defined. The effect that topography has on regional precipitation patterns, for instance, spans the scales of climate and topography, while the effect of snow redistribution on ground temperatures spans the scales of topography and ground conditions (Pogliotti, 2011). These factors and processes can greatly affect the thermal conditions of mountain terrains. For example, in the northern hemisphere, north exposed slopes receive only little solar radiation and are, therefore, significantly colder than nearby south facing slopes (Gruber et al., 2003, 2004). Further, the influence of ground cover characteristics and snow (and its high spatial variability) alters ground surface temperatures (Gubler et al., 2011; Gubler, 2013) and ground temperatures (Keller and Gubler, 1993) within small distances in mountain regions.

Permafrost is a subsurface and invisible phenomenon because of its purely thermal definition. However, mountain permafrost is also an important element of 
landscape evolution because of the characteristic landforms such as rock glaciers (details in 2.1.2 and 2.1.3), which are connected to its existence (Berthling, 2011), and because it affects long-term sediment transfer mechanisms (Barsch, 1977; Brenning, 2005; Otto et al., 2009). In particular, from an exclusively geomorphological standpoint, rock glaciers constitute prominent sedimentary linkages within the alpine environment, and as such modulate large segments of the coarse sediment cascade (Caine, 1974), contributing as much as $20 \%$ (Switzerland, Haeberli, 1985) to $60 \%$ (Colorado, Giardino et al., 1987) of alpine erosion.

\subsubsection{Rock glacier: definition and main characteristics}

Rock glaciers are distinctive and often abundant morphological features of high mountain regions. Rock glaciers are slowly flowing mixtures of rock debris and ice which are formed by a continuum of processes from glacial to periglacial (Haeberli et al., 2006). They are characterised by a distinctive surface topography of transversal and longitudinal ridges and furrows (Giardino et al., 1987) (Fig. 2.1.1). Contradictory opinions have been expressed regarding the origin of rock glaciers based on genetic and morphological criteria which were aligned with the perspectives (i.e., glacial and permafrost) of different researchers (Haeberli et al., 2006). Usually, rock glaciers are considered as the visible expression of long term creep of ice-rock mixtures under permafrost conditions, following the recent definition proposed by Berthling (2011). According to French (2007), the majority of rock glaciers discussed in the 


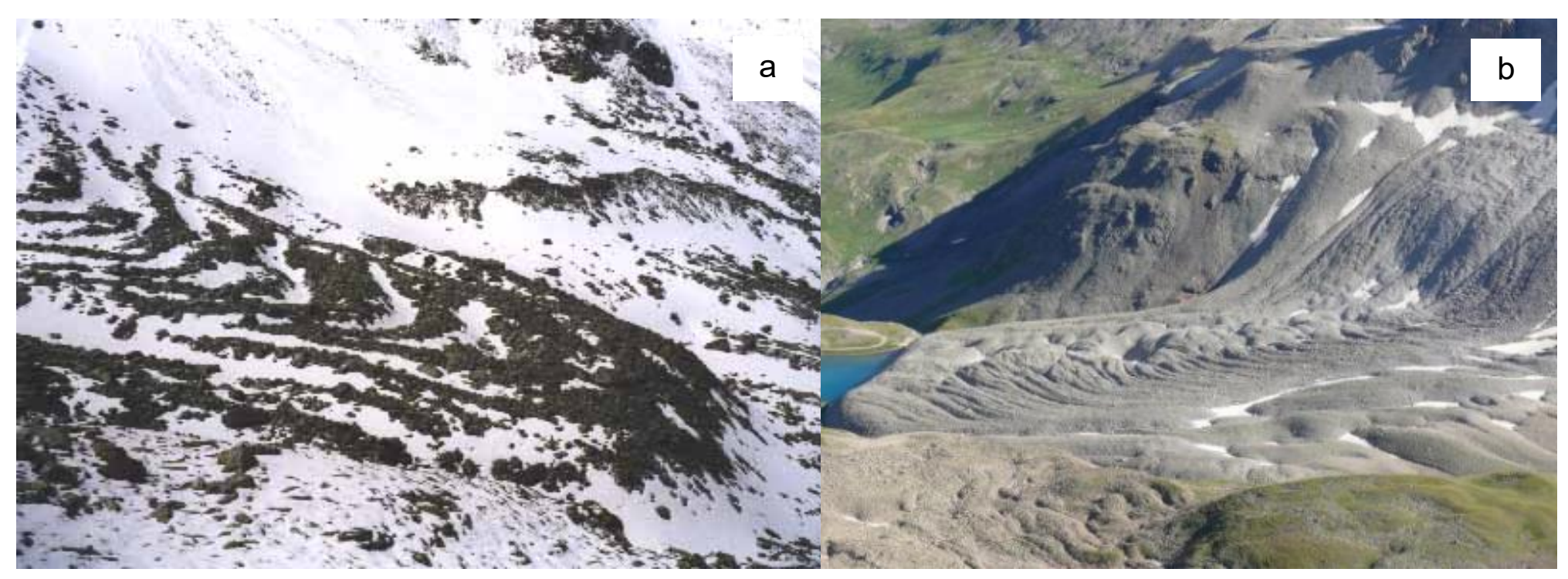

Figure 2.1.1. Characteristic rock-glacier furrows and ridges at (a) Murtèl-Corvatsch (Swiss Alps) (source: www.geo.uzh.ch) and (b) Gilpin Peak (Colorado, USA) (source: www.nsidc.org). 
literature are essentially periglacial, or permafrost related features, i.e., icecemented talus (Haeberli, 1985; Barsch, 1988). Rock glaciers can take several thousand years to develop, so their distribution can provide information about past occurrence of permafrost and related climatological characteristics (Humlum, 1998; Konrad et al., 1999; Rode and Kellerer-Pirklbauer, 2012; Millar et al., 2015). For this reason, rock glaciers are often used for mapping past and current permafrost conditions at macroscopic scales (Barsch 1978; Brenning, 2005; Brenning and Trombotto, 2006; Cremonese et al., 2011; Bollmann et al., 2015).

Rock glaciers are geomorphologically defined as tongue- or lobe-shaped bodies that are separated from their surrounding environment by steep frontal and side slopes. According to the debris source they are termed either talus rock glaciers or glacier-derived rock glaciers. However, the transition between the original landform (talus slope, or moraine) is usually not a sharp boundary, thus an exact discrimination of the onset of the rock glacier is often not easily achievable (Ribolini et al., 2010; Seppi et al., 2015).

The state of activity is also used as one classification criterion: active (moving), inactive (not moving, but still frozen) and relict (not moving, not frozen) (Barsch, 1996). Active rock glaciers typically creep few centimetres to a few metres per year (Kääb et al., 2003; Berger et al., 2004; Necsoiu et al., 2016; Scotti et al., 2017). The development of active rock glaciers typically requires: (i) a cold climate that warrants appropriate ground thermal conditions for the development of permafrost, but which is dry enough to prevent the formation of 
glaciers, and not too dry to prevent the formation of ice in rock glaciers; (ii) sufficient sediment supply deriving from upslope source areas such as rock walls and moraines; and (iii) topographic gradients that can support the creep of the rock-ice mixture (Barsch, 1996; Harris et al., 2009). Lichen growth and degree of vegetation colonisation, evidence of recent movement in the frontal slopes, and marginal slope angles can be used to infer the activity of rock glaciers (e.g., Barsch, 1996; Burger et al., 1999; Millar and Westfall, 2008). The activity of rock glaciers can be also inferred by using remote sensing and aerial imagery (e.g., Strozzi et al., 2004; Angillieri and Yanina, 2009), ground-based surveys (e.g., Konrad et al., 1999; Lambiel and Delaloye, 2004), and geophysical investigations (e.g., Ribolini et al., 2010; Seppi et al., 2015).

The ground thermal regime in rock glaciers is strongly affected by the presence of coarse material at the surface. Harris and Pedersen (1998) described the main processes driving the ground thermal regime in coarse materials: (i) The Balch Effect (Balch, 1990): cold air, being denser than warm air, tends to displace warm air in the pore space; (ii) The chimney effect: during winter, cold air enters into pore space through holes in the snow cover. Warmer air, displaced by the cold air, travels upslope eventually escaping through holes in the snow cover. For this reason, the upper part of a talus slope can often be warmer than the lower part; (iii) Summer time evaporation/sublimation of water/ice in the blocky deposit: latent heat is absorbed by the above mentioned processes, lowering temperatures at depth; (iv) Continuous air exchange with the atmosphere: nearly instantaneous cooling/warming of air in the pore space. The 
cooling effect of the coarse debris cover (Gorbunov et al., 2004) on rock glaciers can then enhance the formation of internal ice and can protect it from direct effects of solar radiation (Barsch, 1996; Haeberli, 1996; Delaloye and Lambiel, 2005; Juliussen and Humlum, 2008; Leopold et al., 2011).

In rock glaciers, regelation ice layers, sedimentary ice bodies (i.e., of glacial origin), alternating debris-ice layers deriving from avalanche and debris inputs, and a combination of these ice types can be found (Potter, 1972; Barsch, 1988; Clark et al., 1996; Guglielmin et al., 2004; Humlum et al., 2007; Stenni et al., 2007). The internal ice content in rock glaciers can vary considerably (Arenson et al., 2002), generally ranging from $40 \%$ to $70 \%$ for active rock glaciers (Barsch, 1977; Barsch, 1996; Haeberli and Vonder Mühll, 1996; Burger et al., 1999; Brenning, 2010; Humlum, 2000; Haeberli et al., 2006; Ikeda and Matsuoka, 2006; Hausmann et al., 2007). Based on ice distributions, Haeberli et al. (2006) proposed a threefold classification of rock glacier internal structure: (i) massive ice with dispersed debris and intercalated debris-laden ice, overlying a basal layer of rock; (ii) a few metres to tens of metres of debris-laden ice overlying massive ice; and (iii) ice/rock mixture throughout. Besides solid rock and ice, icerich core samples of rock glaciers contain air voids with a volumetric air content up to $25 \%$ (Wagner, 1990; Arenson et al., 2004). Thus, zones of circulating water or air can exist within or below the permafrost body of a rock glacier (Haeberli et al., 2006). Above the permafrost body, active-layer thicknesses are typically reported to range from $0.5 \mathrm{~m}$ to $3 \mathrm{~m}$ (Barsch, 1996; Vonder Mühll, 1996; Wagner, 1996; Humlum, 1997; Isaksen et al., 2000). 
Compared to glaciers, rock glaciers are believed to be less sensitive to rising temperature due to insulation of debris mantles (Barsch, 1996). However, there are also emerging observations suggesting that rock glaciers in the European Alps have increased flow rates in response to climate change (e.g., Roer et al., 2005; Delaloye et al., 2008; Ikeda et al., 2008; Scapozza et al., 2014; Scotti et al., 2017). For instance, Kääb et al. (2007) modelled rock-glacier response to warming surface temperatures, establishing a link between warmer permafrost and increased flow velocity in a preliminary phase. In a later phase, the significant loss of ice content by permafrost degradation is able to reduce the deformation rate of the rock glacier towards its entire deactivation. Bodin et al. (2009) evidenced increasing flow velocity after monitoring climate change and movement of a rock glacier in the French Alps over a 20 -year period. Moreover, Bodin et al. (2009) noticed that two high snow fall seasons split by an abnormally warm summer were followed by the rock-glacier surface dropping, indicating the potential loss of ice. Heavy rainfall events during the summer can contribute in increasing rock-glacier velocity, likely due to thermal advection and increase in pore water pressure (Wirz et al., 2016). Finally, due to global warming, melting of the internal ice in rock glaciers may represent an increasing hydrological contribution to downstream areas (Brenning, 2005).

\subsubsection{Rock-glacier hydrology at the landform scale}

Few studies investigated the water discharge from rock glaciers at the landform scale (e.g., Krainer and Mostler, 2002; Berger et al., 2004). Water from rock glaciers is usually released at springs at the snout, flowing off within the debris. 
Mostly, outflows consist of single surficial streams, subordinately groundwater (Berger et al., 2004). Generally, spring/early summer runoff is dominated by intense snowmelt on warm days, summer runoff is dominated by rainfall, and late summer/early fall runoff is dominated by icemelt and groundwater (Krainer and Mostler, 2002; Berger et al., 2004). Williams et al. (2006) annually quantified, through geochemical and isotopic analyses, the different components of a rockglacier outflow in Colorado: $30 \%$ was snowmelt, $32 \%$ was soil water, and $38 \%$ was baseflow, which includes icemelt. The seasonal variation of primary sources in rock-glacier discharge can be classified as follows: (i) Fall to late winter: the active layer is frozen, discharge originates from groundwater; (ii) Late spring to early summer: direct and through flow from snowmelt; (iii) Summer: seasonal ground ice melt within the active layer (which is not part of the permafrost), throughflow from summer rainfall, minimal amounts of groundwater and icemelt; (iv) Late summer to early fall: icemelt and groundwater. This classification is derived from previous research based on qualitative studies rather than built on reliable measurements of individual system components combined with quantitative measurements, thus, it must be considered carefully.

Discharge is usually characterised by strong diurnal and seasonal variations, primarily driven by weather conditions, showing high peaks associated with melting of snow and rainfall events (Johnson, 1981; Haeberli, 1985; Krainer et al., 2007; Krainer et al., 2012). There is a progressive decline in discharge through summer and fall to low or zero flow during the winter (Evin and Assier, 1983; Tenthorey, 1993; Gardaz, 1998). A high portion of the summer rain runs off 
directly over the surface of rock-glacier frozen bodies, because the debris layer is bare of vegetation, coarse-grained and highly permeable, and the frozen body below the debris layer slows the infiltration of rainwater into the ground (Krainer and Mostler, 2002). Supra-permafrost flow and channelised flow along networks of conduits both allow the discharge to respond rapidly to weather inputs, with discharge peaks delayed 3-15 hours after snow melt peaks due to high air temperatures or rainfall (Johnson, 1981; Tenthorey, 1993; Krainer and Mostler, 2002); this type of contribution can be defined as "quickflow". Conversely to quickflow, baseflow has characteristics of water storage with water that can be stored for days, months or years inside and below the rock glaciers (Tenthorey, 1992; Harris et al., 1994; Burger et al., 1999); in this case, active layer allows infiltration beyond the large blocks into a matrix of finer elements, contributing into rock-glacier outflows days later (Harris et al., 1994) or supplying rock-glacier groundwaters (Tenthorey, 1992).

Discharge timing is also highly variable due to flowpaths changing in space and time. For instance, water release can be delayed during the warm season due to the thickening of the active layer (Williams et al., 2006; Buchli et al., 2013), or after several years of changes in permafrost conditions (Mari et al., 2013). Thus, multiple sources and flowpaths (Fig. 2.1.2) can contribute in determining the temporal characteristics of discharge. Giardino et al. (1992) suggested that the rock-glacier hydrological cycle can be viewed as a cascading system in order to define the way water moves through the landform (Fig. 2.1.3). 


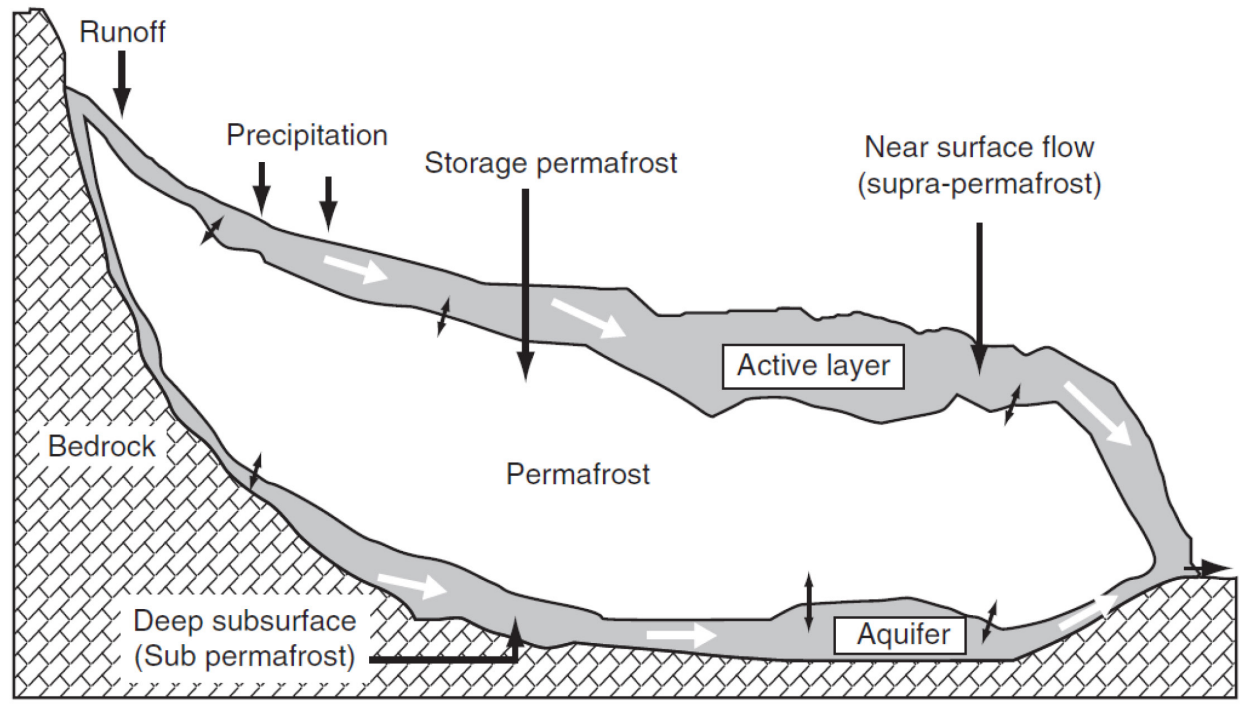

Fig. 2.1.2. A hypothetical model of water flow through a rock glacier. Runoff originates from rockwalls above the rock glacier. Adapted from Giardino et al. (1992). 


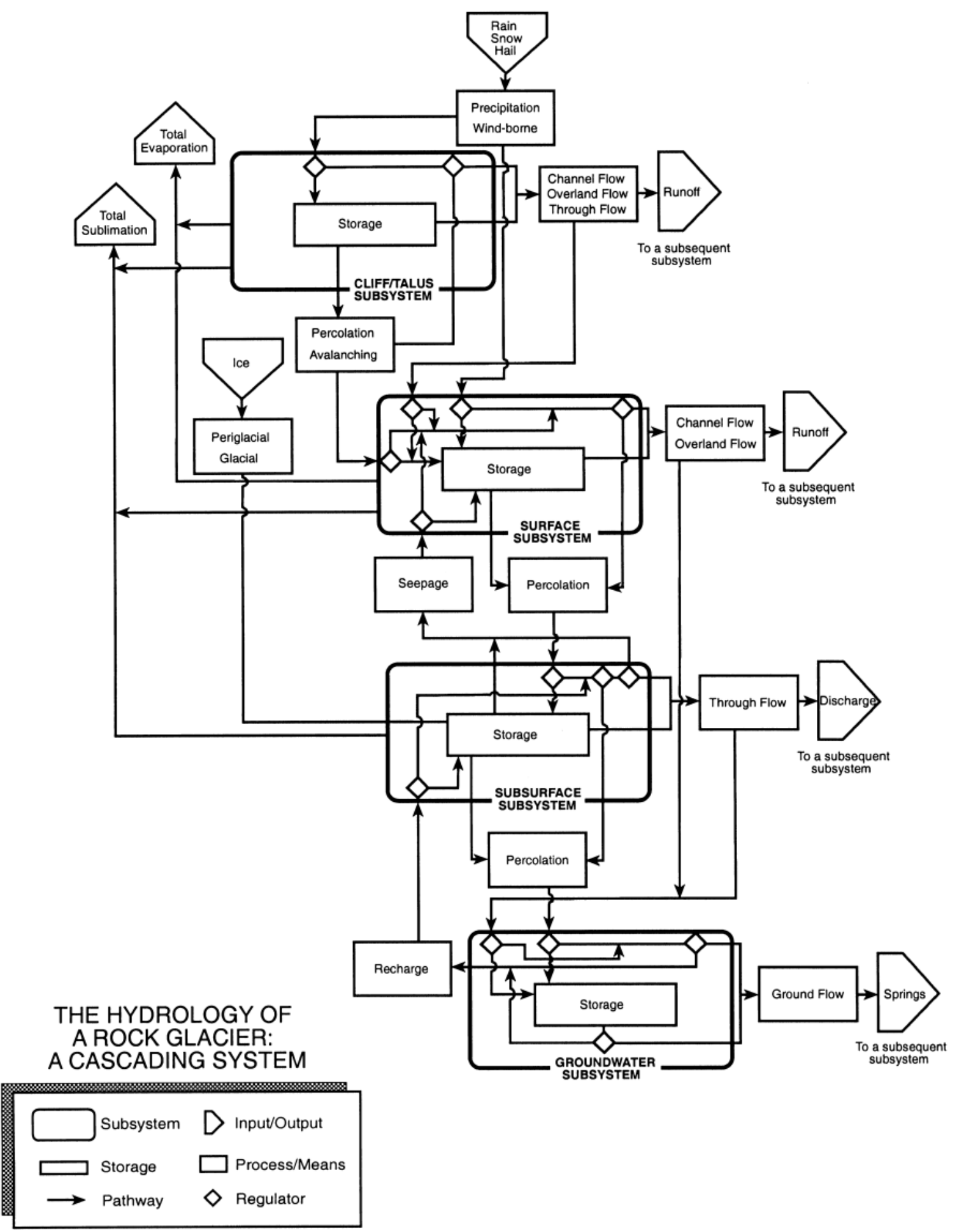

Fig. 2.1.3. Cascading system for a rock-glacier hydrological cycle. From Giardino et al. (1992). 
The cascading system is comprised of four interrelated subsystems: cliff and talus, surface, subsurface, and ground water. The output from one subsystem provides input to another subsystem. Again, these sources and flowpaths have been studied on qualitative basis and are strongly based on empirical assumptions, lacking of reliable quantitative measurements.

Water temperatures in the outlet streams at the termini of active rock glaciers have been found to be constantly near freezing during the whole melt season (Krainer and Mostler, 2002; Berger et al., 2004; Williams et al., 2006; Krainer et al., 2007; Carturan et al., 2016), caused by the direct contact of the water to an ice or permafrost body, and/or by ground ice melting (Haeberli, 1975). Water temperature in rock-glacier outflows usually shows very small temporal variability (Harris et al., 1994; Krainer and Mostler, 2002; Seppi, 2006; Williams et al., 2006; Millar et al., 2013; Carturan et al., 2016).

\subsubsection{Rock-glacier hydrology at the catchment scale}

Rock glaciers have been widely reported to be an important source of fresh water, especially in arid areas and during low flow conditions (e.g., Corte, 1976; Brenning, 2005; Bolch and Marchenko, 2006; Azócar and Brenning, 2010; Millar

et al., 2013; Rangecroft et al., 2013; Janke et al., 2015; Rangecroft et al., 2015). However, dissent has been recently emerging about the relationship between rock glaciers and their hydrological significance at catchment and coarser scales (Duguay et al., 2015). 
Generally, rock glaciers have been described to store significant volumes of water (Johnson, 1981; Haeberli, 1985; Haeberli and Vonder Mühll, 1996; Gardner and Bajewsky, 1987; Bajewski and Gardner, 1989; Giardino et al., 1992; Schrott, 1996; Burger et al., 1999; Clow et al., 2003), spanning seasonal to millennial temporal scales of storage, and covering a much greater area than glaciers in some regions (Azócar and Brenning, 2010). Some authors reported that discharge from rock glaciers can be similar to or even greater than discharge from glaciers of similar size, strongly contributing to mountain-watershed hydrology (Corte, 1978; Gardner and Bajewsky, 1987). Conversely, Krainer and Mostler (2002) and Krainer et al. (2007) suggested that the hydrological contribution of rock glaciers to stream flow is negligible, indicating that a majority of the runoff was derived from snowmelt and rainfall events. The authors also stated that the presence of active rock glaciers in high-alpine catchments exerts little influence on the total runoff due to the relatively small amount of meltwater derived from melting of ground ice. Arenson and Jakob (2010) and Duguay et al. (2015) further supported this, affirming that the only way rock glaciers could be able to supply water to downstream users would be by permafrost degradation and the release of water from ground ice. Due to the slow conduction of heat through the ground and latent heat effect, the degradation of rock glaciers is a slow process. Thus, even in climatic disequilibrium conditions, rock glaciers might not be able to contribute substantially to the hydrological cycle of a mountain catchment. 
Geiger et al. (2014) better defined the rock-glacier influence on hydrology of alpine catchments. Specifically, the authors showed that flood peaks occur later after the onset of precipitation, peaks are higher, and total surface runoff is greater in a rock-glaciated basin than in a non-rock-glaciated basin. In a nonrock-glaciated basin, peaks occur much faster and the total amount of precipitation leaving the basin as stormflow is significantly less than in a rockglaciated basin. Thus, rock glaciers have the net effect of increasing total surface runoff from alpine drainage basins due to the limited losses to deep groundwater storage. Nevertheless, the net contribution of icemelt to the whole rock-glacier contribution was not significant, as demonstrated by the gradual decrease of the discharge from the investigated rock glacier through the summer, even with the onset of higher temperatures, thus confirming the importance of the coarse debris layer in insulating rock glaciers from atmospheric temperatures.

Great uncertainty exists about the role of rock glaciers in influencing the hydrological regime of high-elevation mountain catchments. Different factors might have contributed in creating this situation: (i) unknown and variable ice content in rock glaciers; (ii) omission or underestimation of main physical processes acting on rock-glacier dynamics such as slow heat diffusion at depth, retarding effect of latent heat in melting ice, and complex heat exchange processes between the atmosphere and the ground driven by coarse-grained active layer, which led researchers to overestimate the potential role of icemelt in catchment hydrology; (iii) the majority of works devoted to the study of rockglaciers hydrology based their conclusions on qualitative information with no 
quantitative data support, also ignoring a multitude of other surface and subsurface water sources; (iv) many conclusions have been drawn comparing different settings such as rock glaciers in arid vs. humid climates and small vs. large catchments.

\subsection{Inorganic solute dynamics and driving mechanisms in different permafrost settings}

\subsubsection{Introduction}

Several studies have investigated the impacts of global warming on permafrost inorganic solute release and its effects on water characteristics, and on soil chemistry and vegetation growth. For instance, it has been demonstrated that physical disturbances in ice-rich permafrost terrains such as retrogressive thaw slumps (e.g., French, 1974) and active layers detachments (e.g., Lewkowicz, 2007) can dramatically increase solute concentrations in surface waters in Arctic and sub-Arctic areas (Kokelj et al., 2005, 2009; Bowden et al., 2008; Kokelj et al., 2013; Malone et al., 2013). Moreover, Gooseff et al. (2016) showed how newlydeveloped thermokarst features adjacent to a stream channel in Antarctica can increase the amount of solute concentrations in the affected channel.

Lafrenière and Lamoureux (2013) and Lamhonwah et al. (2017) found that thermal perturbations and summer rainfall runoff can alter the seasonal solute export more than localised physical disturbances of the active layer, enhancing the formation of high solute loads in Arctic permafrost catchments, especially after warm summer conditions. Other studies demonstrated the importance of 
temperature, soil moisture, summer rainfall events and active layer deepening in enhancing high solute flux as a result of increased subsurface weathering and the subsequent transport of ions released from thawing permafrost (Everett et al., 1989; Dugan et al., 2009; Harms and Jones, 2012).

As a response to climate warming, also surface waters in mountain permafrost areas in the European Alps have recently become impacted by the rising export of major ions and heavy metals from active rock-glacier meltwaters (Thies et al., 2007; Ilyashuk et al., 2014). Similar trends were found in another mountain area by Williams et al. (2006) who analysed major ion contents in a rock-glacier outflow in Colorado, USA.

Permafrost degradation can also influence soil chemistry and vegetation dynamics. For instance, degradation of saline permafrost might result in soil salinization and inhibit vegetation growth, but thawing of $\mathrm{Ca}^{2+}$-rich permafrost may enhance soil conditions and improve productivity (e.g., Mackay, 1995; Kokelj et al., 2002; Ukraintseva et al., 2003; Lacelle et al., 2007).

Thus, due to the potential effects of climate change on permafrost degradation and inorganic solute release, the understanding of solute dynamics in permafrost must be considered of fundamental importance. This chapter examines inorganic solute dynamics and their driving mechanisms in different permafrost settings and synthesizes the current knowledge from diverse published sources. It focuses on two topics that currently reflect the main interests in this research field: (i) geochemistry of near-surface permafrost (with a particular focus on 
segregated ice) and ground ice (ice wedges, multi-origin massive ground ice bodies and pingos) in high-latitude regions, and (ii) geochemistry of rock glaciers.

\subsubsection{Geochemistry of near-surface permafrost and ground ice in high- latitude regions}

\section{Geochemistry of frozen soil and ice in near-surface permafrost}

The majority of the literature on geochemistry of permafrost terrain is concerned with processes in near-surface permafrost, in particular within the active and transient layers (Lacelle and Vasil'chuk, 2013). Numerous studies showed the presence of an ice-rich zone immediately below the base of the active layer (e.g., Hughes, 1974; Outcalt, 1982; Kokelj and Burn, 2003). Water movement along thermal and hydraulic gradients in the near-surface permafrost (Cheng, 1983; Mackay, 1983; Burn and Michel, 1988) allows a net supply of moisture to the bottom of the active layer and subjacent transient layer (Shur et al., 2005). In particular, the formation of this ice-rich layer is due to the development of ice lenses at the base of the active layer by segregation at a rising permafrost table (Mackay, 1972; Mackay and Slaymaker, 1989; Mackay and Burn, 2002), and because of a seasonal imbalance between thermally induced winter-upward and summer-downward movement of moisture in the active layer and subjacent permafrost (Cheng, 1983; Mackay, 1983; Burn, 1988). An aggrading permafrost table associated with sedimentation (Mackay and Slaymaker, 1989) or climate change (Kokelj et al., 2002) may result in an ice-rich zone of considerable thickness (Kokelj and Burn, 2003). Permafrost table aggradation and nearsurface ground-ice accumulation are gradual processes. For instance, Burn 
(1988) individuated a discontinuity in the nature and distribution of ground ice defined as "thaw unconformity" in Yukon Territory (Canada) dated at $8870 \pm 200$ years BP. $90 \mathrm{~cm}$ of segregated ice were measured between the thaw unconformity and the base of the present active layer, suggesting that the ice has accumulated in situ over several millennia.

Several studies have examined the distribution of chemical species within the active and transient layers in various permafrost environments and reported a solute enrichment at the base of the active layer (Kokelj et al., 2002; Lacelle et al., 2007, 2008). Keller et al. (2010) and Frey and McClelland (2009) highlighted that in areas with a permafrost table fluctuating on different timescales (annual to centennial), solute accumulation at the base of the active layer can be sequestered in the transient layer. Similar findings were obtained by Kokelj et al. (2002) and Kokelj and Burn (2005), who showed that ionic concentrations in near-surface permafrost below the transient layer are substantially greater than those measured in the active and transient layers.

Kokelj and Burn (2003) found a correspondence between solute enrichment and ice-rich intervals in near-surface permafrost at the Navy Road site in Northwest Territories (Canada), indicating that the ice-rich zones acted as a sink for solutes (Fig. 2.2.1). These ice-rich zones were found immediately below the base of the present active layer and at depths of former permafrost tables (thaw unconformities), deeper in near-surface permafrost (Fig. 2.2.1). The high ionic content in the ice-rich zones was attributed to the ionic redistribution during thermally-induced moisture migration (Cary and Mayland, 1972; Qui et al., 1988; 
Excess ice content (\%)

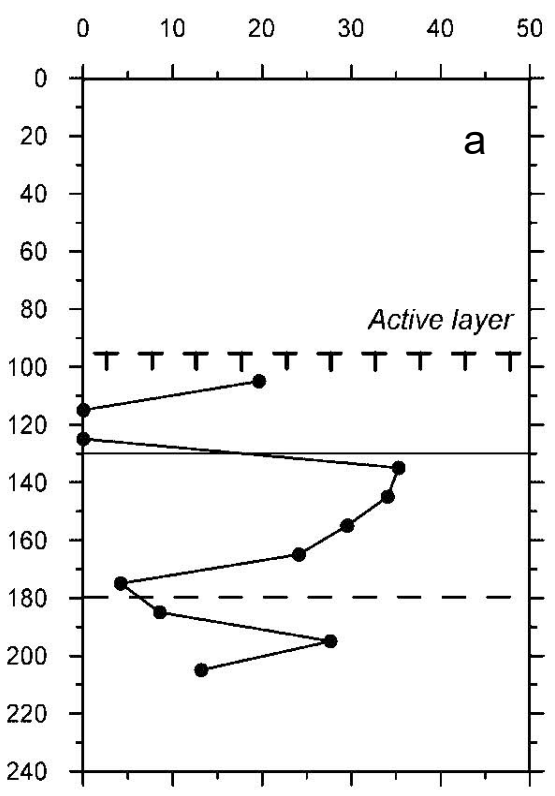

Total soluble cations (meq/100 g dry soil)

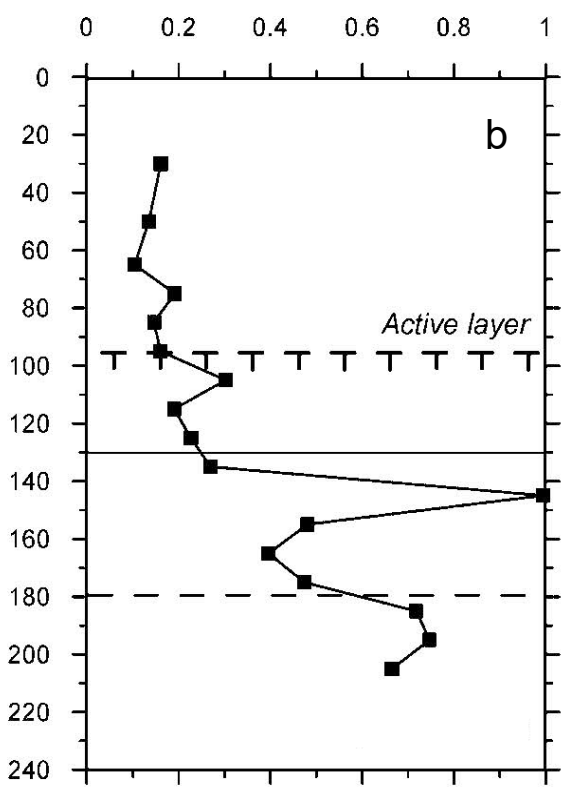

Figure 2.2.1 - Excess ice content (a) and total soluble cation concentrations (b) in active layer and near-surface permafrost at the Navy Road site (Canada). The present permafrost table is indicated by a dashed line with tick marks, the solid line indicates the depth of thaw in 1981 (1st thaw unconformity), and the dashed line indicates the estimated position of a deeper (older, not dated) thaw unconformity (2nd thaw unconformity). Adapted from Kokelj and Burn (2003). 
Chuvilin et al., 1998; Brouchkov, 2000) with the accumulation of soluble nutrients that accompanied segregated ice development. These results were confirmed by Lacelle et al. (2014) using stable water isotopes $\left(\delta^{18} \mathrm{O}\right.$ and $\left.\delta \mathrm{D}\right)$.

Interestingly, Murrman (1973) and Barone et al. (1989) demonstrated that the diffusion velocity of ions in frozen soils can equal the velocity in unfrozen soils, which is fundamentally important to understand the process of ionic migration at negative temperatures. The ionic permeability of frozen soils depends on their cryogenic structure. The existence of ice layers oriented perpendicularly to the moisture migration flow generally results in a reduction of ion transfer (Chuvilin et al., 1998), which could lead to an increased ionic accumulation in ice-rich layers due to reduced permeability. Moreover, Kokelj and Burn (2005) sectioned permafrost sediment cores at high resolution intervals $(5 \mathrm{~cm})$, revealing that, in some cases, ion accumulation occurred immediately above ice-rich intervals in the Mackenzie delta region (Northwest Territories, Canada). They explained this pattern as a result of solute exclusion, which concentrates dissolved materials above or on the warm side of a growing ice lens in near-surface permafrost (Hallet, 1978). This process was explained by Ostroumov et al. (2001), who studied natural permafrost (silty sediment, North Kolyma Lowland, North-Western Siberia, Russia) and artificial samples to analyse the redistribution of lead and potassium during formation of lens-type cryogenic structure in freezing water-rich silt. The results showed that the redistribution of soluble compounds takes place during ice segregation in freezing ground, accumulating the mobile components on the warm interface of a growing ice lens and the mineral layer (Fig. 2.2.2). 

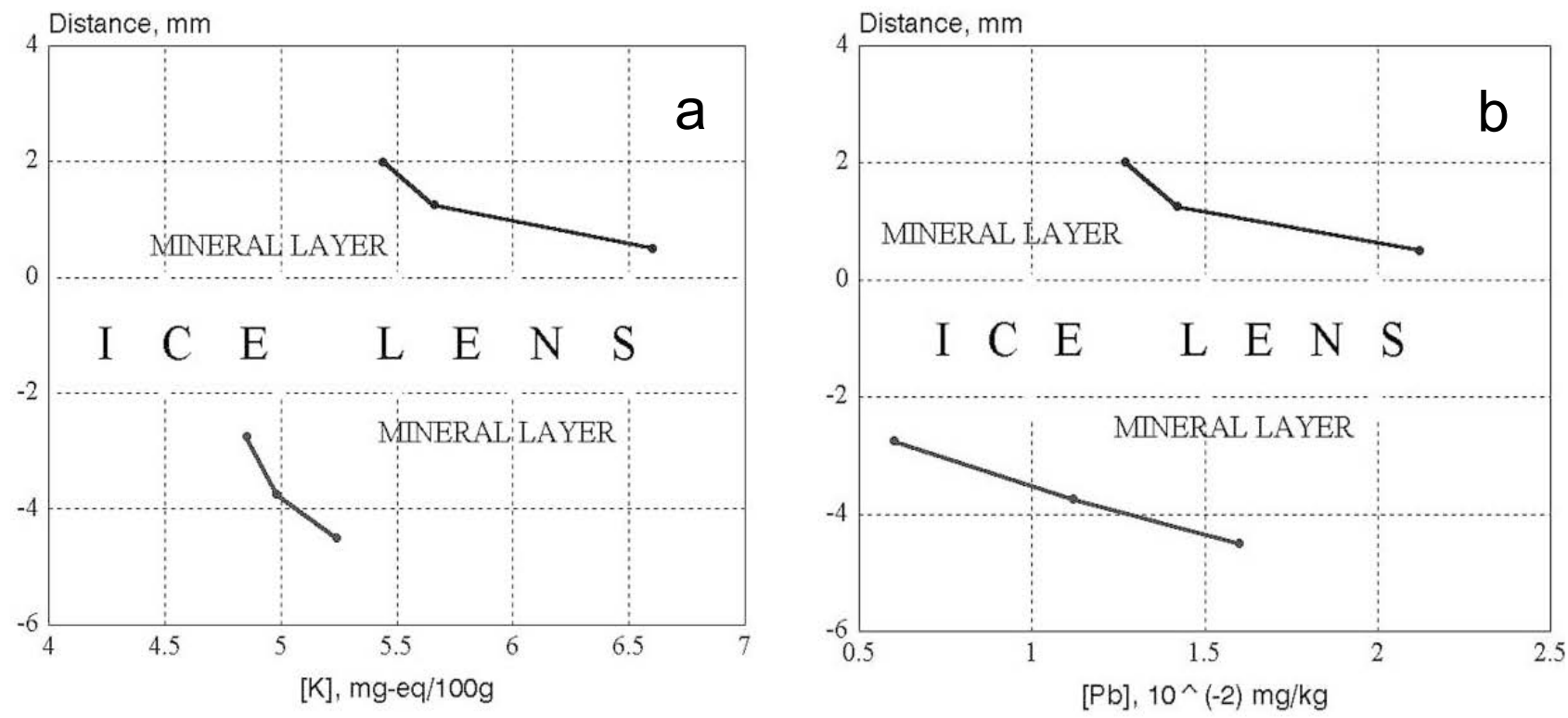

Figure 2.2.2 - (a) Distribution of potassium in mineral layers close to the segregated ice lens in permafrost silt; (b) distribution of lead in the nature permafrost silt close to the ice lens. In both cases freezing is from the bottom. Adapted from Ostroumov et al. (2001). 
The effect of rejecting foreign bodies such as soluble salts, organic compounds, and suspended materials by freezing water has been extensively studied (e.g., Himes et al., 1959; Kammerer and Lee, 1969; Killawee et al., 1998; Parker and Collins, 1999). Recently, Shafique et al. (2011) tested the effects of continuous unidirectional and radial freezing on bulk water solutions carrying $\mathrm{H}^{+}$, $\mathrm{OH}^{-}, \mathrm{CO}_{2}^{3-}$, and $\mathrm{HCO}_{3}^{-}$, as well as gases like $\mathrm{CO}_{2}, \mathrm{O}_{2}$, and $\mathrm{Cl}_{2}$, showing that ions significantly transferred from solidifying portions to those that were still not solid. However, in soil, several factors such as grain size, solid phase characteristics, concentration and composition of pore solution, and freezing rate may determine the ousting (or the capture) of soluble components during soil freezing (Anisimova, 1975; Nechaev and Romanov, 1981; Qui et al., 1986; Yershov and Lebedenko, 1991).

In acidic and limestone permafrost areas (Canada, Arctic), Lacelle et al. (2007, 2008) attributed solute enrichment at the base of the active layer (Fig. 2.2.3) due to the greater availability of water for chemical aqueous reactions, where drainage is inhibited by subjacent permafrost. Similar to the Arctic, a soluteenriched layer was observed at the base of the active layer in Taylor Valley (Antarctica). Here, Levy et al. (2012) investigated water tracks enriched in solutes derived from the chemical weathering of sediments and dissolution of soil salts. The solute enrichment was thereby attributed to both cryogenic concentration of salts during freezing and humidity-driven salt separation at the soil surface. 


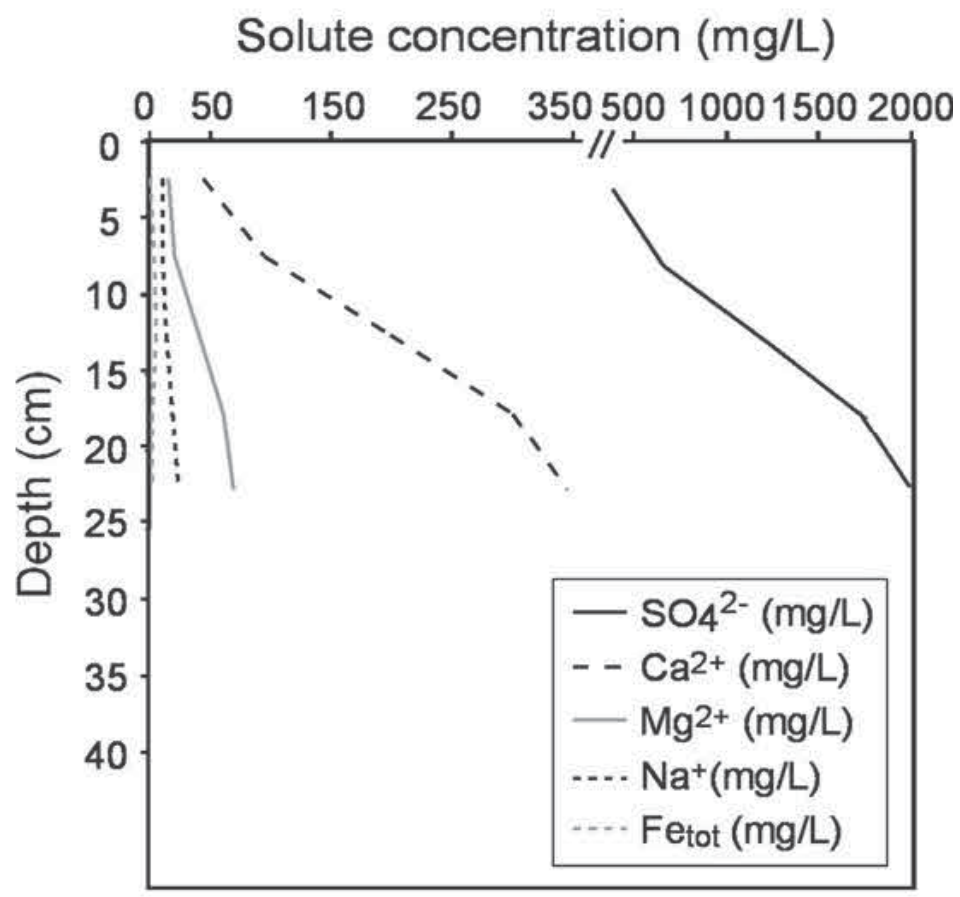

Figure 2.2.3 - Vertical distribution of $\mathrm{SO}_{4}{ }^{2-}, \mathrm{Ca}^{2+}, \mathrm{Fe}, \mathrm{Mg}^{2+}, \mathrm{Na}^{+}$and $\mathrm{Al}$ within the active layer at the site investigated by Lacelle et al. (2007) (Eagle Plains, Yukon Territory, Canada). Adapted from Lacelle et al. (2007). 
In Greenland (llulissat), Jessen et al. (2014) found concentrations of major ions to increase with depth in a loamy active layer overlain by peat in a permafrost wetland. Interestingly, the vertical distributions of dissolved $\mathrm{Cl}$ (conservative chemical species) and $\delta^{18} \mathrm{O}$ were unrelated to ion freeze-out and isotope ice-water fractionation processes, thus, the authors suggested that solute freeze-out was not the main driver on the near surface permafrost geochemistry. Therefore, they proposed a model in which mineral dissolution reactions take place in the loam, which is only slowly flushed by advective flow. Then, the reaction products are transported upward by diffusion to the peat layer which is frequently flushed during summer.

Finally, permafrost thaw and water table lowering may cause oxidation of the soil itself, which may cause the mobilisation and release of major ions and trace elements accumulated during soil development (Chagué-Goff and Fyfe, 1997). Furthermore, the progressive removal of solutes from the active layer mainly due to geomorphic disturbances might enhance the export of chemical species, contributing to the contrast between active-layer and permafrost geochemistry (e.g., Leibman and Streletskaya, 1997; Kokelj and Lewkowicz, 1999).

\section{Geochemistry of massive ground ice}

Ice wedges are one of the most common types of ground ice in continuous permafrost areas and the most widespread periglacial landform within lowland areas underlain by continuous permafrost (French, 2007). They form where thermal contraction cracks open in winter. In the spring, snow meltwater infiltrates these cracks, then the meltwater refreezes in the cracks to form ice 
veins. The repetition of this process causes the formation of vertically foliated ice wedges (e.g., Mackay, 1990a; Mackay, 2000; Fritz et al., 2015). The majority of the literature on ice-wedge geochemistry addresses the dating and the derivation of past environmental conditions (e.g., Vasil'chuk and Vasil'chuk, 1998; Opel et al., 2011; St-Jean et al., 2011). However, there is a paucity of studies that analyse the geochemical characteristics of this typical permafrost feature.

Fritz et al. (2015) investigated major-ion concentrations in ice wedges and other ground ice types. They found that ice wedges are characterised by peculiar chemical properties since they are fed by meltwater from atmospheric sources that had been in contact with surface sediments before the meltwater infiltrated the frost cracks in spring. By contrast, glacier ice, snowbank ice and lake ice are primarily fed by atmospheric waters having less interaction with ion sources. Thus, ice wedges can incorporate sediments and solutes that originate from surface soils carried along with the snow meltwater into the frost crack (Opel et al., 2011). Moreover, the geochemical signature of ice wedges is driven by the climatic and environmental conditions in which they are formed, such as maritime and terrestrial/continental conditions, with maritime settings dominated by $\mathrm{Na}$ and $\mathrm{Cl}$ ions, and with $\mathrm{Mg}, \mathrm{Ca}$ and $\mathrm{HCO}_{3}$ ions prevailing in continental settings (StJean et al., 2011).

Contrary to ice wedges, massive ground ice bodies of other origins such as glacier ice, snowbank ice and lake ice have fewer interactions with ion sources in soil and soil water. Thus, buried surface ice should have low dissolved ion concentrations as measured in glacial ice, whereas ice formed by the freezing of 
groundwater, such as massive intrasedimental ice, should exhibit higher ionic concentrations (Leibman, 1996). The geochemistry of massive ground ice bodies has mostly been studied with the aim of investigating their origin (e.g., Mackay and Dallimore, 1992; Fritz et al., 2011; Slagoda et al., 2012).

Slagoda et al. (2012) compared geochemical and isotopic data from complex massive ice bodies at Marre-Sale Cape, Yamal Peninsula (Russia). The lower massive ice was mainly characterised by $\mathrm{NaCl}(50 \%)$ with subordinate $\mathrm{Ca}(\mathrm{Mg}) \mathrm{CO}_{3}(<10 \%)$, associated with elevated $\delta^{18} \mathrm{O}$ values, suggesting a predominant contribution from a marine water source to the formation of the ice body. The geochemistry of the upper massive ice body was characterised by a $\mathrm{Na}-\mathrm{Ca}-\mathrm{CO}_{3}$ facies and lower $\delta^{18} \mathrm{O}$ values, indicating a predominant contribution of groundwater, which showed similar geochemical characteristics in the investigated region. Similarly, Fritz et al. (2011) combined isotopic measurements $\left(\delta^{18} \mathrm{O}\right.$ and $\left.\delta \mathrm{D}\right)$ with ionic concentrations and ratios such as $\mathrm{Na} / \mathrm{Cl}$, $\mathrm{SO}_{4} / \mathrm{Cl}, \mathrm{HCO}_{3} / \mathrm{Cl}$ and $(\mathrm{Na}+\mathrm{K}) / \mathrm{Ca}$, for the studying of the origin of two massive ground ice bodies along the coast of Herschel Island, Yukon Territory (Canada). They distinguished between glacial meltwater and marine origins that contributed to the formation of the ground ice bodies. In one massive ice body the authors measured higher EC (electrical conductivity) values in conjunction with higher sediment contents, and interpreted this as result of in situ ion-exchange processes between the sediment particles and the ice. In the second massive ice body the total ion content and EC values were generally lower. A progressive symmetrical depletion in heavy isotopes inwards towards the centre of the ice 
body and a strong solute enrichment in the same direction were found (Fig. 2.2.4a). The lowest ionic content and EC values were measured in the very clear and transparent ice in the outer parts of the massive ice body. Fritz et al. (2011) suggested that the ice body was formed under closed-system conditions as a result of complete freezing of a single water body, suggested to be a proglacial water pond. The progressive depletion of heavy isotopes towards the centre of the ice body was due to Rayleigh-type fractionation while the high ionic concentrations in the inner ice section were caused by ionic segregation during slow freezing (Fig. 2.2.4b). The latter process was reproduced by Shafique et al. (2011) using the radial freezing approach (Fig. 2.2.4c). Mackay and Dallimore (1992) also documented the importance of solute expulsion in determining the characteristics of a massive intrasedimental ice body in Northwest Territories (Canada), grown in situ by downward permafrost growth in areas of high groundwater pressures of glacial origin.

While ground ice can exist within permafrost without any resulting surface expression, in some cases the development of ground ice promotes the updoming of overlying sediments, producing typical permafrost landforms called pingos (ice-cored hills). There are two different types of pingos: hydraulic or "open-system" and hydrostatic or "closed-system" pingos (Williams and Smith, 1989; French, 2007).

Irrespective of typology, all pingos undergo a cycle of growth and degradation over hundreds or thousands of years. The nature of the ice forming the pingo core depends on whether the core is in direct contact with the underlying 


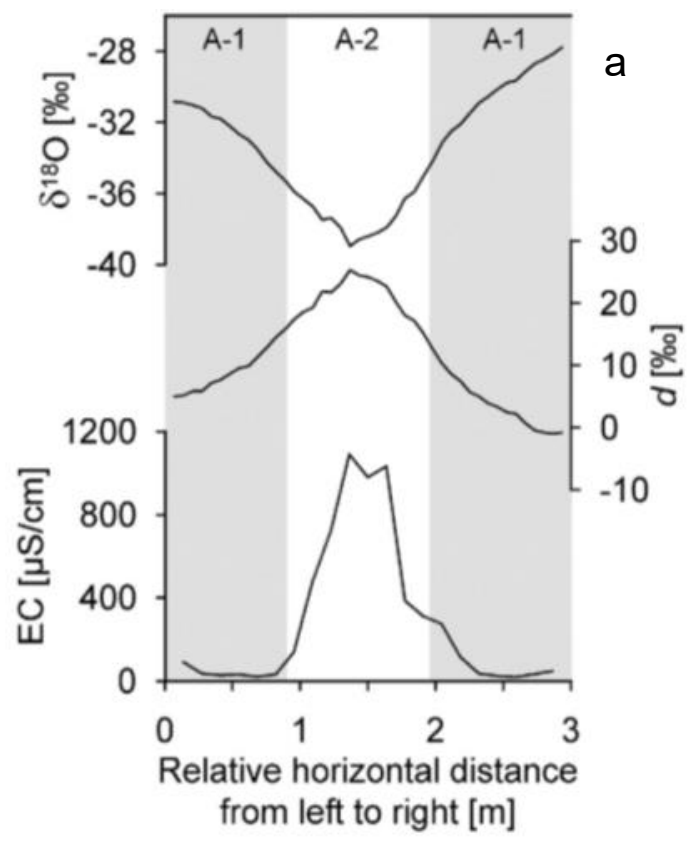

C
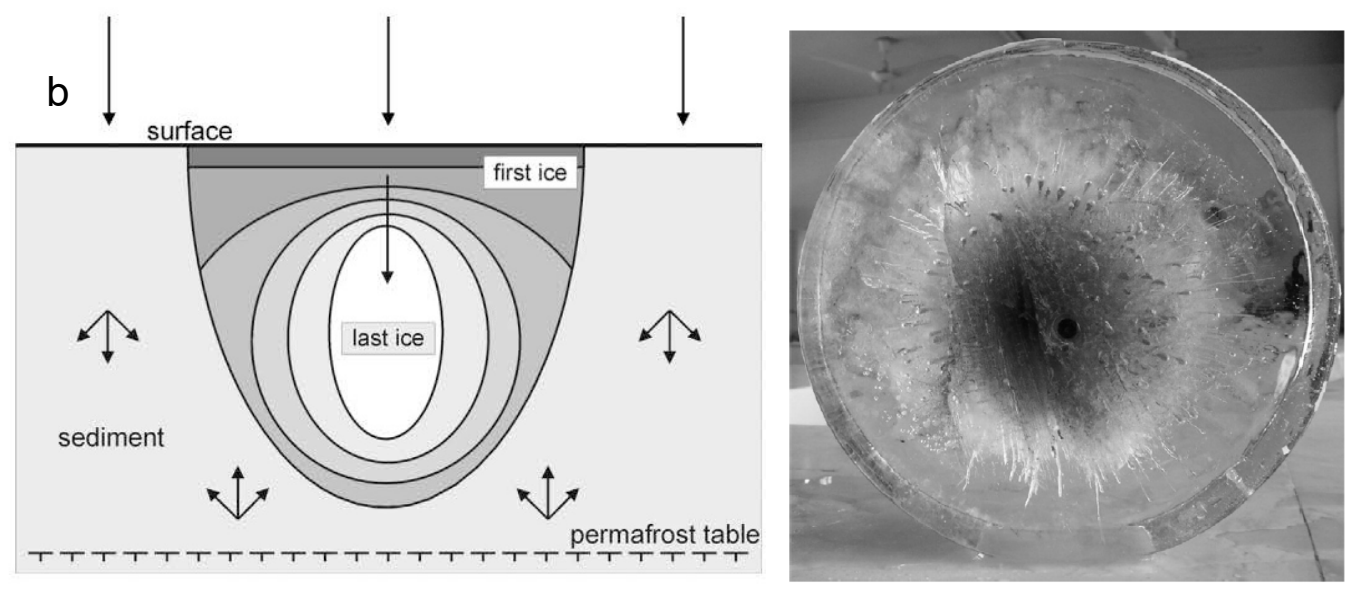

Figure 2.2.4 - (a) $\delta^{18} \mathrm{O}$, deuterium excess (d) and total ion content (expressed as electrical conductivity, EC) across a horizontal transect in the second massive ground ice body. Adapted from Fritz et al. (2011); (b) simplified model of slow closed-system freezing of an enclosed water body. The different grey levels of the water body show successional freezing. The arrows indicate the freezing direction. Adapted from Fritz et al. (2011); (c) effects of radial freezing on bromine water and $\mathrm{KMnO}_{4}$ (potassium permanganate) solution. Note the high potassium permanganate concentration in the centre due to solute expulsion during radial freezing. Adapted from Shafique et al. (2011). 
saturated sediment, allowing the formation of segregation ice, or whether the ice core overlies a sub-pingo water lens (Mackay, 1977, 1978), in which case massive injection ice develops (Mackay, 1994). A mixture of ice types can also be present in the same landform (Mackay, 1985; Mackay, 1990b; Mackay, 1994; Yoshikawa et al., 2013). Isotopic and geochemical analyses of pingo ice and springs have been used to determine origin and age of pingos (e.g., O'Brien, 1971; Yoshikawa, 1998). Allen et al. (1976), Gurney (1998) and Yoshikawa et al. (2003) studied hydraulic pingo geochemistry suggesting a meteoric origin of spring waters, derived from precipitation or glacial meltwater that has flown to the pingo site as intrapermafrost or subpermafrost groundwater. Allen et al. (1976) attributed the origin of some pingo springs to marine environment (direct seawater contact and/or connate sediments characteristics due to the submarine history of the study area) because of the specific $\mathrm{SO}_{4} / \mathrm{Cl}$ and $\mathrm{Na} / \mathrm{K}$ ratios. Yoshikawa (1998) distinguished between pingos with water of marine origin in areas that experienced post glacial uplift from the sub sea surface (high $\mathrm{Na} / \mathrm{K}$ ratio versus low $\mathrm{SO}_{4} / \mathrm{Cl}$ ratio), and water from a shallow and more recent origin (low $\mathrm{Na} / \mathrm{K}$ ratio versus high $\mathrm{SO}_{4} / \mathrm{Cl}$ ratio).

Mackay (1990b) investigated the geochemical characteristics of ice in a pingo located in the Tuktoyaktuk Peninsula region (Canada) where a 31-year record was analysed. The author found rather constant chemical species concentrations with the exception of two well defined highly concentrated layers located in icerich soil with segregated ice (Fig. 2.2.5). These layers formed when the subpingo water lens decreased in diameter and a higher concentration of solutes 


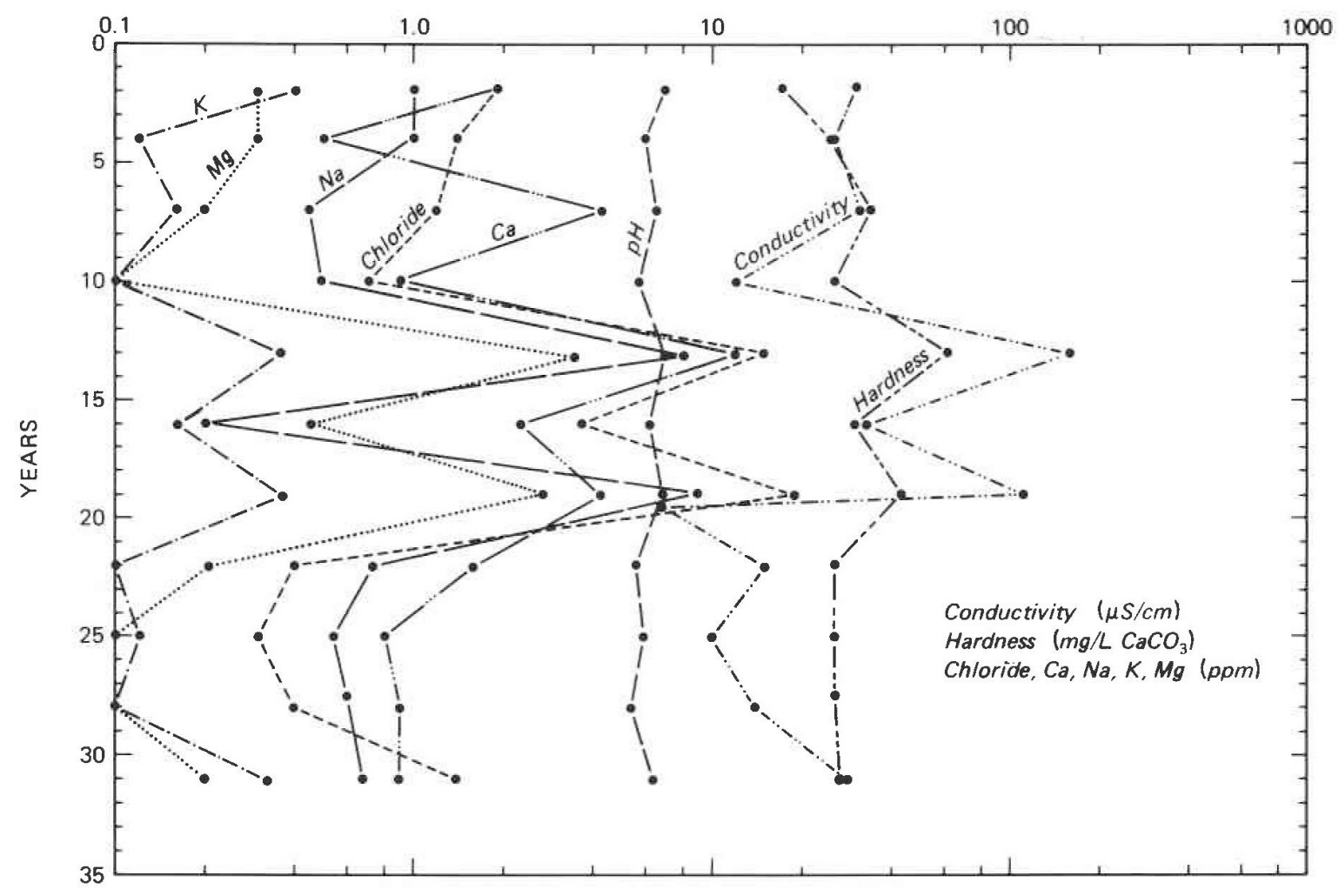

Figure 2.2.5 - Geochemical profile of ice in a pingo in Tuktoyaktuk Peninsula region (Canada). Note the logarithmic scale on x axes. From Mackay (1990b). 
accumulated in the smaller water lens from solute rejection. Comparable results were obtained by Yoshikawa et al. (2013) who reported high elemental concentrations in correspondence of clay layers in an ice record sampled from a pingo in northwestern Mongolia. Interestingly, using $\mathrm{O}-\mathrm{H}$ water stable isotopes, they also discriminated between two different ice-origin processes: (1) opensystem freezing and (2) semi-closed system (or closed system) freezing, suggesting a complex temporal evolution for the investigated pingo, developed during the mid- or late Holocene.

\subsubsection{Geochemistry of rock glaciers}

Generally, active rock glaciers can contain various forms of ground ice such as ice from freezing meteoric and groundwater, ice transformed from snow, and ice of glacial origin (Burger et al., 1999). However, information about the internal structure of rock glaciers is important, but difficult to obtain due to the complicated environmental conditions in which they are formed, that make the accessibility extremely difficult. Moreover, the majority of the observations has analysed ice distribution or ice physical features and chemical characteristics, with the latter mainly focused on isotopic compositions for determining ice origin

and organic impurities for dating purposes (e.g., Barsch et al., 1979; Stauffer and Wagenbach, 1990; Wagner, 1990; Elconin and LaChapelle, 1997; Cecil et al., 1998; Haeberli et al., 1999; Arenson et al., 2002; Krainer et al., 2015). Most of these studies reported that rock-glacier ice can be much older (millennia) than that of "typical glacier" in mountain environments, even though the ground ice formed previously in glacial conditions. Notwithstanding, few investigations have 
been carried out to extract ice cores for geochemical analyses (Baltensperger et al., 1990; Haeberli et al., 1999; Steig et al., 1998; Guglielmin et al., 2004; Krainer et al., 2011).

Steig et al. (1998) investigated a glacier-derived rock glacier in north-western Wyoming (USA) by analysing the EC of the ice-core at $1 \mathrm{~cm}$ resolution. The EC record showed that uniformly spaced debris layers are generally associated with rapid changes in $\mathrm{EC}$, suggesting the presence of a seasonality pattern, as also confirmed by accompanying isotopic analyses. In part, this may have reflected variations in the acidity of the original precipitation due to seasonal changes in atmospheric loading of aerosol species and dust. Concentration of surface debris may have also increased conductivity, due to the greater solubility of acidic species such as sulphate.

Similar results were obtained by Guglielmin et al. (2004), who extracted an ice-core from the Foscagno Rock Glacier in Lombardy (Italy) and found the presence of seasonality in the sulphate profile related to sediment layers, a strong correlation between sodium and chloride (Fig. 2.2.6), and low ionic concentrations in one section of the core. These results suggested an absence of melting and refreezing processes, which are consistent with deposited snow transformed into firn under cold conditions, which is a common process in highelevation glaciers. However, in two other sections of the core, enrichment in calcium and other crustal compounds from surrounding ground or debris was individuated. Comparable concentrations were also found in the MurtèlCorvatsch ice core (Baltensperger et al., 1990) and were attributed to carbonate 


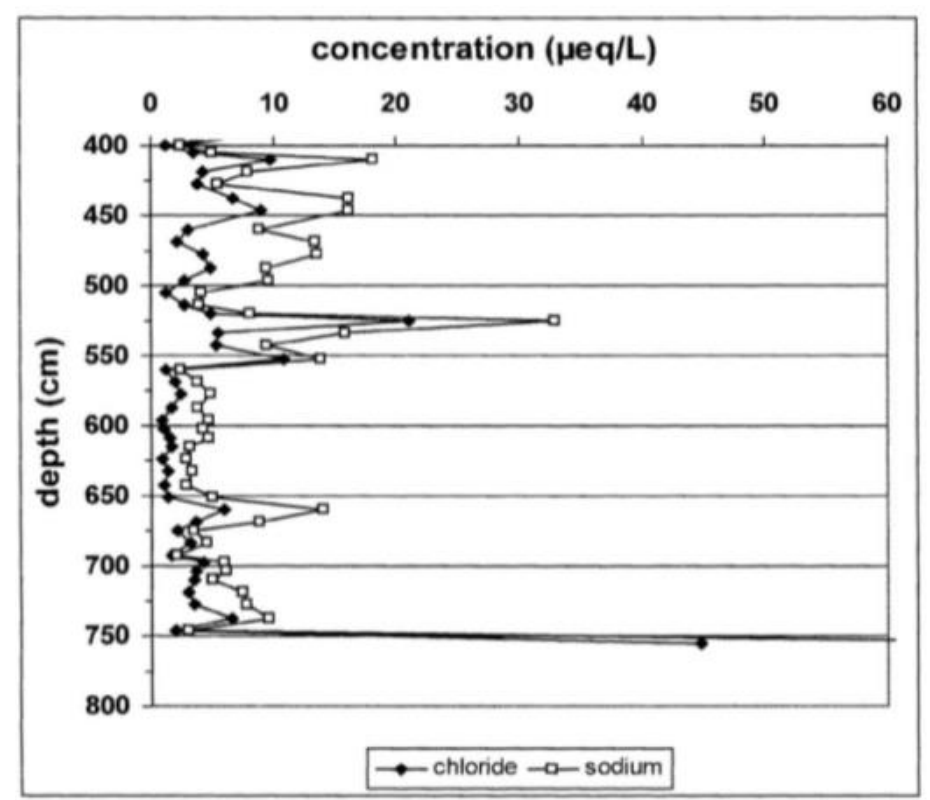

Figure 2.2.6 - Depth profile of the concentrations of $\mathrm{Na}$ and $\mathrm{Cl}$ in the glacierderived ice-core section in the Foscagno Rock Glacier. From Guglielmin et al. (2004). 
dissolution from rocks during percolation of snow meltwater in the ground before refreezing into the still cold active layer during spring (Haeberli et al., 1999). Thus, the Foscagno rock glacier can be considered a result of a complex history in which different types of ice are preserved, characterised by different geochemical facies.

Preliminary results from a geochemical analyses of the ice-core sampled from the Rock Glacier Lazaun in South Tyrol (Italy) are reported by Krainer et al. (2011). The authors described the frozen core as largely composed of a mixture of debris and ice, and at the base of the rock glacier a banded ice layer with low amounts of debris was found. The ion content of the samples showed a high variability along the core, with conductivity values ranging from 40 to $1,300 \mu S$ $\mathrm{cm}^{-1}$ (Fig. 2.2.7). No recognizable distribution patterns were individuated along the depth-profile. The ice near the base was reported to be approximately 10,300 years old and trace elements $(\mathrm{Ni}, \mathrm{Co}, \mathrm{Cu}, \mathrm{Zn})$ were found to be enriched in three horizons within the ice at depths of $4.2 \mathrm{~m}$ (approx. $2600 \mathrm{yr}$ BP), $9.9 \mathrm{~m}$ (approx. 3200y BP) and $12.4 \mathrm{~m}$ (approx. $3500 \mathrm{yr} \mathrm{BP}$ ), with Ni concentrations up to 0.49 $\mathrm{mg} \mathrm{L}^{-1}$ (Krainer et al., 2015). High nickel concentrations (up to $0.175 \mathrm{mg} \mathrm{L}^{-1}$ ) were measured at the rock glacier spring and exceeded the drinking water limit for nickel ( $0.02 \mathrm{mg} \mathrm{L}^{-1}$, European Union limit value) by up to 8 times, indicating the nickel in spring water was correlated with the high levels of the permafrost ice. Since the rocks in the rock-glacier catchment do not contain high concentrations of nickel, the source of nickel remains unknown. 


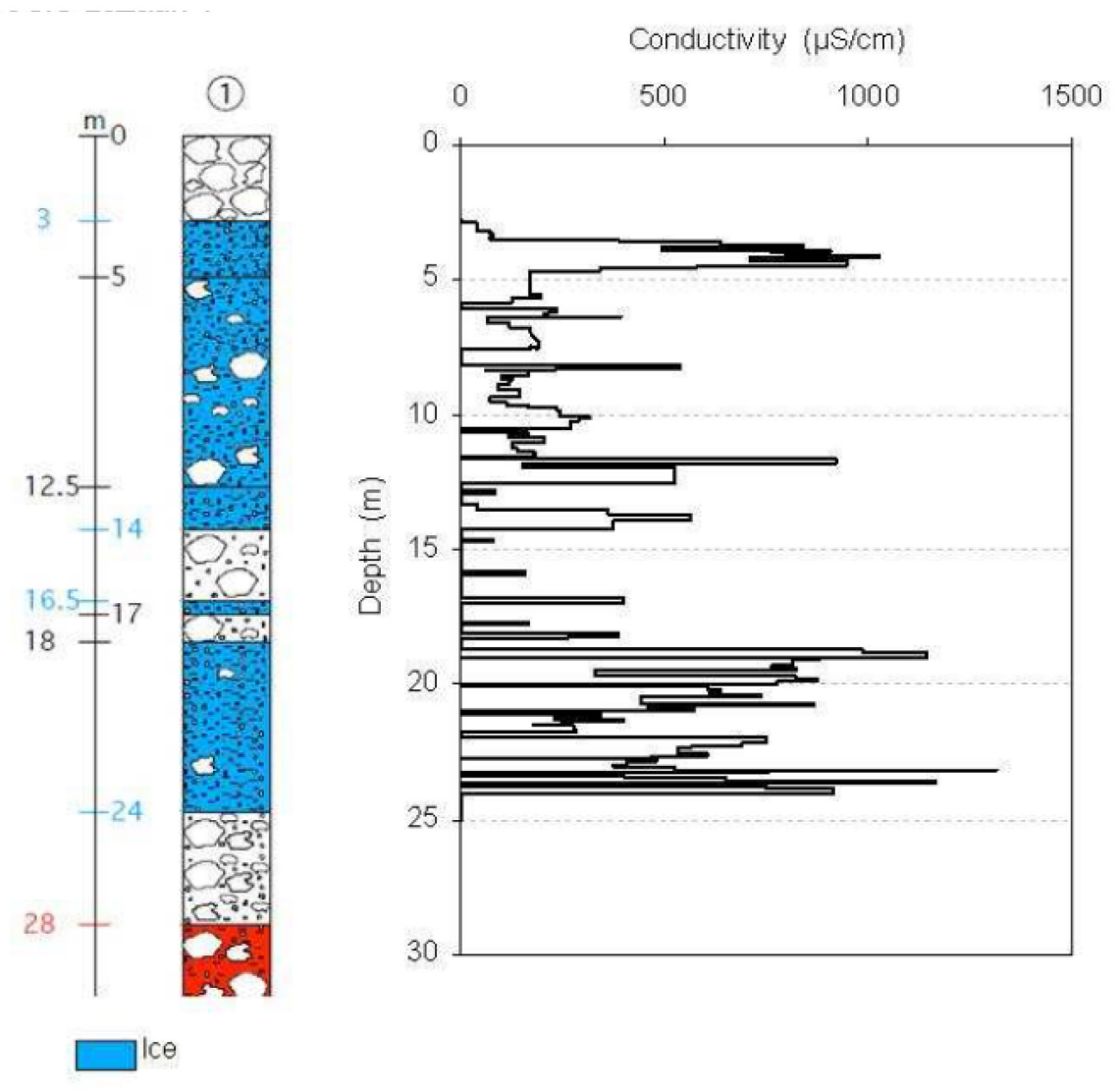

Figure 2.2.7 - Vertical profile of conductivity in the core at the Lazaun Rock Glacier, South Tirol (Italy). Red: bedrock. From Krainer et al. (2011). 
Finally, Williams et al. (2006) attributed the enrichment of solutes in rockglacier outflows due to prolonged interaction with fine-grained rocks and freshlyexposed mineral surfaces directly in contact with the water. Thus, the great release of solutes was not attributed to their high concentrations in the ice, but to the melting of the rock-glacier ice which created highly-mineralised weathering fluxes from newly-eroded mineral surfaces.

\subsection{Impacts of rock-glacier thawing on inorganic chemistry of surface fresh water}

During the last decade, researches in mountainous terrains have demonstrated the role of rock glaciers in exporting high solute-concentrated waters, impacting water quality of surface fresh waters (Williams et al., 2006; Thies et al., 2007; Thies et al., 2013; llyashuk et al., 2014). This chapter reports the observations of the effects of inorganic solute export from rock glaciers into surface fresh waters, discriminating among stable water isotopes $(\mathrm{O}$ and $\mathrm{H})$, major ions (e.g., $\mathrm{Ca}^{2+}$, $\mathrm{Mg}^{2+}, \mathrm{SO}_{4}{ }^{2-}, \mathrm{NO}_{3}{ }^{-}$) and trace elements (e.g., $\mathrm{Ni}, \mathrm{Mn}, \mathrm{Al}$ ). Finally, the potential driving processes responsible for solute export are discussed.

\subsubsection{Stable water isotopes}

Stable isotopes $(\mathrm{O}$ and $\mathrm{H})$ in water can be used as tracers in studying rockglacier hydrogeological dynamics although their use has been relatively limited (Steig et al, 1998; Williams et al., 2006; Krainer et al., 2007). 
Krainer et al. (2007) reported that $\delta^{18} \mathrm{O}$ values of the meltwater released at springs from a rock glacier in the Austrian Alps are lowest during high discharge at the beginning of the melt season. Then, $\delta^{18} \mathrm{O}$ values progressively increase until late July to early August until the winter snowpack is completely melted. The authors attributed this gradual isotopic enrichment during the melt season due to the progressive decrease in the ratio of snowmelt (isotopically depleted) versus icemelt plus groundwater (isotopically enriched). However, isotopic enrichment in rock-glacier outflows during snowpack melting cannot be easily discriminated from the effect of decreasing mixing ratios of snowpack versus icemelt as the melting season progresses. Thus, the role of icemelt in determining isotopic enrichment trends and its contribution in the overall hydrological budget cannot be well constrained (Krainer et al., 2007). Moreover, short-time rainfall episodes during the summer have been shown to cause increases in $\delta^{18} O$ further disturbing the isotopic signal in rock-glacier outflows.

Similarly, Williams et al. (2006) found increasing $\delta^{18} \mathrm{O}$ values in a rock-glacier outflow during the melt season in Colorado (USA). They explained this pattern with a progressive decrease in the contribution of isotopically-depleted snowmelt at the beginning of the melt season and a gradual increase of isotopicallyenriched icemelt contribution. Specifically, post-depositional alteration of the original isotopic values of the internal ice of the investigated rock glacier has been considered responsible for enriched values in late summer and early fall. Systematic enrichment in the isotopic composition of snowmelt have been attributed to fractionation of the melt water as it percolates through the snow 
pack. Indeed, when snow melts at the surface, little isotopic fractionation occurs because the entire layer is melted. As meltwater percolates down, isotopic exchange takes place with enrichment in the ice relative to water, dictated by the isotopic equilibrium between water and ice (Taylor et al., 2001; Unnikrishna et al., 2002). In rock glaciers, the post-depositional alteration of ice might be caused by localised multiple melt/freeze episodes in the frozen body with isotopic fractionation between infiltrating liquid water and ice that preferentially removes the lighter isotopes, leaving the heavier isotopes behind as the liquid water drains (Williams et al., 2006). The authors also proposed that isotopic enrichments could be the result of the combination of isotopically-enriched rain water and icemelt, although this process was reported to be potentially minimal due to the fact that rainfall contributes only about $15 \%$ of annual precipitation in the investigated area.

The $d_{\text {excess }}$ (Dansgaard, 1964) can be also used to infer the main processes occurring in rock-glacier ice. For instance, Hermann et al. (1981) found experimentally that the runoff of meltwater from a snow pack causes enrichment of dexcess in the melt water. The $d_{\text {excess }}$ values have been reported to increase in rock glacier outflows during the melt season (Williams et al., 2006). Again, the enrichment of $d_{\text {excess }}$ from the outflow of RG5 during the late melt season may also be consistent with ice that has undergone multiple melt-freeze cycles. Indeed, Steig et al. (1998) reported that multiple melt-freeze cycles increased the $d_{\text {excess }}$ in some layers of an ice core collected from the Galena rock glacier (USA), reflecting meltwater infiltration and refreezing. Moreover, the use of the $\delta^{2} \mathrm{H}$ - 
$\delta^{18} \mathrm{O}$ relationship has been proven to be helpful in evaluating the importance of evaporation in concentrating geochemical weathering products in rock-glacier outflows (Williams et al., 2006). Generally, source waters for rock-glacier outflows should be subjected to little if any evaporation in the system, consistent with a coarse debris system and limited vegetation characterised by high infiltration rates.

\subsubsection{Major ions}

Thies et al. (2007) found dramatic increases in electrical conductivity (up to 19fold), $\mathrm{SO}_{4}{ }^{2-}$ (up to 26-fold), $\mathrm{Ca}^{2+}$ (up to 13-fold), and $\mathrm{Mg}^{2+}$ (up to 68-fold) from 1985 to 2005 in two lakes at the toe of active rock glaciers in the Central Eastern Alps in Europe (Austria and Italy) (Fig. 2.3.1). The potential causes of these trends have been attributed to the melting of ice in the rock glaciers and associated release of solutes, although no direct evidence of the driving processes and rock glacier-lake links were provided.

Enriched geochemical fluxes from thawing permafrost and ice melt in rock glaciers have been also found to influence the seasonal hydrochemistry of streams in the Austrian Alps (Krainer and Mostler, 2002; Berger et al., 2004; Krainer et al., 2007), although no specific analyses on major ions were conducted but instead, conductivity measurements were used as proxy of solute loads. Williams et al. (2006) in 2003 filled this gap, reporting strong seasonal increases for $\mathrm{SO}_{4}{ }^{2-}(60$-fold $), \mathrm{Mg}^{2+}$ (30-fold) and $\mathrm{Ca}^{2+}$ (20-fold) in the outflow of RG5 in the Colorado Front Range (Rocky Mountains - USA) compared to nearby streams and lakes during the low-flow season. Longer-term measurements 1998- 

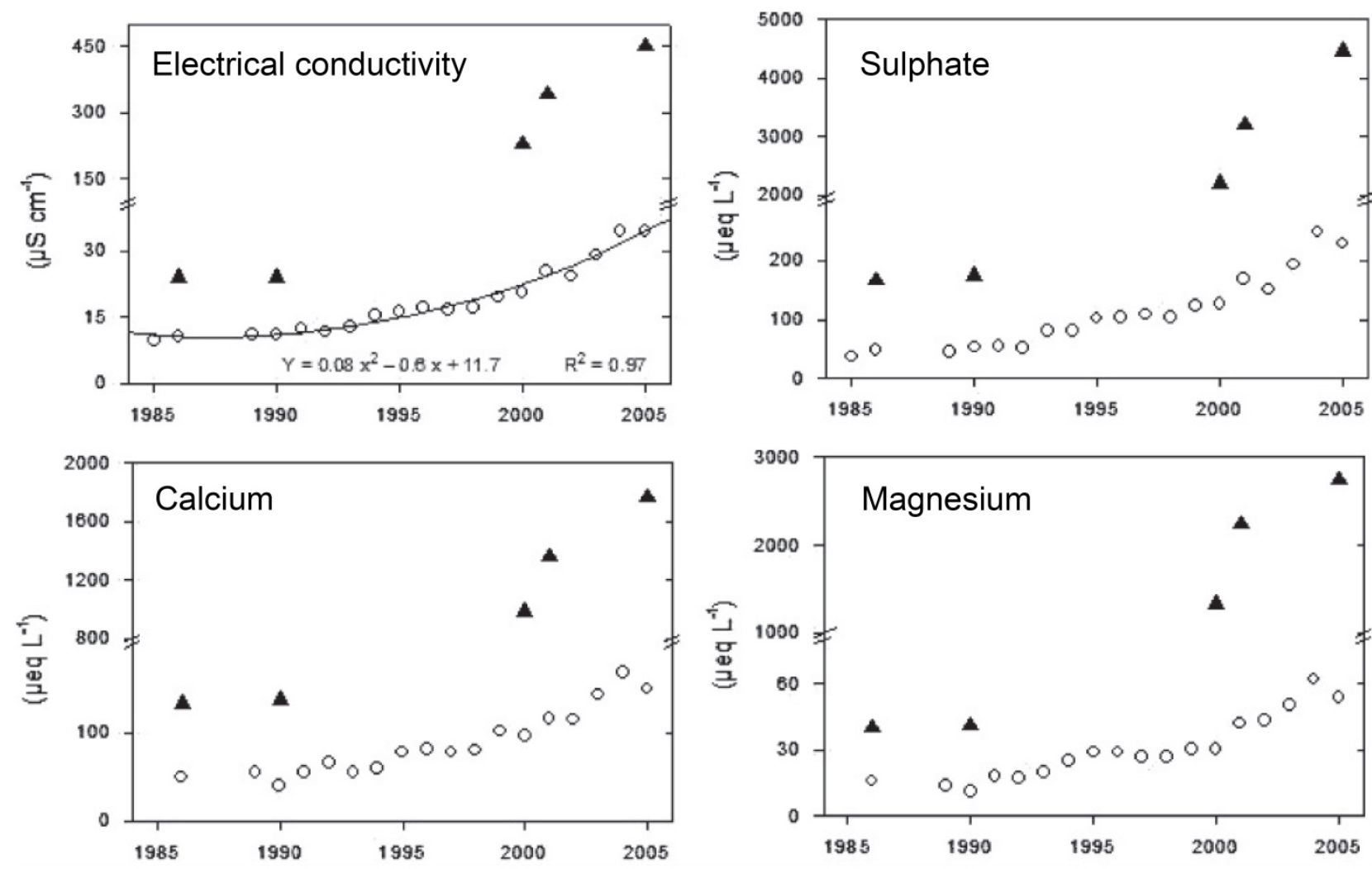

Figure 2.3.1 - Electrical conductivity, sulphate, calcium and magnesium concentrations in lake water of Rasass See (black triangles) and Schwarzsee ob Sölden (open circles) lakes (1985-2005). Values for each lake represent mean values of four to seven discrete samples along the lake vertical profile taken during holomixis. Variability among single values is $<5 \%$. Horizontal lines show break in vertical scale (adapted from Thies et al., 2007). 
2002 showed the same pattern of elevated concentrations of these solutes in the fall. The elevated concentrations of major ions in rock-glacier outflows and downstream lakes are consistent with the results of a precursor study performed by Giardino et al. (1992), who noted that water exiting rock glaciers in the San Juan Mountains of Colorado (USA) acquired a significant dissolved load during movement through the rock glaciers.

Recent findings attributed increases of nitrate concentrations in surface waters located in the Rocky Mountains USA to melting ice in permafrost and rock glaciers (Rocky Mountains - USA, Baron et al., 2009). Williams et al. (2007) found that nitrate concentrations in the outflow of a rock glacier in the Rocky Mountains were higher than all other analysed surface waters from 1998 to 2004 , (Fig. 2.3.2). Fegel et al. (2016) provides addition support that elevated biogeochemical and microbial characteristics of rock glaciers in the Cascade Mountains, Rocky Mountains, and Sierra Nevada (USA) result in increases of nitrate in surface water. Further, microbial communities adapted to the extreme environment of the interior of rock glaciers have been indicated as potential sources of the elevated nitrate in the rock-glacier outflows (Williams et al. 2007). Additional research in the Rocky Mountains suggested the observed increase in nitrate in surface waters may also be a result of melt water flushing microbially active sediments during permafrost degradation (Barnes et al., 2014) and active microbial populations in sediment pockets within talus fields (Ley et al., 2004). 


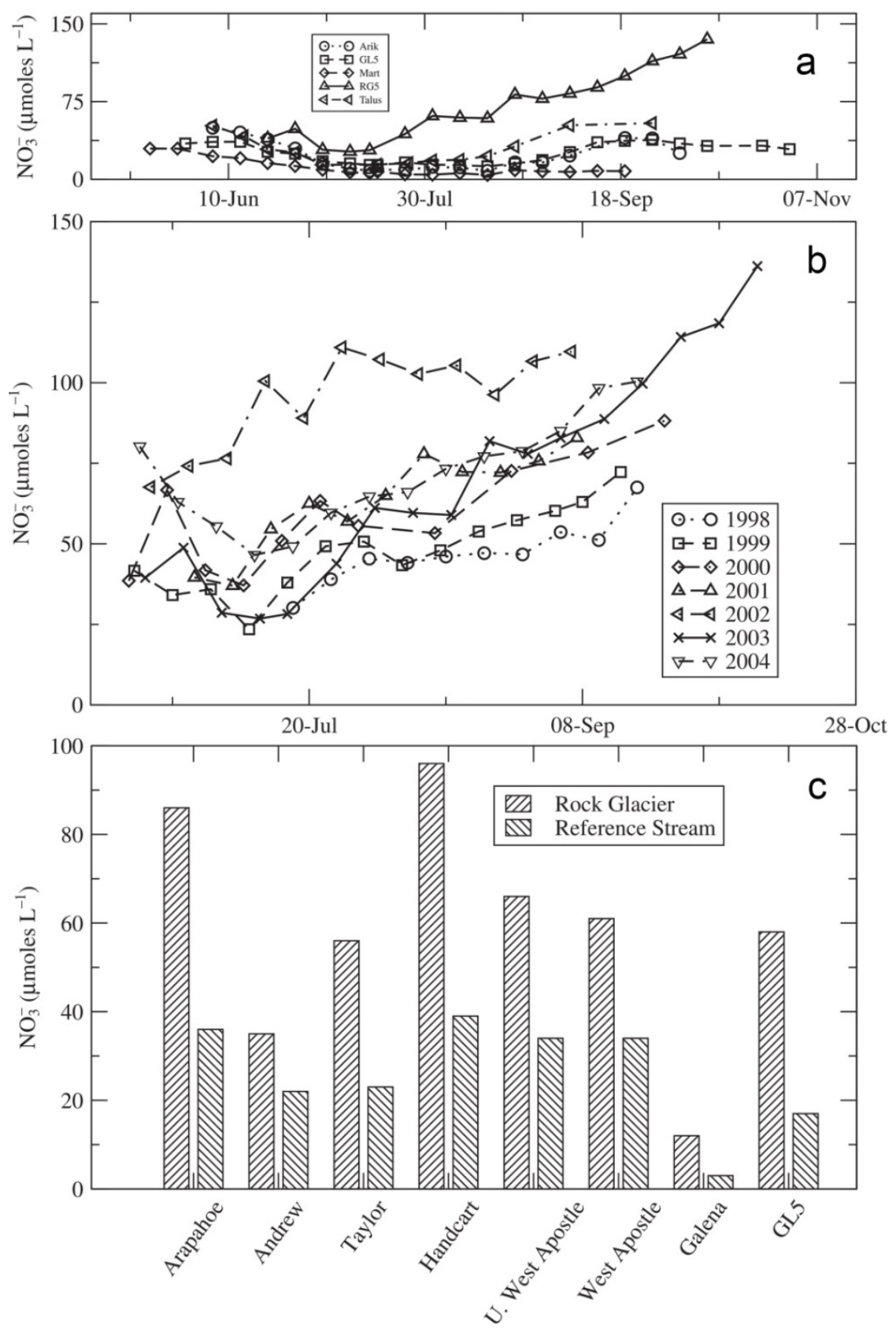

Figure 2.3.2 - (a) Time series of nitrate in surface waters of the Green Lakes Valley, for 2003. Arik is Arikaree Glacier outflow; GL5 is the outlet of Green Lakes 5; Mart is the outlet of the Martinelli catchment; RG5 is the Green Lake 5 rock glacier outflow; talus is the blockfield site (for site details refer to Williams et al., 2007). (b) Time series of nitrate concentrations in the outflow of RG5 during the snow-free season from 1998 to 2004. (c) Comparison of nitrate concentrations from the outflow of 7 rock glaciers and co-located surface waters, August 2003 (adapted from Williams et al., 2007). 


\subsubsection{Trace elements}

Unexpectedly high $\mathrm{Ni}, \mathrm{Mn}$ and $\mathrm{Al}$ concentrations exceeding the appropriate European Union limits for drinking water by more than an order of magnitude have recently been reported in a study investigating water chemistry of a remote high-mountain lake situated at the toe of an active rock glacier. In contrast, negligible concentrations of these elements (and other solutes) have been recorded in the adjacent pond without a rock glacier in the catchment (Central Eastern Alps - Italy, Ilyashuk et al., 2014). Surprisingly, the lithology did not contain high $\mathrm{Ni}$ concentrations, thus the source of $\mathrm{Ni}$ remains unknown. In addition, other springs derived from rock glaciers in the Central Eastern Alps exhibited high concentrations of trace elements such as $\mathrm{Ni}, \mathrm{Co}, \mathrm{Cu}, \mathrm{Fe}, \mathrm{Mn}$ and Zn (Krainer, 2014), peaking during the fall, and indicating a potential origin from rock-glacier ice. Increasing rock-glacier meltwater acidity accompanied by high heavy-metal concentrations have been also reported to cause significant changes in aquatic ecosystems (Tyrol - Austria, Thies et al., 2013).

\subsubsection{Driving processes for solute export}

During the last decades, the increase of solutes in lakes with rock glaciers in their catchments was attributed to the enhanced melting of ice due to atmospheric warming (Thies et al., 2007). Williams et al. (2006) confirmed this hypothesis,

assuming that this process may occur on seasonal basis, with a flushing of mineralised water at the end of the summer season when the zero isotherm proceeds towards the ice under conditions of degrading permafrost. 
Williams et al. (2006) reported the highest concentrations of geochemical weathering in rock-glacier outflows during particularly drought years. In this case there may have been more interior ice melt than in wetter years. The authors also hypothesised that long-lasting snow cover might be able to reduce solute export by delaying subsurface melt and by dilution of solute-rich water with snowmelt. Not only snowmelt, but also rain has been reported to reduce solute contents in rock glacier outflows (Krainer et al., 2007), due to its generally low solute content.

Conversely, Thies et al. (2007) hypothesised that solute fluxes from rock glaciers might intensify after periods of high rainfall in summer and autumn, which might enhance the water flow percolation through rock glaciers, causing the flushing of geochemical products.

\subsection{Summary and research needs}

Several physical and chemical processes govern the solute concentrations in permafrost environments such as ionic redistribution during thermally-induced moisture migration, solute exclusion during freezing and enhanced aqueous reactions at the base of the active layer due to the greater availability of water. Although ground ice composition in permafrost terrains is characterised by an accentuated genetic complexity and solute levels in different settings are related to the ice typology, main solute dynamics and concentration patterns are common. Thus, permafrost degradation and melting of ground ice might bring 
elements that are considered dangerous for drinking water and ecosystem health to the surface.

Particularly evident modifications in water quality of streams, lakes and ponds in Alpine areas have been attributed to ground ice melting in rock glaciers. However, compared with typical glaciers, rock glaciers remain less well described or studied although tens of thousands might exist worldwide (Barsch, 1996). Because these features are rock-covered and appear superficially similar to moraines, rockfalls, talus or scree slopes, and because of their mountainous settings, bouldery surfaces, rugged topographies, and steep frontal slopes, their presence and hydrologic characteristics/significance have been widely overlooked (Schrott, 1996; Burger et al., 1999; Millar and Westfall, 2008). The number of publications focusing on rock-glacier hydrology is small in comparison with published research on other aspects of rock glaciers, such as their morphology or dynamics (Duguay et al., 2015). Moreover, although recent studies proved the capability of rock glaciers to modify chemical characteristics of downstream impounded waters (Thies et al., 2007; llyashuk et al., 2014), how rock-glacier contribute to shaping hydrochemical dynamics of lakes and ponds is barely known. Finally, the atmospheric processes responsible for the export of solutes from rock glaciers are still unclear.

There is a need of further studies for determining the role of rock glaciers in the hydrological cycle in mountain watersheds. This could be firstly achieved increasing the knowledge on the temporal variability of rock-glacier discharge especially after snowpack depletion, in order to better constrain the effects of 
potential ice melting on the hydrological behaviour of rock glaciers. A better assessment of flow sources and pathways in rock glaciers is also required. Moreover, an improved understanding of rock-glacier hydrological systems and their links with impounded surface waters is necessary. Finally, in view of the potential negative effects of the export of solutes from rock glaciers into surface waters, the study of processes leading to solute release is necessary. 


\section{Study area}

The Col d'Olen Rock Glacier Pond (4552'8.22'N, $7^{\circ} 51^{\prime} 46.98^{\prime \prime} \mathrm{E}$, WGS84) is located in the north-western Italian Alps (Fig. 3.1a and 3.1b) along the Aosta Valley and Piemonte Region border, at an elevation of $2722 \mathrm{~m}$ a.s.l. The catchment area is approximately $206,000 \mathrm{~m}^{2}$ (Fig. 3.1c). The research site is a node of the Long-Term Ecological Research (LTER) network in Europe (http://www.Iter-europe.net/). No studies have been previously carried out to investigate the periglacial and permafrost characteristics of this site.

The Col d'Olen area is dominated by glacial and periglacial features and it is situated on the southern slope of the Monte Rosa massif. It contains bedrock outcrops, and typical alpine deposits, landforms and habitat features that include talus slopes, snow beds, patterned ground and alpine meadows. Geologically, the study area is a significant tectonic intersection between major structural/paleogeographic domains of the Alpine orogen. In the investigated area we can find, from North to South: i) the Monte Rosa nappe (micaschists and paragneisses with eclogite maphic rocks and aplitic tabular bodies); ii) the complex Ophiolitic Piedmont Zone, with the "Zermatt-Saas" unit (ophiolitic breccias, quartzite and manganese micaschists, phyllitic schists, and calcschists) and the "Combin Zone" unit (serpentinites and prasinites); iii) the Sesia Lanzo Zone (gneisses of polimetamorphic origin) (Dal Piaz, 2001; Handy et al., 2010; Gasco et al., 2011; Steck et al., 2015). 


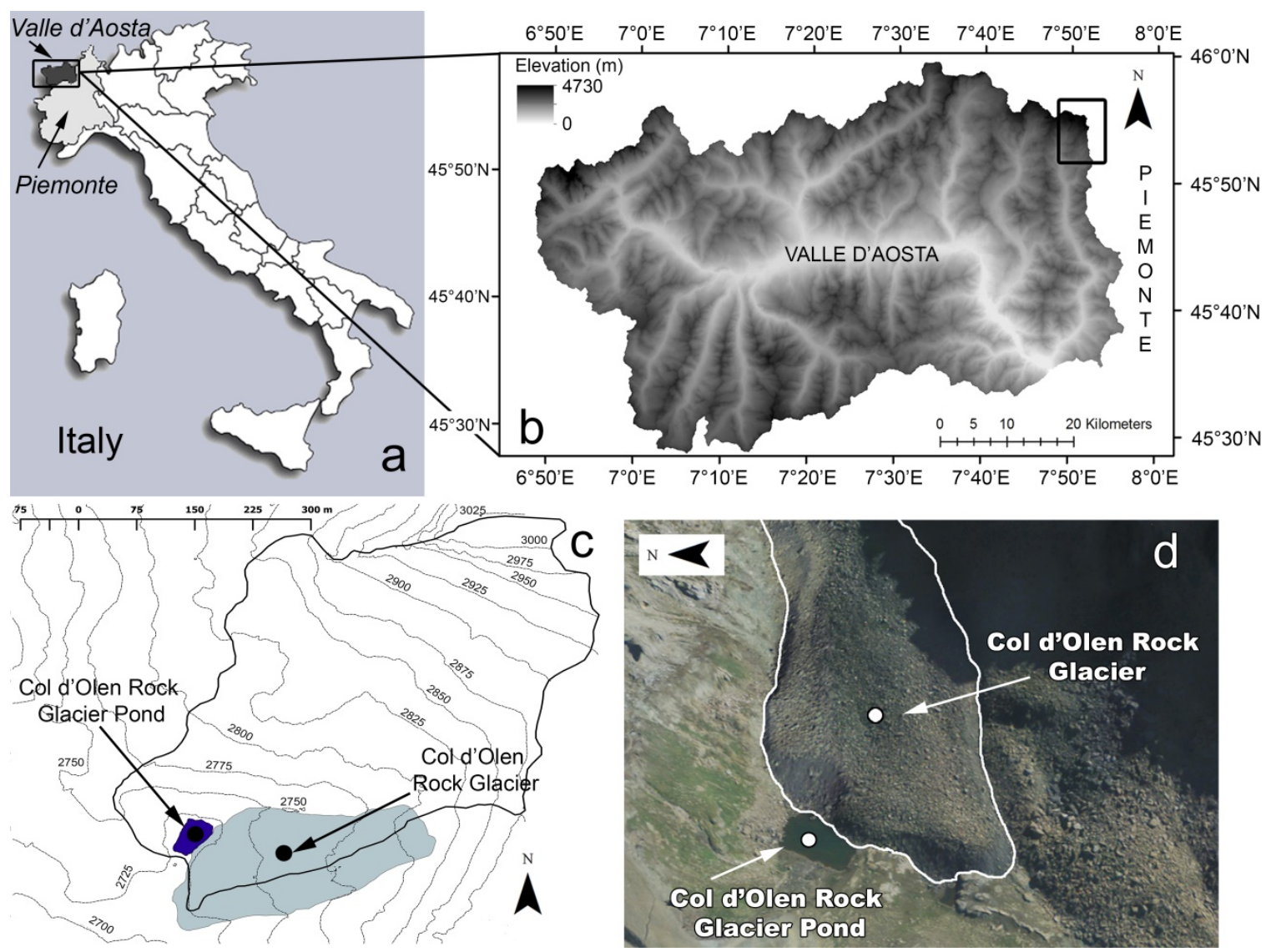

Figure 3.1 - (a) Location of the study area in Italy. (b) Digital Terrain Model (cell size $10 \mathrm{~m} \times 10 \mathrm{~m}$ ) of the Valle d'Aosta Region and the location of the study area in the Region. (c) Elevation map (contour line spacing: $25 \mathrm{~m}$ ) of the Col d'Olen area showing the watershed, the rock glacier, and the pond. (d) Threedimensional view of the rock glacier and the pond (GeoViewer3D Arpa Piemonte, source: $h t t p: / / w e b g i s . a r p a . p i e m o n t e . i t / g e o p o r t a l e)$. 
Several geological studies on the structural setting of the Aosta Valley and the Monte Rosa massif (e.g., Bistacchi and Massironi, 2000; Bistacchi et al., 2000) highlighted an intense brittle reworking of the area at the end of their CretaceousTertiary subductional and collisional history. The regional deformation indicators are in agreement with milestones in the interpretation of long term history of the Alpine orogeny (e.g., Schmid et al., 2004): the collision and SE-directed underthrusting of the European below the Adriatic plate by successive underthrusting, detachment and accretion of the Austroalpine (Sesia-Lanzo) continental crust, the Piemonte oceanic crust and the European continental (Monte Rosa) plate border. In the Col d'Olen area, the tectonic contact between the "Zermatt Sass" unit (Corno Camoscio, $3024 \mathrm{~m}$ a.s.l.) and the overlaying "Combin Zone" unit is characterised by distinctive structural association of brittle faults and fractures whose main systems are approximately $110^{\circ}$ and $60^{\circ}$ oriented.

Main meteorological parameters for the area are recorded by a local highelevation automatic weather station (AWS, Col d'Olen station, $2900 \mathrm{~m}$ a.s.l., located at $800 \mathrm{~m}$ distance from the pond, managed by Military Service Meteomont). For the time span 2008-2015, the area was characterised by a mean liquid precipitation during the ice-free season of $400 \mathrm{~mm}$ and a mean annual air temperature equal to $-2.6{ }^{\circ} \mathrm{C}$. The snowpack generally developed by late October-early November, the initiation of snowmelt began once the snowpack became isothermal in late May-early June, and winter snowpack depletion occurred in July. 
The Col d'Olen Rock Glacier ("Corno Rosso 2 Rock Glacier" in the Aosta Valley rock glacier cadastre, http://www.geonavsct.partout.it) typology is "bouldery" talus-tongue shaped (Haeberli et al., 2006) (rock glacier morphometric characteristics in Tab. 3.1). The surface of the rock glacier is covered by clasts and boulders with common lengths on the order of $0.5-5 \mathrm{~m}$. Fine-grained sediments outcrop at the terminus and at the lateral scarps. Serpentinites constitute the main lithology of the landform body (fine-grained sediments), while calcschists and serpentinites are present as clasts and boulders at the rockglacier surface. Steep slopes of the front, limited lichen growth and absence of vegetation, microform evidences of recent movement in the frontal slopes (e.g., small-size rockfalls and associated new deposit apron formations), in addition to load fresh and unstable boulders on the upper surface indicate the active condition of the rock glacier (Haeberli et al., 2006; Millar and Westfall, 2008), which is also classified as intact rock glacier in the Aosta Valley rock glacier cadastre. The rock glacier shows a main flow direction from NE to SW, toward a small valley depression where the pond is located (Fig. 3.1d). The rock glacier does not have any surficial outflowing springs or streams. The contributing area of the rock glacier to the catchment is $21,800 \mathrm{~m}^{2}$ (i.e., $10.6 \%$ of the catchment).

The pond is situated in front of the rock glacier, placed on the right-marginal side of the tongue (Fig. 3.1d), showing an elongated shape in NE-SW direction (pond morphometric characteristics in Table 3.1). The pond shoreline is surrounded from NE to SE by the rock glacier, with the front dipping into the pond, from $\mathrm{N}$ to SW by weathering deposit slopes (scree accumulations and 


\begin{tabular}{lc}
\hline \multicolumn{2}{c}{ Catchment and rock-glacier morphometric } \\
characteristics \\
\hline
\end{tabular}

Table 3.1 - Catchment, rock-glacier and pond morphometric characteristics. The main geomorphological characteristics in the watershed were obtained from a digital orthoimage from the year 2012 (source: Ministero dell'Ambiente e della Tutela del Territorio e del Mare - Geoportale Nazionale, http://www.pcn.minambiente.it/GN) and morphometric analyses were performed using ESR/® ArcGIS v. 10.1 (Spatial Analyst) and a Digital Terrain Model-DTM (cell size: $2 m \times 2 m$ ) produced by Regione Autonoma Valle d'Aosta. * Given the possibility for sub-surface flow, the actual contribution areas could differ from the DTM analysis. 
pedogenised fine-grained deposits often associated with alpine meadows) and a small rockfall deposit primarily composed of amphibolites, and it is partially bordered on the south by bare bedrock outcrop (calcschists). The pond has no stable surficial inflows. Only a tiny ephemeral snow melting stream is present, that usually disappears during the ice-free season, in July-August; the stream had dried out before the start of the investigated ice-free seasons 2014 and 2015. There are no surficial outflows. It is completely ice-covered during the winter season, with the ice cover than can last from 8 to 9 months. 


\section{Methods: field measurements and laboratory analyses}

\subsection{Waterborne Ground Penetrating Radar (GPR)}

Waterborne GPR on shallow freshwater can be useful for mapping bathymetry, analysing bottom deposit characteristics, and investigating bottom strata (e.g., Arcone et al., 2010; Sambuelli and Bava, 2012; Lachhab et al., 2014; Libohova et al., 2015; Sambuelli et al., 2015).

\subsubsection{Data acquisition}

The GPR survey consisted of 17 profiles acquired using a 200-MHz IDS antenna, for a total length of $530 \mathrm{~m}$, and 13 profiles employing a $500-\mathrm{MHz}$ GSSI antenna, for a total length of $440 \mathrm{~m}$ (Fig. 4.1.1a). Both the surveys were carried out with an IDS K2 GPR unit. To acquire the profiles, a flat-bottom plastic boat tracked with an Ublox EVK-686 GPS was used with an electric engine to maintain a constant speed. The same acquisition parameters were selected both for the $200-\mathrm{MHz}$ and the $500-\mathrm{MHz}$ antennas. The sampling frequency was $4 \mathrm{GHz}$ with 2,048 samples per trace. Boat velocity and GPR scan rate, that was driven by the GPS at 3 readings/second, resulted in a trace interval equal to $0.02 \mathrm{~m}$, on average.

\subsubsection{Data processing}

In order to understand the characteristics of the GPR pulse parameters (i.e., velocity, attenuation and wavelength) in the pond water and the electromagnetic characteristic of the water itself, the main water electromagnetic parameters were estimated. The real dominant frequency of the pulse was estimated calculating 

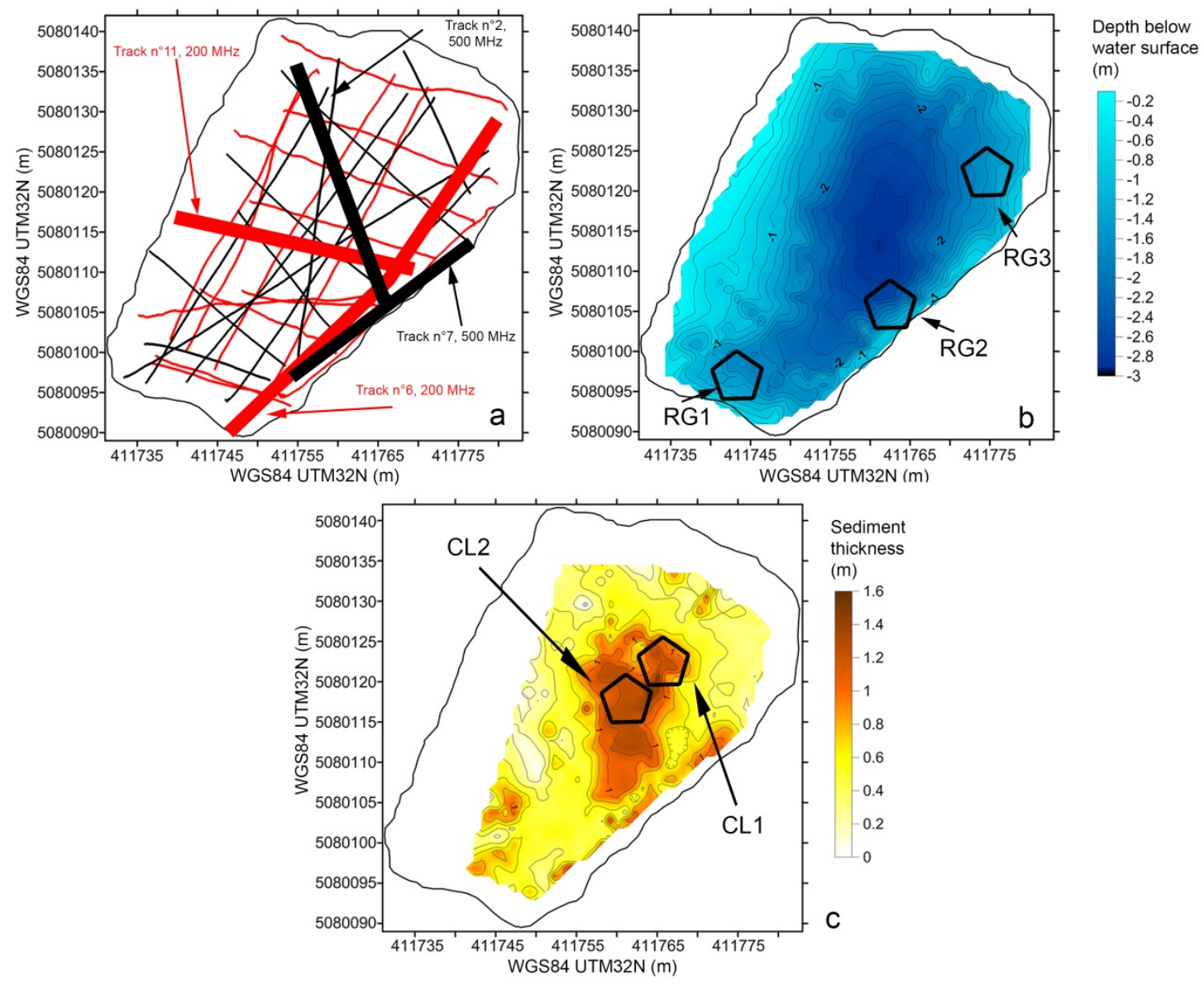

Figure 4.1.1 - (a) Tracks of the GPR surveys (red: $200 \mathrm{MHz}$; black: $500 \mathrm{MHz}$ ) and details (thick lines) of the four tracks showed in Fig. 5.1.1. (b) Pond bathymetry from the triangular interpolation of the picked bottom reflections from all the radargrams. Black bordered polygons: thermal sensor locations. (c) Fine sediment thickness from the difference between the bottom sediment and the bottom pond pickings. Black bordered polygons: locations of the fine sediment lacustrine core locations. 
the spectra of the reflections from the pond bottom. The bottom reflection signals were firstly isolated with a Hanning window (10 ns) centred at the maximum amplitude of reflection. Then, for both 200 and $500 \mathrm{MHz}$ survey lines, the average Fourier spectra were calculated for each profile. The maximum amplitude was found for both the antennas in correspondence to a frequency $f$ equal to $200 \mathrm{MHz}$. The water electrical conductivity $\sigma$, according to several randomly spaced measurements in the pond using a conductivity meter $\mathrm{HI} 98130$ (HANNA instruments, accuracy at $20{ }^{\circ} \mathrm{C}$ of $\pm 2 \%$, resolution of $10 \mu \mathrm{S} \mathrm{cm}{ }^{-1}$ ), was about $50 \mu \mathrm{S} \mathrm{cm} \mathrm{cm}^{-1}$. At the bottom of the pond there are numerous pebbles and small blocks generating diffraction hyperbolas; 56 particularly clear and complete diffraction hyperbolas were selected to estimate the velocity of the GPR pulse in water. Only few diffraction hyperbolas with an average apparent velocity of $45 \pm 1$ $\times 10^{-3} \mathrm{~m} \mathrm{~ns}^{-1}$ were observed in the fine bottom sediments. Giving the scarcity of diffraction events, the sediment thickness was calculated using the velocity in water. In doing so, the sediment thickness was likely underestimated, and it could be from 1.2 to 1.4 times thicker, depending on the true pulse velocity within the sediments

The raw GPR data were processed with Reflexw software, using the following steps: i) spatial resampling of radagrams at equidistant traces of $0.02 \mathrm{~m}$ to keep a high-spatial resolution, ii) start time delay to remove data before main bang (the first reflection deriving from the air-water interface), iii) dewow to filter out low frequencies, iv) removal of average trace to attenuate ringing, v) divergence compensation to recover the geometrical attenuation, vi) diffraction stacking 
using the water velocity, and vii) muting above the pond bottom reflection. Within radargrams, fine sediment deposits showed organised parallel lines while pebbles and rocks showed chaotic and waving reflections with broken and discontinuous lines due to the scattering of the electromagnetic wave. The sediment-bottom reflections were picked only where the boundaries between ordered and chaotic reflections were clear. After assembling all the pickings, the bathymetry map of the pond and the fine sediment thickness map were obtained (Fig. 4.1.1b and 4.1.1c). The depth values were gridded with triangular interpolation into a $10 \mathrm{~cm} \times 10 \mathrm{~cm}$ mesh to obtain the bathymetry of the pond.

\subsection{Waterborne Electrical Resistivity Tomography (ERT) and Self-Potential (SP)}

Waterborne resistivity methods such as electrical resistivity tomography with floating cables can be used to image the resistivity variation along sections. In shallow water, floating electrodes are preferable over bottom electrodes from a logistical point of view even though this causes loss of resolution with depth (Loke and Lane, 2004). This technique can delineate groundwater-lake interactions (Befus et al., 2012), characterise lacustrine sediments (Rucker et al., 2011) and geological settings (Colombero et al., 2014). Moreover, self-potential data can be used for determining upflow (positive anomalies) and downflow (negative anomalies) regions in subsurface flow (Ishido and Pritchett, 1999) and map groundwater-lake water exchange (Grangeia and Matias, 2012). 


\subsubsection{Data acquisition}

The electrical surveys were conducted with the use of floating equi-spaced electrodes stretched across the pond in two different configurations: longer arrays were used along the main length of the pond (4 profiles with 48 electrodes at $1.5-\mathrm{m}$ spacing) while shorter arrays were adopted, to increase the data coverage, transversally to the pond shorter dimension (4 profiles with 24 electrodes at 2-m spacing). Adopted arrays are reported in Fig. 4.2.1a. Polyethylene foam floaters were used in order to allow the cables to be submerged. Cable takeouts were left directly in contact with water (Fig. 4.2.1b), obtaining fully submerged floating electrodes, while stainless steel electrodes were connected to the cable for measuring additional points on shore. Each of these last electrodes was geo-referenced using an Ublox EVK-686 GPS to record the position of the survey line. For both configurations, a WennerSchlumberger sequence was adopted, with a total of 545 measuring quadrupoles for long arrays and 126 for short arrays, to take advantage of both vertical and lateral resolution. A multichannel resistivity meter (Syscal Pro - Iris Instruments) was used for data acquisition.

The Syscal-Pro also allowed for a contemporary acquisition of SP data which were later mapped along the pond. In particular, the SP data were collected along the ERT lines 1, 2, 3 and 4 (electrode spacing $1.5 \mathrm{~m}$ ), which were the longest available survey lines along the pond (Fig. 4.2.1a). SP was measured for 

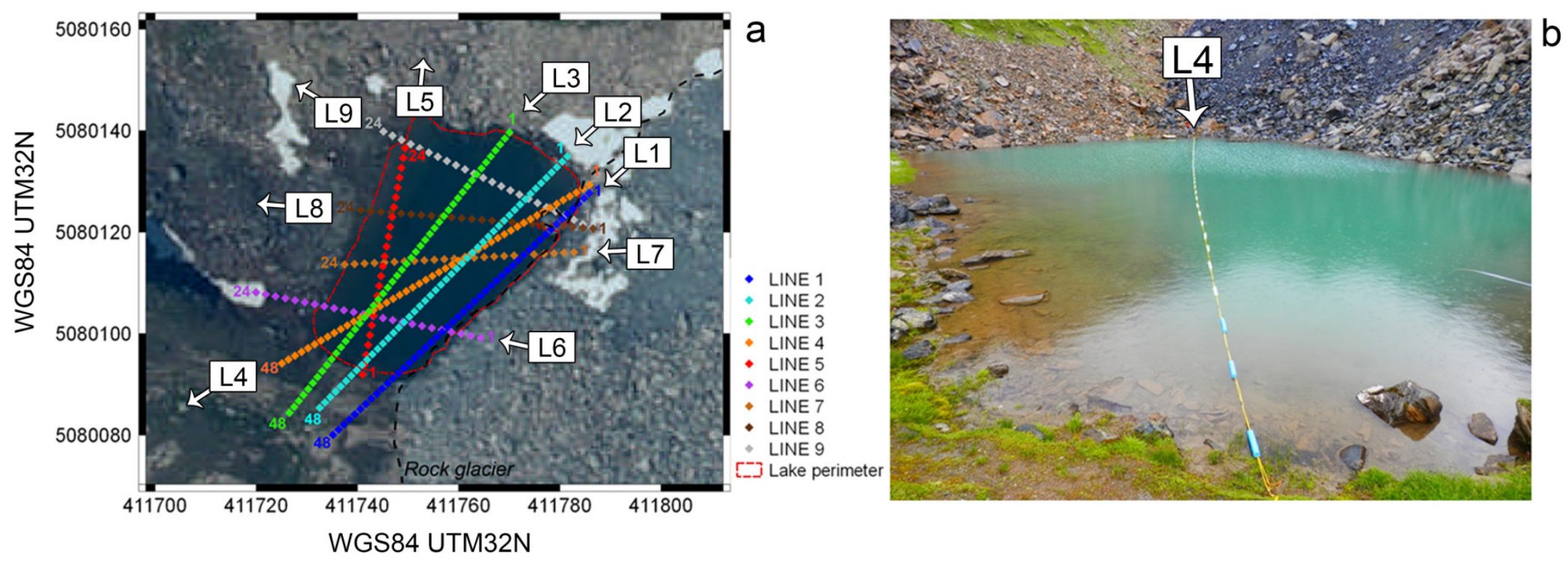

Figure 4.2.1 - ERT survey: (a) survey lines (the arrows indicate the line directions) and (b) picture of the floating electrodes (line 4, SW-NE view). 
each multiple of the electrode spacing, obtaining values with different electrodes separation $(1.5,3,4.5,6 \mathrm{~m})$.

\subsubsection{Data processing}

ERT data were inverted by means of the commercial software Res2DInv (Geotomo Software). To concentrate the inversions in both the sediments below the water and in the underlying bedrock a strong a-priori constraint was imposed to depth and resistivity of the water layer. The first elements of the model were therefore fixed and used to model the water layer, while only the lower part was used for the evaluation of the sub-bottom resistivity distribution. In this way, the inversion program only iterates on the resistivity of the lower part of the model, with a fixed water layer above, to reproduce the observed apparent resistivity measurements. For robust inversion in water covered environments, the water column resistivity and its geometry must indeed be known accurately as a large portion of the electric current may flow through the water layer (Loke and Lane, 2004). This can be taken into account using a finite-element grid to calculate the apparent resistivity values (to be compared with the acquired data) with the nodes along the bottom row of the water mesh adjusted so that the water geometry matches the bathymetry data. In this study, the bathymetry was extracted from the GPR survey (Fig. 4.1.1b). Water resistivity was imposed on the basis of the mean apparent resistivity measured with electrodes having the shortest spacing. These raw data showed a consistent and spatially homogeneous electrical resistivity as confirmed also by several independent randomly spaced measurements carried out with a conductivity meter HI 98130 
(same as in the GPR section). The adopted water resistivity was about $200 \Omega \mathrm{m}$; with this resistivity value the problem of the electric current channelled in the water layer is almost negligible, so a correct penetration of current lines in the bottom sediments is guaranteed.

The SP data obtained with the potential electrode separation of $3 \mathrm{~m}$ were used for mapping. This separation was chosen to reduce short wavelength noise in raw data and to focus on potential anomalies near the bottom of the pond (electrode separation similar to maximum water depth). A total number of $130 \mathrm{SP}$ values were then mapped after a gridding with triangulation on a $2 \mathrm{~m} \times 2 \mathrm{~m}$ mesh, and filtered with a Gaussian $3 \times 3$ square filter to smooth the map and enhance larger scale anomalies.

\subsection{Lacustrine sediment properties}

\subsubsection{Lacustrine sediment probing}

Lacustrine sediments were analysed to support the results obtained from the geophysical investigations. In particular, grain size, sulphur concentrations and electrical conductivity were analysed to compare the laboratory data with the potential porosity value obtained by GPR data processing and resistivity values derived from ERT. In order to do this, two 10-cm-long surficial fine sediment cores were collected from the pond bottom using a boat anchored to the pond shores to ensure enough stability during the coring activities, and a Beeker vibracore sampler (Eijkelkamp, NL), equipped with a polyethylene tube with a diameter of $6 \mathrm{~cm}$ and a 2-m steel extension at the top of the sampler in order to 
reach the bottom of the pond. The core locations (Fig. 4.1.1c) were selected using the GPR-derived fine sediment thickness map to identify sites undisturbed by boulders and pebbles at the pond bottom; an Ublox EVK-686 GPS mounted on the boat was used to identify the selected sites.

\subsubsection{Laboratory analyses}

Samples were immediately sealed with a tight stopper to avoid oxygen infiltration and stored at $4{ }^{\circ} \mathrm{C}$ until laboratory analysis. The presence of sulphidic material was observed through the colour response of the matrix after adding some drops of $3 \% \mathrm{H}_{2} \mathrm{O}_{2}$ and by recording the odour description of each sample (Fanning and Fanning, 1989; Fanning et al., 2002; McVey et al., 2012). The samples were then air-dried and sieved to $2 \mathrm{~mm}$ (Balduff, 2007), and sediment particle size distribution was determined by pipette method (Gee and Bauder, 1986). A wet subsample of each core was aerobically incubated for 16 weeks in 1:1 (w:v) soil:distilled water in order to detect the lowering of $\mathrm{pH}$ due to acid sulphate weathering oxidation in soil horizon which contain reduced sulphides (Bradley and Stolt, 2003). Total S (TS) was quantified by ICP-OES (Ametek, Germany) after aqua regia digestion in a Millestone 1200 microwave oven (Vittori Antisari et

al., 2011). Finally, electrical conductivity measurements were performed using a VWR Multi 340i - WTW multimeter (accuracy $\pm 0.5 \%$, resolution $1 \mu \mathrm{S} \mathrm{cm}{ }^{-1}$ ).

\subsection{Hydrological measurements}

Although waterborne geophysical techniques allow one to infer the hydrogeological setting, they cannot discriminate among different water sources 
contributing to impounded surface waters. Moreover, interactions between surface and subsurface waters are usually quantified through water balance investigations, although water balance cannot distinguish among different subsurface components (e.g., Siegel, 2008). Conversely, the use of tracers can be helpful in discriminating among different contributions in remote and logistically difficult areas (e.g., Anderson, 2005, Langston et al., 2013), which could include the use of natural tracers, such as heat or artificially introduced chemical tracers. Chemical tracers are more invasive and, considering the remoteness and harshness of high-elevation environments, can usually be only used for short periods (e.g., Anderson, 2005). Conversely, heat is an effective natural tracer and can be used efficiently to determine groundwater seepage flux across streambeds (e.g., Schmidt et al., 2007; Constantz, 2008) and at the bottom of lakes and ponds (e.g., Langston et al., 2013).

\subsubsection{Hydrological observations}

Air temperature and snow height were measured at the Col d'Olen AWS. Rain data were obtained from the Gressoney-La-Trinité - Lago Gabiet AWS (2379 m a.s.I., located $2.5 \mathrm{~km}$ distance from the pond, managed by Arpa Valle d'Aosta). Hourly meteorological data were aggregated to daily values and used for the hydrological observations in the ice-free periods 2014 (July-October) and 2015 (June-October).

Water level was measured approximately on a weekly basis during the ice-free seasons using a hydrometric station with direct field observations. The pond watershed area $\left(206,000 \mathrm{~m}^{2}\right)$ was delineated using a Digital Terrain Model-DTM 
(cell size: $2 \mathrm{~m} \times 2 \mathrm{~m}$ ) produced by Regione Autonoma Valle d'Aosta. The surface area of the rock glacier contributing to the pond watershed was quantified on the base of the DTM equal to $21,800 \mathrm{~m}^{2}$ (i.e., $10.6 \%$ of the whole watershed). Given the possibility for sub-surface flow, the actual contribution area, however, could differ.

\subsubsection{Water temperature and heat tracers}

To explore the potential thermal stratification of the pond the temperature profile was measured using an inflatable boat and a hand-held portable thermometer $\mathrm{HI}$ 98130 (HANNA instruments, accuracy $\pm 0.5^{\circ} \mathrm{C}$, resolution $0.1^{\circ} \mathrm{C}$ ). Measurements were performed twice, on 12 July and 9 September 2015, investigating from the surface to the deepest part at 20,100, 200 and $300 \mathrm{~cm}$ depth.

Water temperature in the pond was continuously measured during the water sampling periods at three sites in the pond (Fig. 4.1.1b) defined as RG1, RG2, and RG3 (25 August $\div 9$ October 2014; 9 July $\div 12$ October 2015). Miniature temperature loggers Onset $\mathrm{HOBO}{ }^{\circledR}$ TidbiT v2 Temp loggers (accuracy $\pm 0.21^{\circ} \mathrm{C}$, resolution $\left.0.02{ }^{\circ} \mathrm{C}\right)(\mathrm{RG} 1)$ and Maxim iButton ${ }^{\circledR} \mathrm{DS} 1922 \mathrm{~L}$ (accuracy $\pm 0.5{ }^{\circ} \mathrm{C}$, resolution $\left.0.0625^{\circ} \mathrm{C}\right)(\mathrm{RG} 2$ and $R G 3)$ were programmed to record every three hours. Miniature temperature loggers Maxim iButton ${ }^{\circledR}$ DS1922L were waterproofed using pouches made by $127 \mu \mathrm{m}$ thick laminate material (polyamide - $15 \mu \mathrm{m}$, polyethylene - $100 \mu \mathrm{m}$, aluminium - $12 \mu \mathrm{m}$ ) and sealed using a constant hand heat sealer (WSZ HAWO 300) in order to avoid malfunctions due to the water entry. Loggers were installed at the pond bottom approx. $3 \div 5 \mathrm{~m}$ from the 
shoreline at $1.5 \mathrm{~m}$ (RG1 and RG3) and $1.8 \mathrm{~m}$ (RG2) depth, placed at the sediment-water interface, among blocks (diameter $25 \div 60 \mathrm{~cm}$ ) to shield them from direct solar radiation. RG3 was placed in an area into the pond showing maximum positive SP values (potential subsurface water inflow indicators); RG2 was installed in an area evidencing minimum negative SP values (potential subsurface water outflow indicators); RG1 was placed far from the rock glacier in order to detect and quantify the thermal influence of a potential inflow coming from the rock glacier and affecting the closest sensors (RG2 and RG3), in an area with $\mathrm{SP}$ values close to $0 \mathrm{mV}$ (potential absence of subsurface water inflow and outflow) (details in SP section and discussion).

The total daily discharge flow into the pond $\left(Q_{\text {tot }_{\mathrm{i}}}\right)$ can be calculated as the sum of the rock-glacier discharge $\left(\mathrm{Q}_{\text {rock }_{\mathrm{i}}}\right)$ and all other possible inputs (effective precipitation, run off, subsurface flow, etc.) $\left(Q_{e^{e x t}}\right)$ :

$Q_{\text {tot }_{i}}=Q_{\text {ext }_{i}}+Q_{\text {rocki }_{i}}$

In this equation, the three terms are unknown. The absence of surface inflows and outflows does not allow to derive the rock-glacier discharge. In this context, a classical water balance approach at daily scale would not help in determining these parameters. Conversely, calculation of the pond energy balance using heat tracer allows to obtain more information on rock-glacier inflow contributions to the pond.

The energy balance of the pond can be written as 


$$
c_{\mathrm{w}} \varphi_{\mathrm{w}} \mathrm{T}_{3 \mathrm{i}} \mathrm{Q}_{\text {tot }_{\mathrm{i}}}=\mathrm{c}_{\mathrm{w}} \varphi_{\mathrm{w}} \mathrm{T}_{\mathrm{i}_{\mathrm{i}}} \mathrm{Q}_{\mathrm{ext}_{\mathrm{i}}}+\mathrm{c}_{\mathrm{w}} \varphi_{\mathrm{w}} \mathrm{T}_{0} \mathrm{Q}_{\text {rock }_{\mathrm{i}}}
$$

where $\varphi_{\mathrm{w}}\left(\mathrm{kg} \mathrm{m}^{-3}\right)$ is the density of water, $\mathrm{c}_{\mathrm{w}}\left(\mathrm{J} \mathrm{kg}^{-1} \mathrm{~K}^{-1}\right)$ is the specific heat of water, $T_{2}$ and $T_{3 i}$ are RG2 and RG3 temperatures $\left({ }^{\circ} \mathrm{C}\right)$ at the $i_{\text {th }}$ day, and $T_{0}$ is the meltwater temperature of the rock glacier. RG3 and RG2 were chosen because of their locations, one in correspondence of strong positive SP values (RG3) and one located in an area with strong negative SP values (RG2). The eq. 4.4.2 was solved estimating the relative rock-glacier discharge with meltwater at $0.5^{\circ} \mathrm{C},+0{ }^{\circ} \mathrm{C}$ and $+0.5^{\circ} \mathrm{C}$, and assumed constant over time (e.g., Williams et al., 2006; Krainer et al., 2007; Millar et al., 2013). A negative water temperature was chosen as lower threshold considering the accuracy of the sensors deployed in the pond and due to possible freezing point depression from dissolved salts (e.g., Banin and Anderson, 1974; Davis, 2001). Both $\mathrm{c}_{\mathrm{w}}$ and $\varphi_{\mathrm{w}}$ are constant and thus can be neglected (Langston et al., 2013).

To solve the problem of the unknown terms $Q_{\text {tot }_{i}}$ and $Q_{\text {ext }_{i}}, Q_{\text {tot }_{i}}$ was posed $=$ 1 for all considered days, deriving the eq. 4.4.3 as function of $Q_{\text {rock }}$

$$
T_{3 i}=\mathrm{T}_{2_{\mathrm{i}}}\left(1-Q_{\text {rock }_{\mathrm{i}}}\right)+T_{0_{i}} Q_{\text {rock }_{i}} \text { if } Q_{\text {tot }_{i}}=1
$$

Then, $Q_{\text {rock }_{i}}$ has been obtained as function of $T_{3 i}$ and $T_{2 i}$. However this simplification induces a loss of information. In fact, $Q_{\text {rock }_{i}}$ in the resulting eq. 4.4.4 is not expressed as daily absolute value of the discharge coming from the 
rock glacier, but it represents the rate of rock-glacier discharge on total discharge reaching the RG3 sensor in $i_{\text {th }}$ day.

$$
Q_{\text {rock }_{i}}=\frac{T_{3 i}-T_{2 i}}{T_{0 i}-T_{2 i}} \text { if }\left(T_{3 i} \leq T_{2 i} \text { and } T_{3 i} \geq \mathrm{T}_{0}\right)=>0 \leq{\text { Q } \text { rock }_{i}} \leq 1
$$

The application of this approach allows to know the periods when the contribution of the rock glacier is detectable. However, in absence of further hydrological balance terms such as inflow runoff or pond outflow, that is a common deficiency at all high-elevated water bodies, this method provides qualitative information (eq. 4.4.4), since it is not able to quantify the rock-glacier contribution in absolute terms. It is important to note that no measurements were performed during periods in which rock-glacier discharge is usually reported to be the highest due to snowpack melting (May-June) (e.g., Krainer and Mostler, 2002; Krainer et al., 2007) because of the presence of ice cover on the pond. Thus, in this thesis, rock-glacier discharge generally refers to periods with higher export of cold water from the rock glacier not attributable to conspicuous snow melting at the beginning of the melt season (details in Section 6.1.2 and 6.2.1).

\subsection{Field observations}

The main geological and geomorphological features in the catchment were investigated using digital orthoimages from the years 2006 and 2012 (source: Ministero dell'Ambiente e della Tutela del Territorio e del Mare - Geoportale Nazionale, http://www.pcn.minambiente.it/GN) in QuantumGIS (Geographic 
Information System). Several detailed field visits were conducted in 2014 and 2015 to validate the geological and geomorphological interpretations.

\subsection{Snow duration}

Given the key role of snow in the geochemistry of source water in alpine catchments (e.g., Williams et al., 2006), snowpack duration in the catchment and on the rock glacier was estimated applying three approaches to account for different spatial and temporal resolutions in order to adequately assess snow presence/absence in the catchment. Specifically, the three approaches are: (i) local meteorological measurements, (ii) spatially distributed coarse-scale approach, and (iii) spatially distributed fine-scale approach.

(i) Hourly data on snow thickness were obtained from the Col d'Olen AWS to monitor local snowpack melt progression during the ice-free seasons. Data were aggregated to daily values. No data gaps were present in the series.

(ii) Landsat 8 imageries (pixel 30 m geolocation uncertainty: 3-6 m, Storey et al., 2014) were used during the considered ice-free seasons 2014 and 2015. This approach provided coarse spatial-resolution estimation of snowpack lasting in the catchment on weekly to two-weekly basis in order to determine the duration of a widespread and continuous snowpack in the catchment. Landsat 8 data were downloaded from www.earthexplorer.usgs.gov by setting the desired time span and by using the catchment shapefile to define temporally and spatially the desired dataset. By the employment of R script ( $R$ Development Core Team, 2011) originally developed by the authors (Godone et al., 2011; Minora et al., 
2015) for MODIS datasets, in each Landsat scene the snow cover was detected and processed according to the following algorithm. Every scene was subsetted by the boundaries of the study area. Landsat scenes were then processed in order to compute snow covered pixels by NDSI (Normalized Difference Snow Index), computed by linear combination of Landsat bands (Riggs et al., 1994):

$$
N D S I=\frac{\text { band } 3-\text { band } 6}{\text { band } 3+\text { band } 6}
$$

where, band 3 has wavelengths of 0.53 to $0.59 \mu \mathrm{m}$ (the green band) and band 6 has 1.57 to $1.65 \mu \mathrm{m}$ wavelengths (the short-wavelength infrared band). When the NDSI value is greater than 0.4 the pixel is classified as snow covered. The whole categorised raster dataset was then converted into tabular form to proceed to the counting phase and snow cover duration quantification.

(iii) For a fine-scale spatially distributed analysis of long-lasting snow patches, especially among the coarse blocks at the rock-glacier surface, a network of miniature sensors was established to monitor snowpack melt using the ground surface temperature (GST) (e.g., Gadek and Leszkiewicz, 2010; Staub and Delaloye, 2016). The melt-out date of snow (MD, the time when the snow cover is depleted and no further release of meltwater occurs) was calculated based on the methodology proposed by Schmid et al. (2012). GSTs were measured using miniature temperature loggers Maxim iButton ${ }$ DS1922L, programmed to record every three hours from 25 August 2014 to 12 October 2015. Loggers were waterproofed using the methodology described in chapter 4.4.2. 34 sensors were 
distributed on a regular grid $(26 \mathrm{~m} \times 26 \mathrm{~m})$ in the contributing area of the rock glacier to the pond catchment. The regular grid was generated in QuantumGIS environment using the Regular Points tool. The grid was then established on the rock glacier surface using compass and tape measure, following the grid azimuth and distance node-to-node extracted from QuantumGIS. Coordinates for each sensor were acquired using a Garmin GPSMAP® 64. 34 loggers were buried approximately $10 \mathrm{~cm}$ into the ground or placed between and underneath boulders to shield them from direct solar radiation. 32 were retrieved after the deployment period (Fig. 4.6.1). Each sensor was fixed to a yellow-red string (nylon, ø $3.5 \mathrm{~mm}$ ) and attached to an iron stick (ca. $50 \mathrm{~cm}$ ) with a red-and-white tape to facilitate the retrieving of sensors after the period of deployment, installed among blocks and in fine-grained material, and distanced from each sensor by at least 2 meters. To prevent iButtons from falling down steep slopes or in holes among boulders, loggers were further attached to large, stable boulders. Threehourly data were aggregated to daily values. No data gaps were present in the series.

\subsection{Chemical analyses}

Sampling activities in the pond were carried out during the ice-free seasons 2014

and 2015 (same time-span of water temperature measurements), collecting samples from the shore, approximately on weekly basis at three different locations in the pond (in correspondence of the water temperature sensors, Fig. 4.1.1b), using a telescopic sampling beam. A $300 \mathrm{~cm}$-deep snow profile was dug 


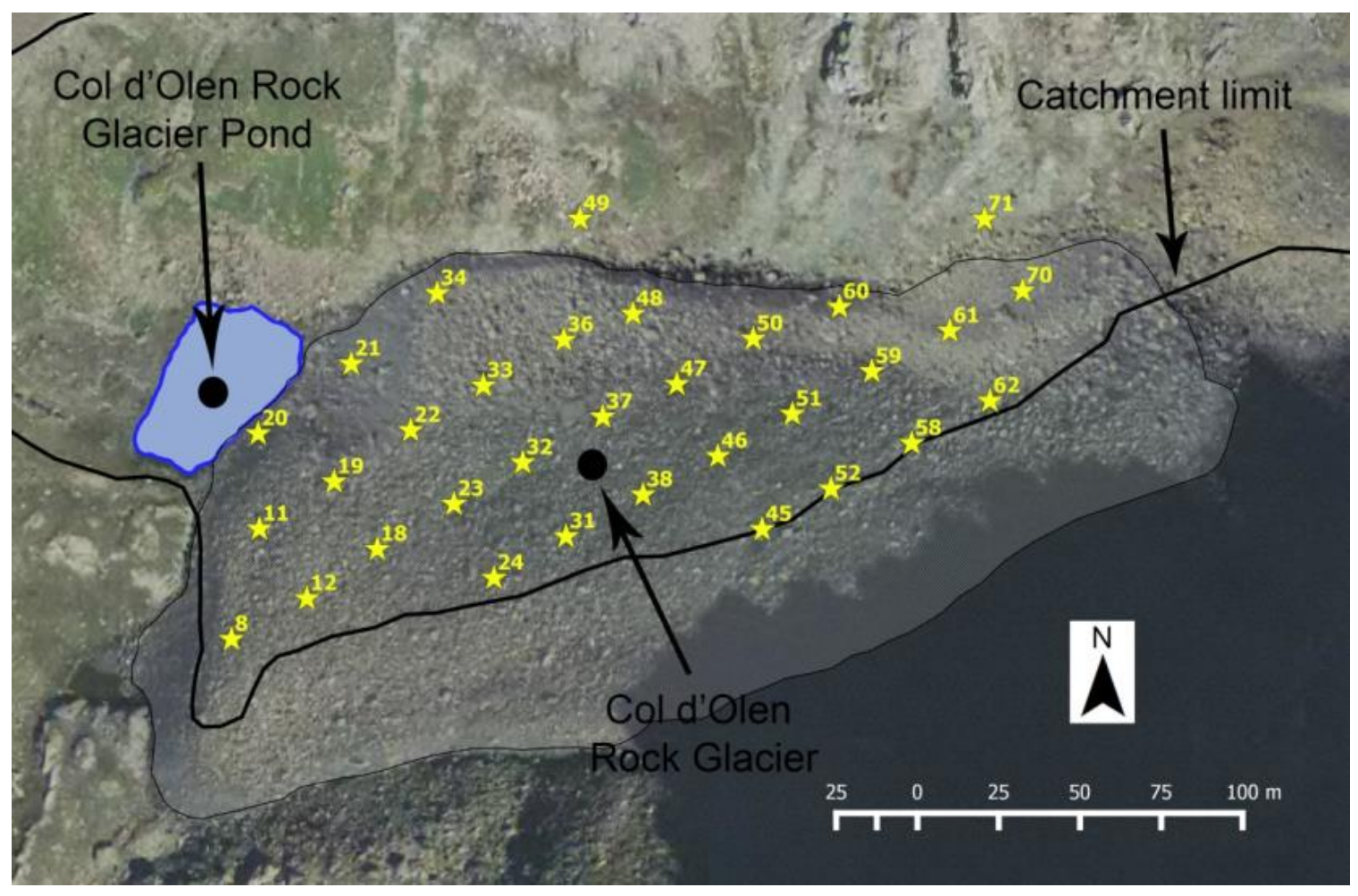

Figure 4.6.1 - Sensor regular grid. Numbers refer to the ID of each sensor (base map: digital orthoimage from the year 2006; source: Ministero dell'Ambiente e della Tutela del Territorio e del Mare - Geoportale Nazionale, http://www.pcn.minambiente.it/GN). 
and sampled before the melting season near the Col d'Olen station in April 2015, and 6 samples were collected at $50 \mathrm{~cm}$-step for isotopic analyses. One rain collector was installed on the southern part of the pond and sampled for isotopic analyses when precipitation occurred (13 observations).

At each water sampling point and date, two water samples were collected in new $50 \mathrm{ml}$ Falcon tubes for solute analyses. The content of one $50 \mathrm{ml}$ Falcon tube was immediately filtered through a $0.2 \mu \mathrm{m}$ membrane filter for the subsequent chromatographic analysis of major anions, while another aliquot of the filtered samples was acidified to $\mathrm{pH}<2$ for the analysis of major cations and trace elements. The first $15-20 \mathrm{ml}$ of the filtrate in the Falcon tube used for major cations and trace elements analyses was discarded to condition the filter and then the tube was pre-rinsed three times with filtered sample water. The second Falcon tube, used for measurements of electrical conductivity (EC) and $\mathrm{pH}$, remained unfiltered and was pre-rinsed three times with sample water. All the tubes were completely filled without headspace. Samples were stored in an icepacked cooler (KERN FRIO Diagnosach) during transport and immediately transferred to the laboratory where they were refrigerated $\left(+4{ }^{\circ} \mathrm{C}\right)$. Snow samples were stored frozen $\left(-20^{\circ} \mathrm{C}\right)$ until analysis, then placed in covered polyethylene buckets and melted at room temperature. $\mathrm{pH}$ was measured using a WTW InoLab 7110 pH-meter, equipped with Hamilton GelGlass electrode. EC was measured using a Crison - Micro CM 2201. The concentration of major anions $\left(\mathrm{Cl}^{-}, \mathrm{NO}_{2}{ }^{-}, \mathrm{NO}_{3}{ }^{-}, \mathrm{PO}_{4}{ }^{3-}, \mathrm{SO}_{4}{ }^{2-}\right)$ was determined with a Dionex DX-500 (Dionex Corp., California), $2 \mathrm{~mm}$ system, equipped with an auto-sampler AS50, AS9 
analytical column, and AG9 pre-column. The eluent was $9 \mathrm{mM}$ sodium carbonate pumped at a flow rate of $0.25 \mathrm{ml} \mathrm{min}{ }^{-1}$. Major cations $\left(\mathrm{Ca}^{2+}, \mathrm{Mg}^{2+}, \mathrm{K}^{+}, \mathrm{Na}^{+}\right)$were determined using a Perkin Elmer AAnalyst 400 (Perkin-Elmer Inc., Waltham, Massachusetts). Potential toxic trace elements (Ni, Mn, Co) from weathering of serpentinites (main lithology in the rock glacier body) (e.g., Brooks, 1987; Schreier et al., 1987) and generally reported to be highly concentrated in rockglacier outflows (Thies et al., 2013) and lakes (Thies et al., 2007; llyashuk et al., 2014) were analysed. These elements were determined using a Thermo Finnigan Element 2 Inductively Coupled Plasma-Mass Spectrometer, able to work at low, medium and high resolution. The quality of chemical analyses was checked by including method blanks and repeated measurements of internal and certified samples. Analytical precision for major anions was $<10 \%$, and for major cations and for trace elements was $<5 \%$.

Samples for stable water isotopic analyses $\left(\delta^{18} \mathrm{O}\right.$ and $\left.\delta^{2} \mathrm{H}\right)$ were collected using new vials with airtight caps. To determine isotope concentrations an Isotopic Liquid Water Analyzer used a time based, optical absorption spectroscopy of the target gasses (Picarro L2130-i). Analyses for $\delta^{18} \mathrm{O}$ and $\delta^{2} \mathrm{H}$ were performed at the INSTAAR (Institute of Arctic and Alpine Research) Kiowa Environmental Chemistry Laboratory of the University of Colorado at Boulder (USA). Isotopic compositions are expressed as a $\delta$ (per mil) ratio of the sample to the Vienna standard mean ocean water (VSMOW), where $\delta$ is the ratio of ${ }^{18} \mathrm{O} /{ }^{16} \mathrm{O}$ or ${ }^{2} \mathrm{H} /{ }^{1} \mathrm{H}$. Analytical precision was $0.05 \%$ for both $\delta^{18} \mathrm{O}$ and $\delta^{2} \mathrm{H}$. Deuterium excess ( $\left.d_{\text {excess }}\right)$ (Dansgaard, 1964) was also analysed to provide 
insight into the potential importance of melt-freeze cycles characterising the outflow from the rock glacier (Steig et al., 1998; Williams et al., 2006). $d_{\text {excess }}$ was computed for each sample following the protocol developed by Johnsen and White (1989) based on the equation for the Global Meteorological Water Line (GMWL, Craig, 1961). Finally, the $\delta^{2} \mathrm{H}-\delta^{18} \mathrm{O}$ relationship was investigated in order to identify dissimilarities in water sources in the pond sampling sites based on the discrimination of potential different evaporative rates (Williams et al., 2006). The equations were related to the Local Meteoric Water Line (LMWL) which was derived from precipitation data collected close to the pond.

\subsection{Statistical analyses}

Statistical analyses were performed using the programming language $R(R$ Development Core Team, 2011). Principal Component Analysis (PCA), a multivariate ordination technique, was conducted to interpret the major patterns of variation in the chemical data. Data were centred and standardised to mean zero and unit variance so that all variables were comparable. The degree of correlation among data was verified through the correlation coefficient (r) (e.g., Venables and Ripley, 2002).

A conceptual map (model flow chart) of the methodological approach presented in this chapter is reported in Fig. 4.8.1. 
Hydrology and structural setting of the Col d'Olen Rock Glacier Pond

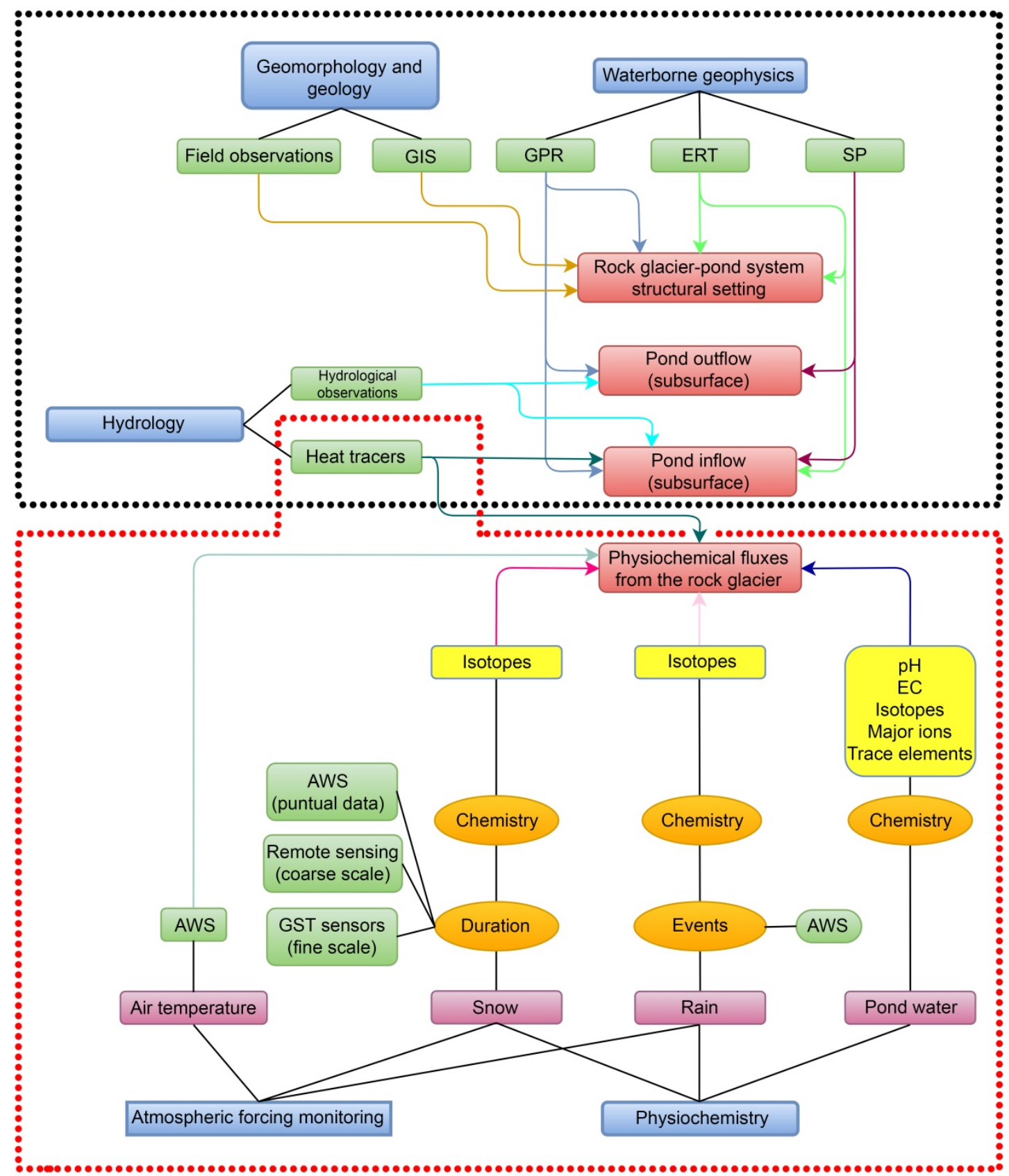

Atmospheric forcing of physicochemical fluxes from the Col d'Olen Rock Glacier

Figure 4.8.1 - Model flow chart representing the applied methodological approach. Blue rectangles denote main methodological approaches. Methods are marked in green, analysed variables are shown in purple, and analytes are reported in yellow. Orange ovals specify the type of analyses performed on variables. Red rectangles denote the different objectives of the study. Coloured arrows are used to simply the visualizations of connections among the different components of the flow chart. 


\section{Results}

\subsection{Hydrology and structural setting of the Col d'Olen Rock}

\section{Glacier Pond}

\subsubsection{GPR}

The velocity of the GPR pulse in water was calculated to be $34 \pm 0.5 \times 10^{-3} \mathrm{~m} \mathrm{~ns}^{-1}$, resulting in a relative permittivity $\varepsilon_{\mathrm{r}}$ of $77.8 \pm 2.3$. The uncertainty on velocity, together with the one on the time picking (around 1 ns) give an uncertainty of the water depth determination from 0.05 to $0.20 \mathrm{~m}$ respectively for the shallowest and the deepest reflections. Applying the Maxwell equations to the pond water, giving $\sigma$, $f$ and $\varepsilon_{r}$, an intrinsic attenuation at $200 \mathrm{MHz}$ equal to $0.93 \mathrm{~dB} \mathrm{~m}^{-1}$ and a dominant wavelength $\lambda$ of $0.17 \mathrm{~m}$ were calculated (Sambuelli and Bava, 2012). Similar values have been found in the literature (e.g., Arcone et al., 2010). Although the sediment thickness was calculated using the velocity of the GPR pulse in water, the average apparent velocity $\left(45 \pm 1 \times 10^{-3} \mathrm{~m} \mathrm{~ns}^{-1}\right)$ of the few diffraction hyperbolas in the sediment was used to estimate the porosity of the material. Supposing a relative permittivity of the solid mixture equal to 6.5 (Vaccaneo et al., 2004), and using the CRIM formula (Birchak et al., 1974), a porosity of approximately $65 \%$ was obtained.

The GPR tracks clearly show a series of dense diffractions along the pond eastern bank, parallel to the rock-glacier front, characterised by a rough surficial appearance (Fig. 5.1.1a). The coarse diffractions progressively disappear towards the centre of the pond, ending in a bouldery apophysis located at ca. 5-7 m distance from the shore (Fig. 5.1.1b). In the southeastern corner of the pond, 

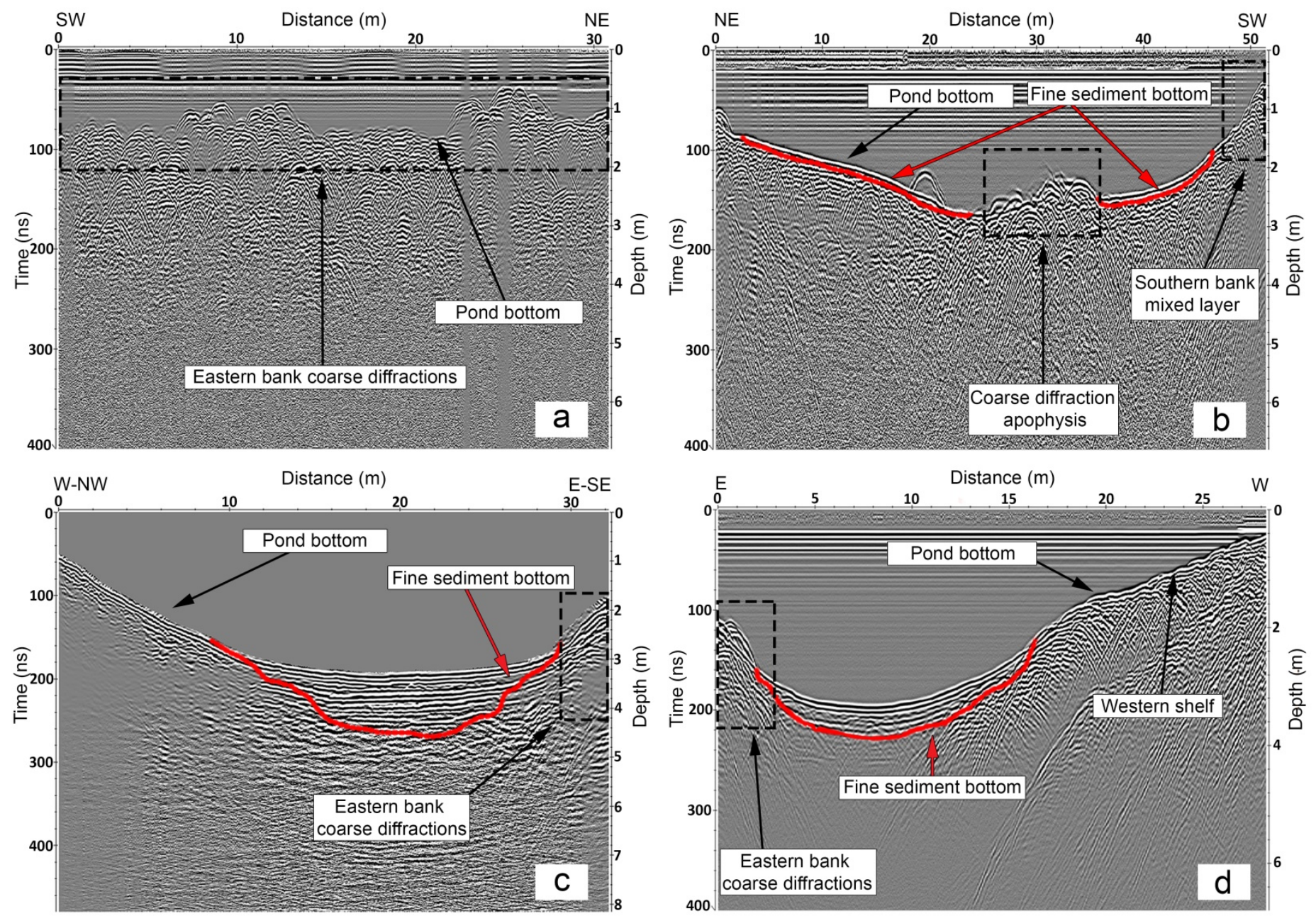

Figure 5.1.1 - GPR tracks in the pond: (a) track $n^{\circ} 7,500 \mathrm{MHz}$; (b) track $n^{\circ} 6,200 \mathrm{MHz}$; (c) track $n^{\circ} 2,500 \mathrm{MHz}$; (d) track $n^{\circ} 11,200 \mathrm{MHz}$. The red line in figures $a, b$ and $c$ highlights the limit of the fine-sediment bottom. Refer to Fig. 4.1.1a for track codes. 
the waterborne GPR profiles highlight the presence of surficial coarse diffractions mixed to a generally smooth-reflecting horizon at shallow depths (Fig. 5.1.1b).

From the bathymetric and fine-sediment thickness maps (Fig. 4.1.1b and 4.1.1c), a directional depression pattern can be observed in the central and northern parts of the pond, showing a N-S preferential elongated orientation, where water depth and fine-sediment thickness are greater. This elongated depression can be seen in the GPR track shown in Fig. 5.1.1c and 5.1.1d, which highlights an evident asymmetrical structure of this pond section. Slopes are greater along the rock glacier front in the East whereas the western portion of the pond is characterised by a shelf area, where the bottom surface is nearly horizontal and generally beneath less than $1.2 \mathrm{~m}$ of water.

\subsubsection{ERT and SP}

In Fig. 5.1.2 the results of the 2D inversion along some selected lines are reported (for line locations see Fig. 4.2.1). For all the sections, given the good electric coupling of injecting and measuring electrodes, high quality data were acquired with RMS convergence values of the inverse problem always below $2.3 \%$. On each imaged section, bathymetry and sediment thickness are shown (Fig. 4.1.1b and 4.1.1c). Remarkably, the depth of shallow sediments beneath the pond bottom, which was not included as a constraint in the inversion, is correctly depicted by the ERT results. Most of the ERT lines indeed resolve a layer of sediments, with a thickness matching GPR data. These sediments just 
NE

L1 RMS $=2.14 \%$
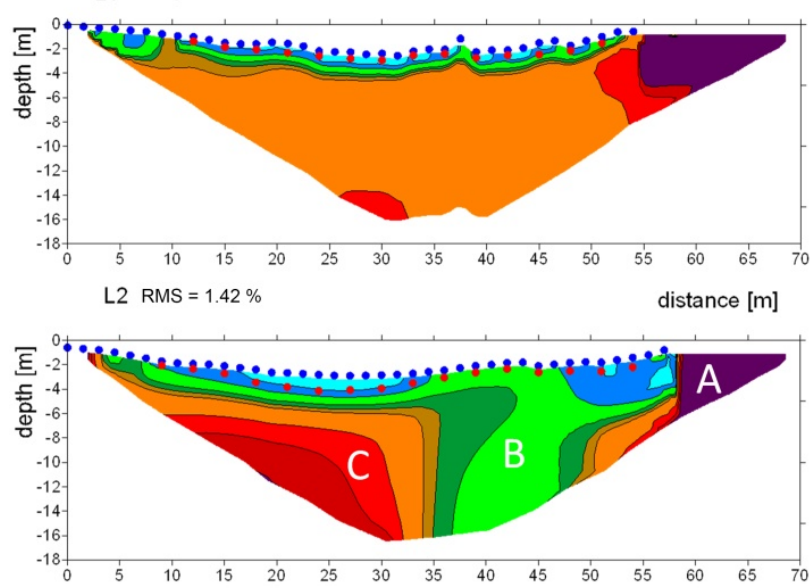

L3 RMS $=2.23 \%$

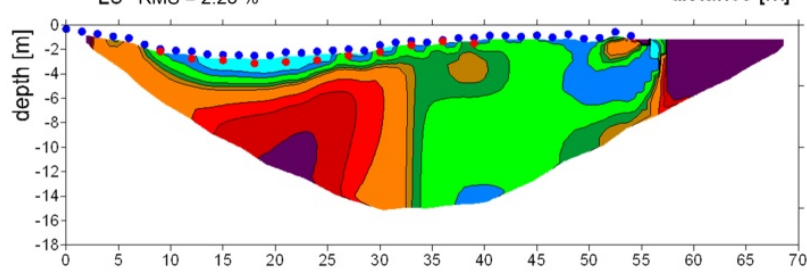

L4 RMS $=1.13 \%$

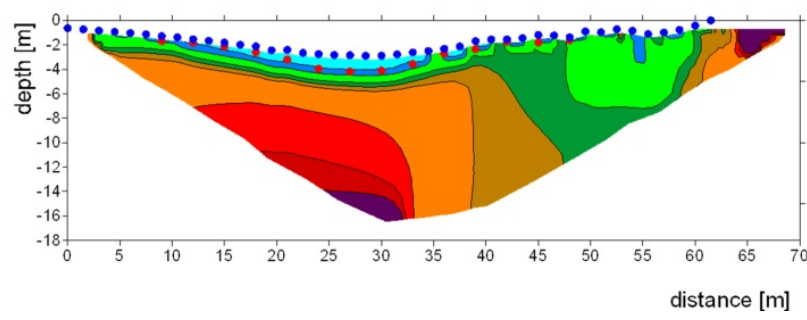

Resistivity [Ohm.m]

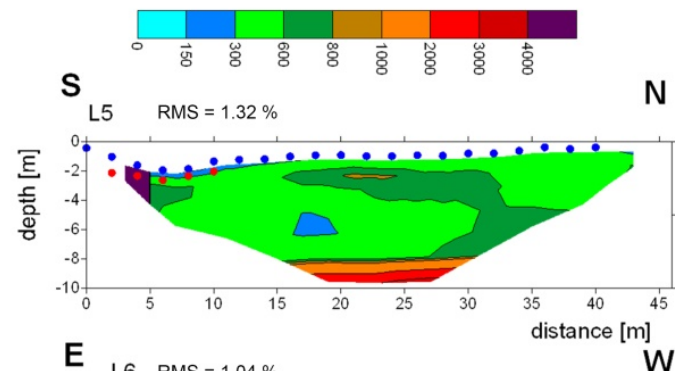

E L6 RMS $=1.04 \%$
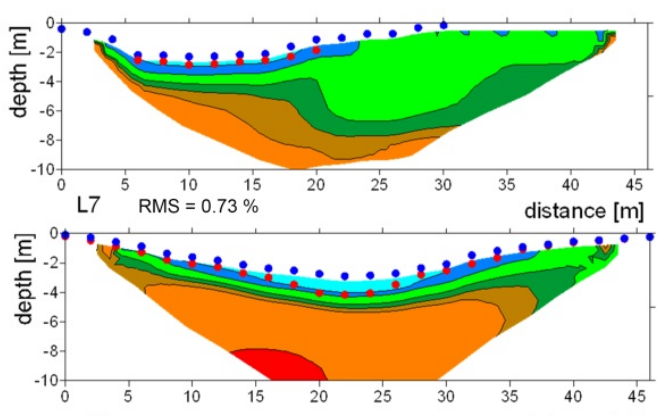

L8 RMS $=1.12 \%$

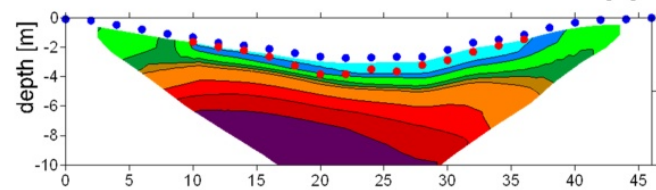

L9 $\mathrm{RMS}=1.07 \%$

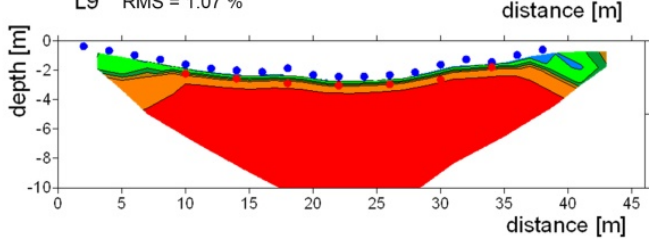

Figure 5.1.2 - Interpreted resistivity sections in the pond. For the location of each survey line make reference to Fig. 4.2.1a. Blue dotted line: pond bottom from GPR; red dotted line: depth of shallow sediments (second reflector in the GPR). $A$ (massive bedrock), B (low resistivity anomaly) and C (high resistivity body) in L2 highlight the subsurface structures identified in the pond (details in the text). The boundaries of the pond correspond to the presence of bathymetry data. 
below the bottom of the pond have a resistivity (about $150 \mathrm{Ohm} \cdot \mathrm{m}$ ) lower than one of the water layer (200 Ohm.m). Laboratory measurements of electrical conductivity of the two surface lacustrine sediment samples are coherent with the results obtained from the resistivity surveys.

Beneath the low-resistivity lacustrine sediment layer, the pond bed does not show horizontally constant resistivity values. From the ERT results it is evident that higher resistivity values in the sub-sediment zones are in the northern part of the pond $(1000-4000 \mathrm{Ohm} \cdot \mathrm{m})$, while in the southern zones a strong continuous anomaly (3000-5000 Ohm. $\mathrm{m})$ is located at the pond margin and on the shore (Fig. 5.1.2). Moreover, most survey lines report a wide zone with relatively low resistivity (300-600 Ohm $\cdot \mathrm{m})$ truncating the two higher resistive areas. For the line nearest to the rock glacier ( $\mathrm{L} 1$, close to the southern shore), this anomaly is concealed (Fig. 5.1.2) probably due to 3D effects. A 3D fence diagram of the ERT results is also reported in Fig. 5.1.3; from this representation, it is possible to understand the good correspondence of the inverted resistivity values at the lines intersections and the orientation of the low resistivity anomaly within the bedrock. From this last representation, a plan view of the $2000 \mathrm{Ohm} \cdot \mathrm{m}$ isosurface, obtained by 3D interpolation of the resistivity data is compared with the SP map (Fig. 5.1.4). The SP map shows a remarkable spatial coherency of maxima and minima in NW-SE bands that correspond with the ERT results. A good agreement with the minima of SP and the NW-SE band with low resistivity values is evident if the volumes with resistivity higher than $2000 \mathrm{Ohm} \cdot \mathrm{m}$ are 


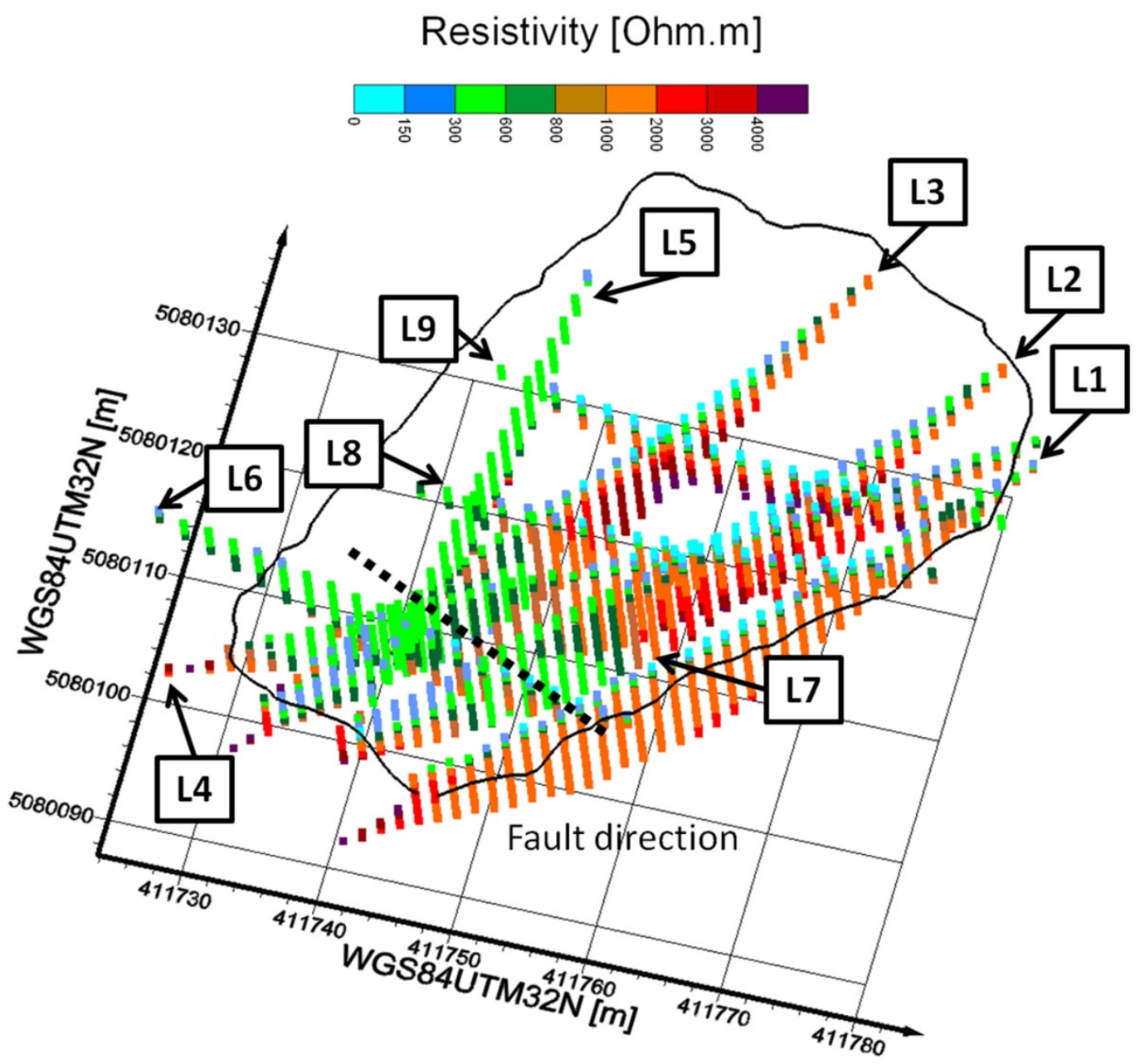

Figure 5.1.3 - 3D fence diagram of the ERT inversions with evidence of the survey lines (the arrows indicate the line directions) and of the pond perimeter. 

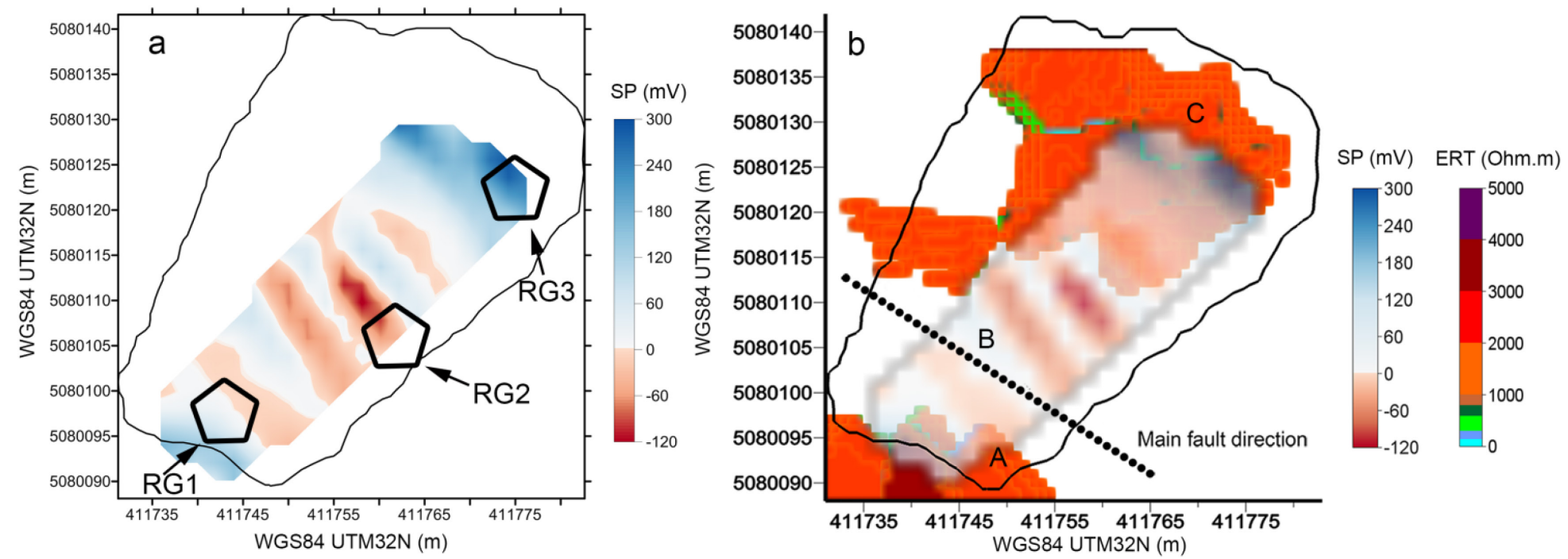

Figure 5.1.4 - (a) SP map of survey anomalies (black bordered polygons: thermal sensor locations) and (b) SP map superimposed to the $2000 \mathrm{Ohm} \bullet \mathrm{m}$ isosurface from the interpolation of the acquired lines. A (massive bedrock), B (low resistivity anomaly) and C (high resistivity body) (make reference to Fig. 5.1.2, L2). 
plotted (Fig. 5.1.4). In Fig. 5.1.4 the low resistivity discontinuity is clearly visible as a WNW-ESE elongated band affecting the pond bedrock for a width between 10 and $15 \mathrm{~m}$. SP results evidence the presence of 4 low potential anomalies indicated by negative potentials $(-10$ to $-120 \mathrm{mV})$, with a similar orientation of the low resistivity discontinuity. The SP map has been obtained from L1-L4 SP profiles, showing a good alignment of maxima and minima. Thus, giving the unlikely occurrence of a replica of the same artefact in all the acquired profiles, we consider this spatial SP result to reveal the geological structure beneath the pond. One main negative band (minimum: $-120 \mathrm{mV}$ ) was detected along the resistivity anomaly identified by the ERT investigations. One main positive anomaly (maximum: $300 \mathrm{mV}$ ) was found in the northern part of the pond (Fig. 5.1.4). A secondary slightly positive anomaly was found on the southern shore of the pond (Fig. 5.1.4).

\subsubsection{Lacustrine sediment properties}

The granulometric analyses show that the sample $n^{\circ} 1$ (CL1 in Fig. 4.1.1c) is mainly composed of silt (82.8\%), sand $(9.6 \%)$ and clay $(7.6 \%)$. Sample $n^{\circ} 2$ (CL2 in Fig. 4.1.1c) is similar with silt $(82.9 \%)$, sand $(11.8 \%)$ and clay $(5.3 \%)$. The sediments appear dark brown to black coloured with a strong sulphidic odour, suggesting the presence of organic sulphur compounds. The evidence of sulphidation process was further demonstrated by acidification during aerobic incubation (Ferronato et al., 2016), which occurred in both the samples, losing up to $1.8 \mathrm{pH}$ units. The accumulation of reduced organic $\mathrm{S}$ compounds was also

confirmed by high TS content measured in the two cores $\left(0.6 \mathrm{~g} \mathrm{~kg}^{-1}-\mathrm{CL} 1\right.$ and 
$0.4 \mathrm{~g} \mathrm{~kg}^{-1}$ - CL2). Furthermore, laboratory measurements of electrical conductivity of the two samples reported a mean value of $62 \mu \mathrm{S} \mathrm{cm}$. This value in accordance with ERT results for the same layer (around $150 \mathrm{Ohm} \cdot \mathrm{m}$ ).

\subsubsection{Hydrological evidence}

The liquid precipitation during the ice-free seasons 2014 and 2015 was $478 \mathrm{~mm}$ and $567 \mathrm{~mm}$ (Fig. 5.1.5a and 5.1.5b). A water-level decrease throughout the summer was observed during the weekly water level measurements at the hydrometric station, reaching the minimum at the end of the ice-free season, with almost the same drop of $30 \mathrm{~cm}$ in both 2014 and 2015 (Fig. 5.1.5c and 5.1.5d).

The water temperature profiles in the deepest zone of the pond were approximately isothermal both on 12 July and 9 September 2015, showing a slight temperature decrease toward the bottom (300 cm depth) of $0.9^{\circ} \mathrm{C}$ and 0.8 ${ }^{\circ} \mathrm{C}$ (Tab. 5.1.1). Thus, the pond is not thermally stratified during the ice-free season.

Fig. 5.1.6a and 5.1.6b show daily air and water temperature trends for RG1, RG2, and RG3 during the two ice-free seasons (2014-2015) and Fig. 5.1.6c and 5.1.6d report precipitation. The difference between $R G 1$ and $R G 2$ is low $\left(0.18^{\circ} \mathrm{C}\right.$, on average). Conversely, in the same periods the difference between RG3 and $R G 1$ or $R G 2$ can reach $10^{\circ} \mathrm{C}$. 


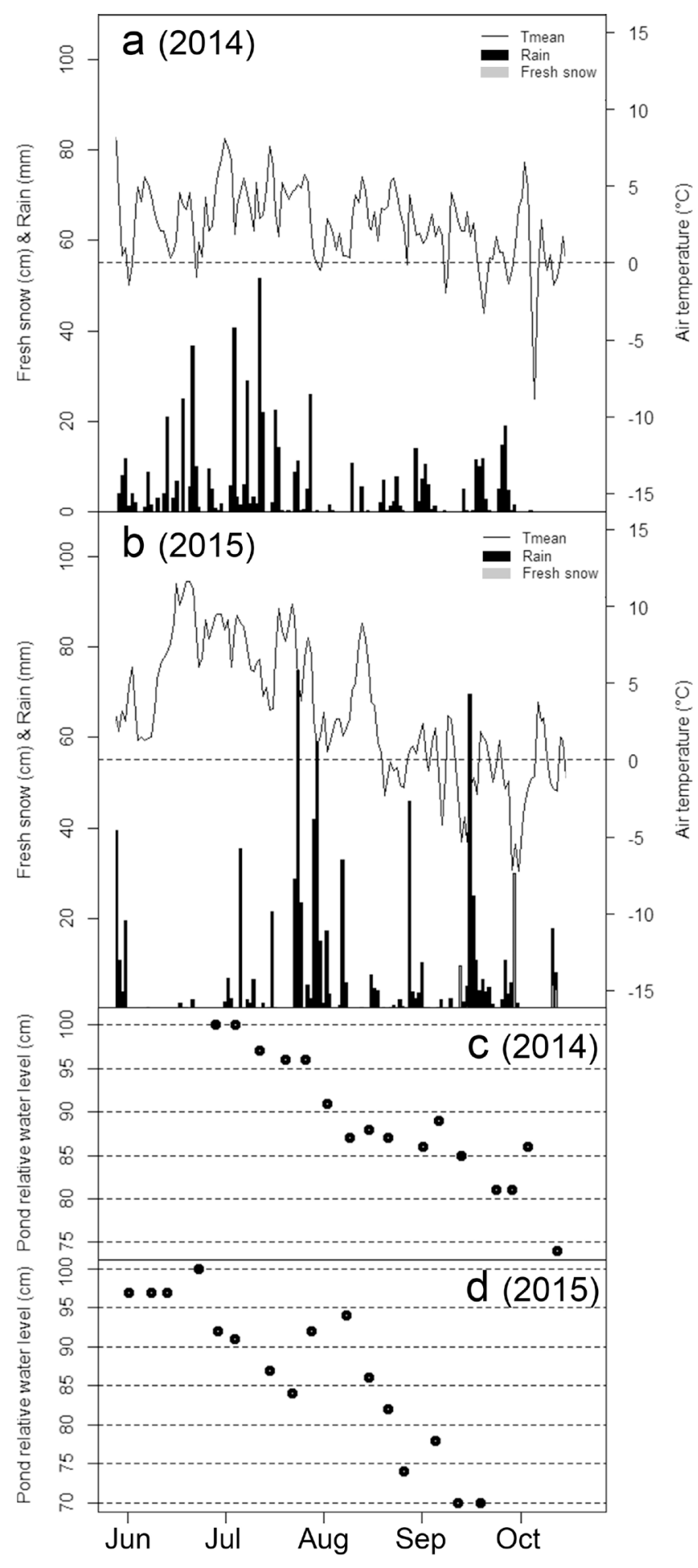

Figure 5.1 .5 - Precipitation (as fresh snow and rain) and mean daily air temperature for 2014 and 2015 are reported in figures a and b, respectively. Pond relative water level during 2014 (c) and 2015 (d) (hydrometric observations). 


\begin{tabular}{lcc}
\hline Date (2015) & $\begin{array}{c}\text { Water profile } \\
\text { depths } \\
\text { (cm) }\end{array}$ & $\begin{array}{c}\text { Water profile } \\
\text { temperatures } \\
\left({ }^{\circ} \mathbf{C}\right)\end{array}$ \\
\hline 12 July & 20 & 10.2 \\
& 100 & 10.0 \\
& 200 & 9.7 \\
& 300 & 9.3 \\
9 September & 20 & 9.4 \\
& 100 & 9.3 \\
& 200 & 9.0 \\
& 300 & 8.6 \\
\hline
\end{tabular}

Table 5.1.1 - Pond-water temperature profile on 12 July and 9 September 2015. 

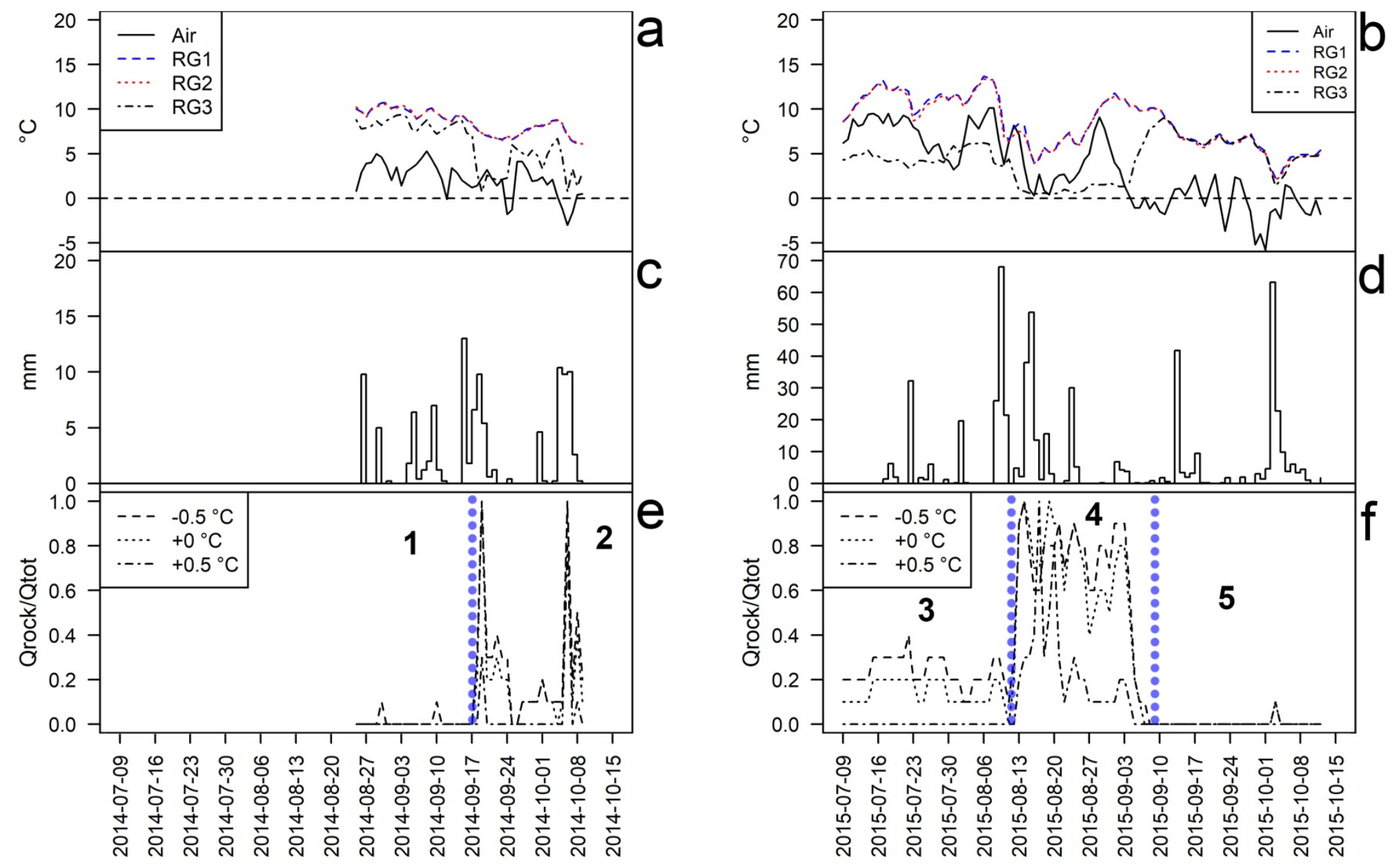

Figure 5.1.6 - Air and water temperatures during the investigated periods 2014 (a) and 2015 (b). Precipitation in 2014 (c) and 2015 (d). Rock glacier contribution at RG3 site calculated with the heat tracer approach in 2014 (e) and 2015 (f) assuming meltwater at $-0.5,0$, and $+0.5{ }^{\circ} \mathrm{C}$. Black numbers and vertical blue dotted lines highlight periods of differing hydrological contribution of the rock glacier (details in the text). 
The difference between RG2 and RG3 can be used to infer the relative amount of water coming from the rock glacier. Assuming that its temperature is constant, the temperature at RG3 is the result of a heat balance between heat flow coming from the rock glacier and heat stored in the lake (RG2). The cold water flux from the rock glacier, expressed as ratio between the discharge of the rock glacier and the total runoff reaching the pond, was investigated through heat tracers. Results show that in 2014, the main contribution of the rock glacier can be observed from mid-September until mid-October (period 2 in Fig. 5.1.6e), after a period with almost no hydrological contribution from the end of August to midSeptember (period 1 in Fig. 5.1.6e). In 2015, the main contributing period of the rock glacier is one month earlier than in 2014 (mid-August until mid-September, period 4 in Fig. 5.1.6f), after a period of lower contribution (mid-July until midSeptember, period 3 in Fig. 5.1.6f); from mid-September to mid-October 2015 the hydrological contribution of the rock glacier is absent. The main hydrological contribution periods in both 2014 and 2015 occurred before the air temperature becomes negative or close to $0{ }^{\circ} \mathrm{C}$. It was also observed that highest contributions from the rock glacier detected in the pond were often associated with precipitation events. 


\subsection{Atmospheric forcing of physicochemical fluxes from the Col d'Olen Rock Glacier}

\subsubsection{Snow duration}

The two ice-free seasons 2014 and 2015 were different. Col d'Olen AWS data evidenced that snowpack lasted until 8 August in 2014 (Fig. 5.2.1a). Differently, snowpack was already absent at the beginning of the ice-free season 2015 (Fig. 5.2.1b), with depletion occurring on 8 July (not shown). Landsat data showed that in 2014 the last snow in the catchment was present on 19 July (catchment $1 \%$ snow covered) (Fig. 5.2.1a). In 2015, no snow was found at the beginning of the ice-free season (Fig. 5.2.1b). The spatially distributed fine-scale approach showed that, in 2014 , no snow was present on the rock-glacier surface from the first water sampling date (25 August), when the GST sensors started recording. During the ice-free season 2015, MD of snow ranged from 6 June to 7 July 2015 (appendix, Fig. 1), with snowpack depletion occurring before the start of the sampling season on 9 July.

\subsubsection{Meteorological conditions}

Similar to snow duration, air temperature during the ice-free season 2014 and 2015 was different. In July-August 2014 the mean air temperature was colder (mean: $+3.4{ }^{\circ} \mathrm{C}$ ) (Fig. 5.2.1c) than air temperature in the same period in 2015 (mean: $+6.4{ }^{\circ} \mathrm{C}$ ) (Fig. 5.2.1d). Conversely, air temperature in September and during the first decade of October 2014 was warmer (mean: $+1.8^{\circ} \mathrm{C}$ ) (Fig. 5.2.1c) than air temperature in the same time-span in 2015 (mean: $-0.2^{\circ} \mathrm{C}$ ) (Fig. 5.2.1d). 

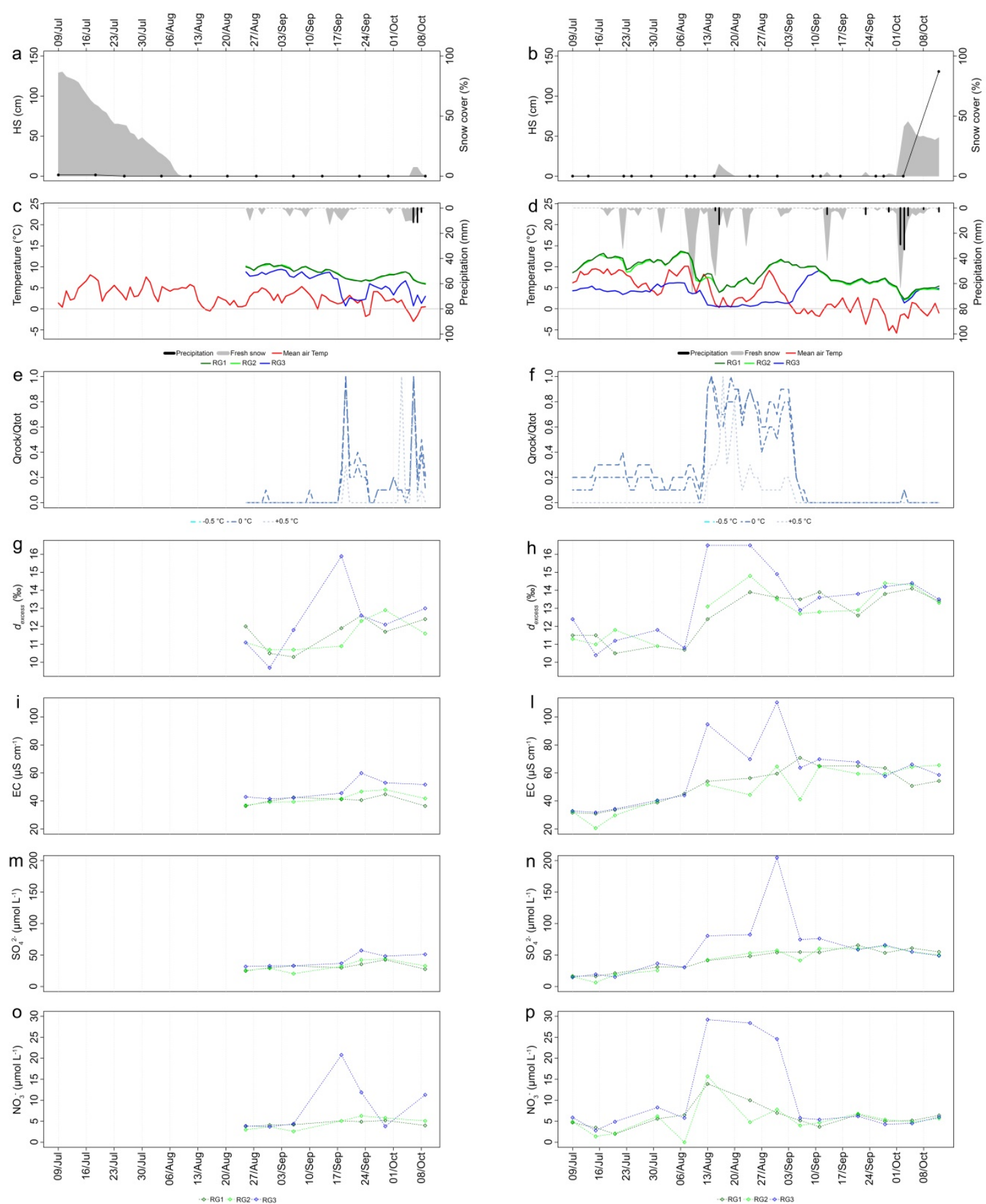

Figure 5.2.1 - Data series for the ice-free seasons 2014 (left) and 2015 (right). Snow height (HS) (cm) and percentage of catchment covered by snow (\%) from Landsat data (dots represent analysed imageries. Imageries showing cloud cover were excluded from the analysis) (a-b). Mean daily liquid precipitation ( $\mathrm{mm}$ ), 
fresh snow (cm), air temperature $\left({ }^{\circ} \mathrm{C}\right)$, and water temperature $\left({ }^{\circ} \mathrm{C}\right)$ at $R G 1, R G 2$ and RG3 (c-d). Relative rock-glacier contribution expressed as ratio Qrock/Qtot (details in the main text) in the pond with temperature of the cold water flux from the rock glacier estimated at $-0.5{ }^{\circ} \mathrm{C}, 0{ }^{\circ} \mathrm{C}$ and $+0.5{ }^{\circ} \mathrm{C}(e-f)$. $d_{\text {excess }}$ values (\%o) at RG1, RG2 and RG3 (g-h). EC values (i-l) $\left(\mu \mathrm{S} \mathrm{cm}^{-1}\right) . \mathrm{SO}_{4}{ }^{2-}$ concentration (m-n) $\left(\mu \mathrm{mol} \mathrm{L}^{-1}\right) \cdot \mathrm{NO}_{3}{ }^{-}$concentration (o-p) $\left(\mu \mathrm{mol} \mathrm{L}^{-1}\right)$. 
Liquid precipitation events were less abundant in 2014 (Fig. 5.2.1c) than in 2015 (Fig. 5.2.1d), with precipitation mainly concentrated in September and early October 2014 (Fig. 5.2.1d), and in August 2015 (Fig. 5.2.1d).

\subsubsection{Rock-glacier discharge}

Daily water temperature during the ice-free seasons 2014 and 2015 at RG3 (mean: $+4.7^{\circ} \mathrm{C}$ ) was lower than water temperature at RG1 (mean: $+8.5^{\circ} \mathrm{C}$ ) and RG2 (mean: $+8.4{ }^{\circ} \mathrm{C}$ ) (Fig. 5.2.1c and 5.2.1d). In the ice-free season 2014 a higher rock-glacier discharge (methodological details in 4.4.2) was estimated from mid-September until the end of the ice-free season (max Qrock/Qtot value: 1) (period 2 in Fig. 5.2.1e). In the ice-free season 2015, a higher rock-glacier discharge was estimated from mid-July until mid-September (period 4 in Fig. 5.2.1f), with one main discharge period starting from mid-August (max Qrock/Qtot value: 1).

\subsubsection{Water isotopes}

Isotopic values of water samples showed differences among the sampling points, especially at RG3 during higher rock-glacier discharge periods. Higher $d_{\text {excess }}$ values were observed at RG3 (Tab. 5.2.1), with main heterogeneous periods from mid-September to the end of the ice-free season 2014 (Fig. 5.2.1g), and from mid-August to mid-September 2015 (Fig. 5.2.1h). Although less evident than dexcess, $\delta^{18} \mathrm{O}$ and $\delta^{2} \mathrm{H}$ became more enriched at RG3 than at RG1 and RG2 during the previously described periods (Tab. 5.2.1). Among all the sampling points, snow was characterised by the lowest $\delta^{18} \mathrm{O}$ (mean: $-18.9 \%$ ), 


\begin{tabular}{ccccccccccc}
\hline & \multicolumn{3}{c}{$\boldsymbol{\delta}^{\mathbf{1 8}} \mathbf{O}(\%)$} & \multicolumn{3}{c}{$\boldsymbol{\delta}^{2} \mathrm{H}(\% \mathrm{0})$} & \multicolumn{3}{c}{$\boldsymbol{d}_{\text {excess }}(\%)$} \\
\hline & RG1 & RG2 & RG3 & RG1 & RG2 & RG3 & RG1 & RG2 & RG3 \\
\hline & & & & & & & & & & \\
Homogeneous & -12.74 & -12.74 & -12.75 & -89.93 & -89.82 & -89.79 & 11.97 & 12.08 & 12.20 \\
(13 observations) & $(0.96)$ & $(1.01)$ & $(0.98)$ & $(8.80)$ & $(9.25)$ & $(9.04)$ & $(1.41)$ & $(1.38)$ & $(1.55)$ \\
& & & & & & & & & \\
Heterogeneous & -12.02 & -12.01 & -11.83 & -83.40 & -83.38 & -80.34 & 12.75 & 12.72 & 14.31 \\
(8 observations) & $(0.82)$ & $(0.77)$ & $(0.62)$ & $(6.92)$ & $(6.87)$ & $(6.31)$ & $(0.83)$ & $(1.19)$ & $(1.84)$ \\
& & & & & & & & & \\
\hline
\end{tabular}

Table 5.2.1 - Isotopic measurements for the sampling sites during homogenous and main heterogeneous periods in 2014 (from mid-September to the end of the ice-free season) and 2015 (from mid-August to mid-September). Mean value and standard deviation (in brackets) are reported. 
$\delta^{2} H$ (mean: $-139.26 \%$ ), and $d_{\text {excess }}$ (mean: $11.7 \%$ ) values. Contrarily, rain showed the highest $\delta^{18} \mathrm{O}$ (mean: $-10 \%$ ), $\delta^{2} \mathrm{H}$ (mean: - 64\%), and $d_{\text {excess }}$ (mean: $15.9 \%$ ) values, with no temporal pattern in the series (not shown). The investigation of the $\delta^{2} \mathrm{H}-\delta^{18} \mathrm{O}$ relationship showed that the slope was similar among the LMWL (8.9), RG1 (8.9) and RG2 (9), while RG3 showed a slope of 9.6, higher than the other sampling points (Tab. 5.2.2 and appendix, Fig. 2 and Fig. 3).

\subsubsection{Water chemical composition}

EC showed higher values in correspondence of greater rock-glacier discharge at RG3 (Tab. 5.2.3), than at RG1,2 from mid-September until the end of the ice-free season 2014 (Fig. 5.2.1i), and from mid-August to mid-September 2015 (Fig. 5.2.11). For major anions, main differences among the sampling points in the pond were found for $\mathrm{SO}_{4}{ }^{2-}$ (Fig. 5.2.1m and 5.2.1n) and $\mathrm{NO}_{3}{ }^{-}$(Fig. 5.2.10 and 5.2.1p), with higher concentrations at RG3 during main heterogeneous periods similar to ones for EC (Tab. 5.2.3), as expected. Increases of the major cations $\mathrm{Mg}^{2+}$ (Fig. 5.2.2a and 5.2.2b) and $\mathrm{Ca}^{2+}$ (Fig. 5.2.2c and 5.2.2d) were measured in the same periods in which EC at RG3 showed heterogeneous behaviour in comparison to $\mathrm{RG} 1,2$ (Tab. 5.2.3). $\mathrm{Na}^{+}$and $\mathrm{K}^{+}$concentrations were lower compared with those of $\mathrm{Mg}^{2+}$ and $\mathrm{Ca}^{2+}$ and did not evidence specific temporal patterns (not shown) although during high rock-glacier discharge (main heterogeneous periods) they were slightly less concentrated at RG3 than at RG1,2 (Tab. 5.2.3). Trace elements $\mathrm{Ni}, \mathrm{Mn}$ and Co were more concentrated at RG3 than at RG1,2 (Tab. 5.2.3) from mid-September to the end of the ice- free 


\begin{tabular}{|c|c|c|c|c|}
\hline \multicolumn{5}{|c|}{ All dataset (2014-2015) } \\
\hline Site & $\delta^{2} \mathrm{H}-\delta^{18} \mathrm{O}$ relationship & $\mathbf{R}^{2}$ & $\begin{array}{c}\mathbf{p} \\
\text { value }\end{array}$ & $\begin{array}{c}\text { Number of } \\
\text { samples }\end{array}$ \\
\hline LMWL & $\delta^{2} H=8.9( \pm 0.6) \delta^{18} O+24.5( \pm 5.6) \%$ & 0.96 & $p<0.01$ & 13 \\
\hline RG1 & $\delta \mathrm{H}=8.9( \pm 0.2) \delta \mathrm{O}+23.9( \pm 2.7) \%$ & 0.99 & $p<0.01$ & 21 \\
\hline RG2 & $\delta^{2} \mathrm{H}=9.0( \pm 0.2) \delta^{18} \mathrm{O}+24.7( \pm 2.7) \%$ & 0.99 & $p<0.01$ & 20 \\
\hline RG3 & $\delta^{2} H=9.6( \pm 0.3) \delta^{18} O+32.4( \pm 3.6) \%$ & 0.98 & $p<0.01$ & 21 \\
\hline
\end{tabular}

Table 5.2.2 - The $\delta^{2} H-\delta^{18} O$ relationship for $L M W L, R G 1, R G 2$ and $R G 3$. 


\begin{tabular}{|c|c|c|c|c|c|c|c|c|c|}
\hline & \multicolumn{3}{|c|}{$E C\left(\mu S \mathrm{~cm}^{-1}\right)$} & \multicolumn{3}{|c|}{$\mathrm{pH}$} & \multicolumn{3}{|c|}{$\mathrm{Cl}^{-}\left(\mu \mathrm{mol} \mathrm{L}{ }^{-1}\right)$} \\
\hline & RG1 & RG2 & RG3 & RG1 & RG2 & RG3 & RG1 & RG2 & RG3 \\
\hline $\begin{array}{l}\text { Homogeneous } \\
\text { (13 observations) }\end{array}$ & $\begin{array}{c}46.0 \\
(12.6)\end{array}$ & $\begin{array}{c}46.0 \\
(15.7)\end{array}$ & $\begin{array}{c}48.5 \\
(13.7)\end{array}$ & $\begin{array}{c}7.5 \\
(0.2)\end{array}$ & $\begin{array}{c}7.4 \\
(0.2)\end{array}$ & $\begin{array}{l}7.4 \\
(0.2)\end{array}$ & $\begin{array}{c}2.5 \\
(2.0)\end{array}$ & $\begin{array}{c}2.2 \\
(1.5)\end{array}$ & $\begin{array}{c}2.4 \\
(1.4)\end{array}$ \\
\hline \multirow[t]{3}{*}{$\begin{array}{l}\text { Heterogeneous } \\
\text { (8 observations) }\end{array}$} & $\begin{array}{c}50.5 \\
(11.7)\end{array}$ & $\begin{array}{l}47.5 \\
(7.8)\end{array}$ & $\begin{array}{c}68.6 \\
(22.7)\end{array}$ & $\begin{array}{l}7.5 \\
(0.1)\end{array}$ & $\begin{array}{c}7.6 \\
(0.3)\end{array}$ & $\begin{array}{c}7.5 \\
(0.1)\end{array}$ & $\begin{array}{c}2.4 \\
(1.9)\end{array}$ & $\begin{array}{c}1.5 \\
(0.4)\end{array}$ & $\begin{array}{l}3.0 \\
(0.8)\end{array}$ \\
\hline & \multicolumn{3}{|c|}{$\mathrm{SO}_{4}^{2-}\left(\mu \mathrm{mol} \mathrm{L}{ }^{-1}\right)$} & \multicolumn{3}{|c|}{$\mathrm{NO}_{3}^{-}\left(\mu \mathrm{mol} \mathrm{L} \mathrm{L}^{-1}\right)$} & \multicolumn{3}{|c|}{$\mathrm{Mg}^{2+}\left(\mu \mathrm{mol} \mathrm{L}{ }^{-1}\right)$} \\
\hline & RG1 & RG2 & RG3 & RG1 & RG2 & RG3 & RG1 & RG2 & RG3 \\
\hline $\begin{array}{l}\text { Homogeneous } \\
\text { (13 observations) }\end{array}$ & $\begin{array}{l}38.0 \\
(17.5)\end{array}$ & $\begin{array}{l}36.0 \\
(20.5)\end{array}$ & $\begin{array}{c}40.0 \\
(19.5)\end{array}$ & $\begin{array}{c}4.7 \\
(1.4)\end{array}$ & $\begin{array}{l}3.9 \\
(2.0)\end{array}$ & $\begin{array}{c}5.1 \\
(1.4)\end{array}$ & $\begin{array}{c}98.9 \\
(27.0)\end{array}$ & $\begin{array}{c}89.9 \\
(35.8)\end{array}$ & $\begin{array}{l}103.6 \\
(33.4)\end{array}$ \\
\hline \multirow[t]{3}{*}{$\begin{array}{l}\text { Heterogeneous } \\
\text { (8 observations) }\end{array}$} & $\begin{array}{c}41.8 \\
(10.3)\end{array}$ & $\begin{array}{l}43.2 \\
(8.8)\end{array}$ & $\begin{array}{c}79.5 \\
(53.2)\end{array}$ & $\begin{array}{c}6.9 \\
(3.4)\end{array}$ & $\begin{array}{c}6.8 \\
(3.8)\end{array}$ & $\begin{array}{c}17.0 \\
(10.1)\end{array}$ & $\begin{array}{l}111.8 \\
(21.0)\end{array}$ & $\begin{array}{l}110.0 \\
(14.9)\end{array}$ & $\begin{array}{l}165.4 \\
(23.1)\end{array}$ \\
\hline & \multicolumn{3}{|c|}{$\mathrm{Ca}^{2+}\left(\mu \mathrm{mol} \mathrm{L} \mathrm{L}^{-1}\right)$} & \multicolumn{3}{|c|}{$\mathrm{K}^{+}\left(\mu \mathrm{mol} \mathrm{L}{ }^{-1}\right)$} & \multicolumn{3}{|c|}{$\mathrm{Na}^{+}\left(\mu \mathrm{mol} \mathrm{L}{ }^{-1}\right)$} \\
\hline & RG1 & RG2 & RG3 & RG1 & RG2 & RG3 & RG1 & RG2 & RG3 \\
\hline $\begin{array}{l}\text { Homogeneous } \\
\text { (13 observations) }\end{array}$ & $\begin{array}{l}101.4 \\
(24.3)\end{array}$ & $\begin{array}{l}100.0 \\
(31.9)\end{array}$ & $\begin{array}{l}102.1 \\
(25.6)\end{array}$ & $\begin{array}{l}10.7 \\
(3.8)\end{array}$ & $\begin{array}{c}9.9 \\
(4.1)\end{array}$ & $\begin{array}{l}10.6 \\
(4.4)\end{array}$ & $\begin{array}{c}5.9 \\
(2.0)\end{array}$ & $\begin{array}{l}5.7 \\
(3.0)\end{array}$ & $\begin{array}{l}5.3 \\
(1.4)\end{array}$ \\
\hline \multirow[t]{3}{*}{$\begin{array}{l}\text { Heterogeneous } \\
\text { (8 observations) }\end{array}$} & $\begin{array}{l}121.6 \\
(11.4)\end{array}$ & $\begin{array}{l}124.7 \\
(14.8)\end{array}$ & $\begin{array}{l}143.7 \\
(25.4)\end{array}$ & $\begin{array}{l}10.9 \\
(4.5)\end{array}$ & $\begin{array}{c}9.6 \\
(3.1)\end{array}$ & $\begin{array}{c}6.9 \\
(3.4)\end{array}$ & $\begin{array}{c}4.7 \\
(1.1)\end{array}$ & $\begin{array}{l}5.7 \\
(2.1)\end{array}$ & $\begin{array}{c}4.6 \\
(1.9)\end{array}$ \\
\hline & \multicolumn{3}{|c|}{$\mathrm{Ni}\left(\mathrm{nmol} \mathrm{L}{ }^{-1}\right)$} & \multicolumn{3}{|c|}{ Mn (nmol L $\left.{ }^{-1}\right)$} & \multicolumn{3}{|c|}{ Co $\left(n m o l ~ L^{-1}\right)$} \\
\hline & RG1 & RG2 & RG3 & RG1 & RG2 & RG3 & RG1 & RG2 & RG3 \\
\hline $\begin{array}{l}\text { Homogeneous } \\
\text { (12 observations) }\end{array}$ & $\begin{array}{l}197.2 \\
(78.0)\end{array}$ & $\begin{array}{l}217.6 \\
(79.3)\end{array}$ & $\begin{array}{l}257.3 \\
(135.6)\end{array}$ & $\begin{array}{c}24.1 \\
(45.4)\end{array}$ & $\begin{array}{c}24.3 \\
(48.7)\end{array}$ & $\begin{array}{c}39.2 \\
(60.2)\end{array}$ & $\begin{array}{c}0.9 \\
(0.6)\end{array}$ & $\begin{array}{c}0.8 \\
(0.6)\end{array}$ & $\begin{array}{c}1.1 \\
(0.7)\end{array}$ \\
\hline $\begin{array}{l}\text { Heterogeneous } \\
\text { (8 observations) }\end{array}$ & $\begin{array}{l}192.2 \\
(53.9)\end{array}$ & $\begin{array}{l}213.0 \\
(43.4)\end{array}$ & $\begin{array}{c}509.1 \\
(192.8)\end{array}$ & $\begin{array}{c}22.5 \\
(18.7)\end{array}$ & $\begin{array}{c}31.2 \\
(26.3)\end{array}$ & $\begin{array}{l}94.5 \\
(66.9)\end{array}$ & $\begin{array}{c}1.1 \\
(0.6)\end{array}$ & $\begin{array}{c}1.3 \\
(0.7)\end{array}$ & $\begin{array}{l}2.3 \\
(0.9)\end{array}$ \\
\hline
\end{tabular}

Table 5.2.3 - Solute concentrations in the water sampling sites during homogeneous and main heterogeneous periods in 2014 (from mid-September to the end of the ice-free season) and 2015 (from mid-August to mid-September). Mean value and standard deviation (in brackets) are reported. $\mathrm{NO}_{2}^{-}$and $\mathrm{PO}_{4}{ }^{3-}$ were below the detection limits. 

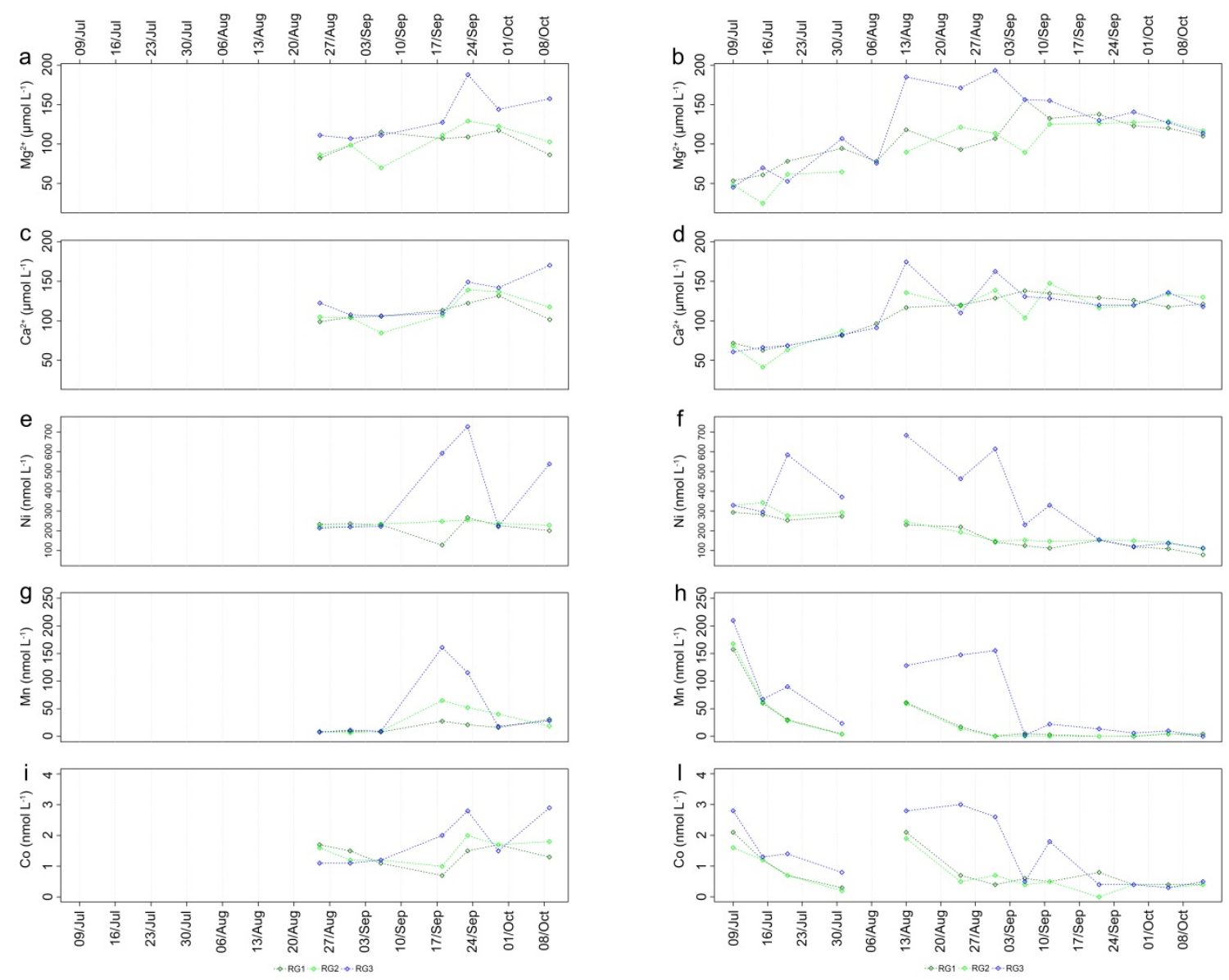

Figure 5.2.2 - Data series for the ice-free seasons 2014 (left) and 2015 (right). $\mathrm{Mg}^{2+}$ concentration at RG1, RG2 and RG3 (a-b) $\left(\mu \mathrm{mol} \mathrm{L} \mathrm{L}^{-1}\right)$. Ca ${ }^{2+}$ concentration (c-d) $\left(\mu \mathrm{mol} \mathrm{L}^{-1}\right)$. Ni concentration $(e-f)\left(n m o l L^{-1}\right)$. Mn concentration $(g-h)\left(n m o l ~ L^{-}\right.$ $\left.{ }^{1}\right)$. Co concentration (i-l) $\left(\mathrm{nmol} \mathrm{L}^{-1}\right)$. 
season 2014 (Fig. 5.2.2e, 5.2.2g and 5.2.2i), and from mid-July to midSeptember 2015, with the greatest differences measured from mid-August to mid-September 2015 (Fig. 5.2.2f, 5.2.2h and 5.2.2l). An initial peak in trace element concentrations was also found at the beginning of the ice-free season 2015, with slightly higher concentrations at RG3 than at RG1,2 (Fig. 5.2.2f, 5.2.2h and 5.2.21).

\subsubsection{Isotopic and geochemical relationships in the rock-glacier inflow area}

Isotopes, EC, pH, major ions and trace elements measured at RG3 were grouped within a PCA to provide an integrated overview of the characteristics of the rock-glacier inflow into the pond. The bottom and left axes represent the "scores" of the analysis. The top and right axes show the "factor loadings". The black points represent the positions of sampling dates with reference to the first pair of axes, while the lengths of the arrows refer to the second factor loadings. Factor loadings, representing the weightings of variables into each component, are the key to understanding the underlying nature of a particular factor. PCA revealed two main directions of variation, with axis 1 explaining $47 \%$ of the total variance and axis 2 explaining an additional $27 \%$. An examination of the inter-set correlations of variables, together with the position and length of the arrows, revealed that the strongest direction of variation (axis 1) was primarily a gradient of $\mathrm{EC}$, major ions $\left(\mathrm{SO}_{4}{ }^{2-}, \mathrm{NO}_{3}{ }^{-}, \mathrm{Mg}^{2+}, \mathrm{Ca}^{2+}\right), \mathrm{pH}$ and isotopes $\left(\delta^{18} \mathrm{O}, \delta^{2} \mathrm{H}, d_{\text {excess }}\right)$, which had positive correlations with PCA axis 1 (Fig. 5.2.3) and to each other (Tab. 5.2.4), and plotted towards the right of the ordination. Ni, Mn and Co were 


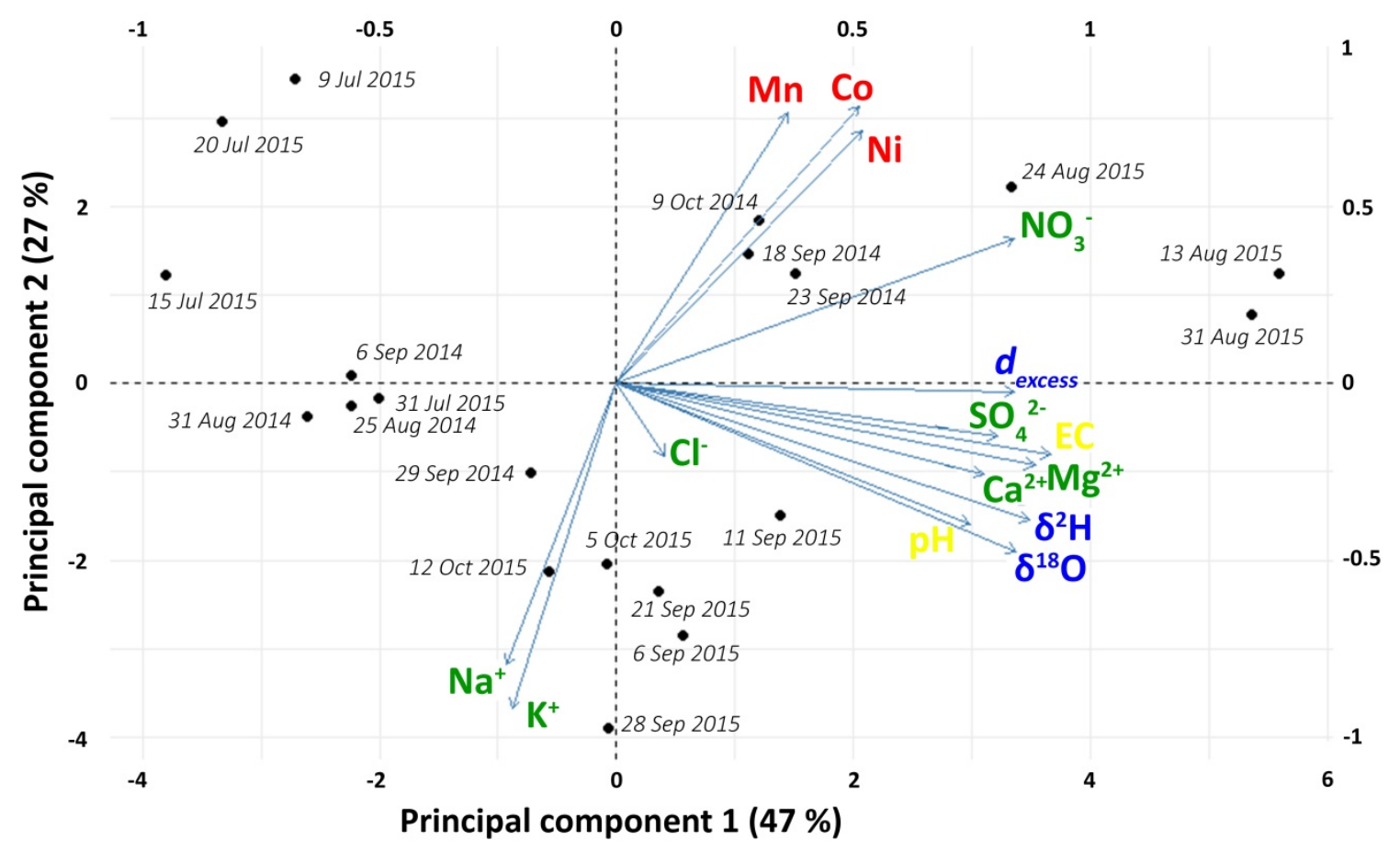

Figure 5.2.3 - Summary of results: PCA among isotopes (blue labels), EC and pH (yellow labels), major ions (green labels) and trace elements (red labels) of 20 sampling dates in which all variables were measured at RG3. Refer to the text for details on this figure. 


\begin{tabular}{|c|c|c|c|c|c|c|c|c|c|c|c|c|c|c|c|}
\hline & EC & $\mathrm{pH}$ & $\mathrm{SO}_{4}{ }^{2-}$ & $\mathrm{NO}_{3}^{-}$ & $\mathrm{Cl}^{-}$ & $\mathrm{Mg}^{2+}$ & $\mathrm{Ca}^{2+}$ & $\mathrm{Na}^{+}$ & $\mathrm{K}^{+}$ & $\mathrm{Ni}$ & Mn & Co & $\boldsymbol{d}_{\text {excess }}$ & $\delta^{18} 0$ & $\delta^{2} H$ \\
\hline EC & 1 & & & & & & & & & & & & & & \\
\hline pH & $0.79^{\star \star *}$ & 1 & & & & & & & & & & & & & \\
\hline $\mathrm{SO}_{4}^{2}$ & $0.91^{* * *}$ & $0.68^{* * *}$ & 1 & & & & & & & & & & & & \\
\hline $\mathrm{NO}_{3}^{-}$ & $0.65^{\star * *}$ & $0.41^{*}$ & $0.57^{* * *}$ & 1 & & & & & & & & & & & \\
\hline $\mathrm{Cl}^{-}$ & 0.08 & 0 & 0.16 & 0.13 & 1 & & & & & & & & & & \\
\hline $\mathrm{Mg}^{2+}$ & $0.80^{* * *}$ & $0.67^{* \star *}$ & $0.73^{* * *}$ & $0.60^{* * *}$ & 0.23 & 1 & & & & & & & & & \\
\hline $\mathrm{Ca}^{2+}$ & $0.74^{* * *}$ & $0.56^{* * *}$ & $0.61^{* * *}$ & $0.42^{\star}$ & 0.04 & $0.88^{* * *}$ & 1 & & & & & & & & \\
\hline $\mathrm{Na}^{+}$ & -0.10 & 0.15 & -0.01 & $-0.47^{* *}$ & $0.47^{* *}$ & 0.02 & -0.06 & 1 & & & & & & & \\
\hline $\mathrm{K}^{+}$ & -0.03 & 0.23 & -0.07 & $-0.56^{* *}$ & 0.11 & -0.03 & -0.01 & $0.78^{* * *}$ & 1 & & & & & & \\
\hline $\mathrm{Ni}$ & 0.30 & 0.02 & 0.29 & $0.69^{* * *}$ & 0.12 & 0.36 & 0.26 & $-0.58^{* * *}$ & $-0.76^{\star \star \star}$ & 1 & & & & & \\
\hline Mn & 0.18 & 0.07 & 0.21 & $0.65^{\star \star *}$ & -0.01 & 0.03 & -0.12 & $-0.50^{* *}$ & $-0.67^{* * *}$ & $0.70^{* * *}$ & 1 & & & & \\
\hline Co & 0.26 & 0.13 & 0.27 & $0.68^{* * *}$ & -0.09 & 0.34 & 0.26 & $-0.69^{* * *}$ & $-0.82^{\star \star \star}$ & $0.80^{* \star *}$ & $0.78^{* * *}$ & 1 & & & \\
\hline$d_{\text {excess }}$ & $0.69^{* * *}$ & $0.60^{* * *}$ & $0.53^{* *}$ & $0.78^{* * *}$ & -0.04 & $0.60^{* * *}$ & $0.48^{* *}$ & -0.18 & -0.07 & 0.33 & $0.41^{*}$ & 0.35 & 1 & & \\
\hline$\delta^{18} 0$ & $0.80^{* * *}$ & $0.76^{* * *}$ & $0.61^{* * *}$ & $0.53^{\star *}$ & 0.16 & $0.82^{* * *}$ & $0.76^{* * *}$ & 0.12 & 0.26 & 0.11 & -0.09 & 0.03 & $0.79^{* * *}$ & 1 & \\
\hline$\delta^{2} \mathrm{H}$ & $0.80^{* * *}$ & $0.76^{\star * *}$ & $0.61^{* * *}$ & $0.60^{\star * *}$ & 0.10 & $0.80^{* * *}$ & $0.72^{* * *}$ & 0.04 & 0.19 & 0.16 & 0.02 & 0.11 & $0.86^{* * *}$ & $0.99^{* * *}$ & 1 \\
\hline
\end{tabular}

Table 5.2.4 - Correlation matrix for measured variables of 20 sampling dates in which all variables were measured. Negative correlation coefficients mean inverse relationship. ${ }^{*},{ }^{* *}$, and ${ }^{* * *}$ indicates significant correlation at $P<0.1, P<0.05$ and $P<0.01$, respectively. 
highly correlated each other and with $\mathrm{NO}_{3}{ }^{-}$but not correlated with other major ions $\left(\mathrm{SO}_{4}{ }^{2-}, \mathrm{Mg}^{2+}, \mathrm{Ca}^{2+}\right)(\mathrm{Tab}$. 5.2.4), confirming the different behaviour of these trace elements in the rock-glacier inflow zone in the pond. $\mathrm{Na}^{+}$and $\mathrm{K}^{+}$were negatively correlated with trace elements and $\mathrm{NO}_{3}{ }^{-}$(Tab. 5.2.4), and plotted along the PCA axis 2 (Fig. 5.2.3). From the PCA, it is also possible to observe that the sampling dates in which higher rock-glacier discharge was found (e.g., mid-September to October 2014 and August 2015) plotted almost exclusively on the right side of the first ordination (Fig. 5.2.3), indicating that these sites were characterised by higher concentrations of some major ions $\left(\mathrm{SO}_{4}{ }^{2-}, \mathrm{NO}_{3}{ }^{-}, \mathrm{Mg}^{2+}\right.$, $\mathrm{Ca}^{2+}$ ) and trace elements, and they were also isotopically enriched, as described before. Differently, some sampling dates (e.g., July 2015) plotted on the left side of the first ordination and they partially influenced the second direction of variation (Fig. 5.2.3), indicating higher concentrations in trace elements but lower major ion concentrations. This behaviour is explained by the higher trace element concentrations associated with relatively low major ion concentrations measured at the beginning of the ice-free season 2015 (Fig. 5.2.1 and 5.2.2). 


\section{Interpretation}

\subsection{Hydrology and structural setting of the Col d'Olen Rock}

\section{Glacier Pond}

\subsubsection{Influence of rock-glacier geomorphological characteristics and structural setting in the evolution and potential subsurface outflowing dynamics of the pond}

The GPR tracks show rough diffractions along the eastern bank, parallel to the rock-glacier front, which were interpreted as the bouldery rock-glacier tongue flowing into the pond (Fig. 5.1.1a). These coarse diffractions progressively disappear towards the centre of the pond ending in a bouldery apophysis (Fig. 5.1.1b). This represents the deep foot of the rock glacier that flows into the pond. This evidence together with the asymmetrical structure of the pond (Fig. 5.1.1c and 5.1.1d) suggest that the advancing movement of the rock glacier has progressively filled the small valley depression in which the pond is located, emphasising its "V" shape (Fig. 6.1.1a1 and 6.1.1a2).

The bottom of the depression is filled with fine sediments with an estimated porosity of $65 \%$, that likely is attributable to silty material (e.g., Das, 2008). This was confirmed by granulometry performed on the two cores extracted from fine sediment at the bottom of the pond. The high silt content (and expected relatively high porosity) and the presence of organic material, as described in 5.1.3, explain why the overall resistivity within the fine-sediment samples is lower than the water $(200 \mathrm{Ohm} \cdot \mathrm{m})$ in the resistivity sections. No evidence of deformed features was found in these fine lacustrine sediments along the rock-glacier front 

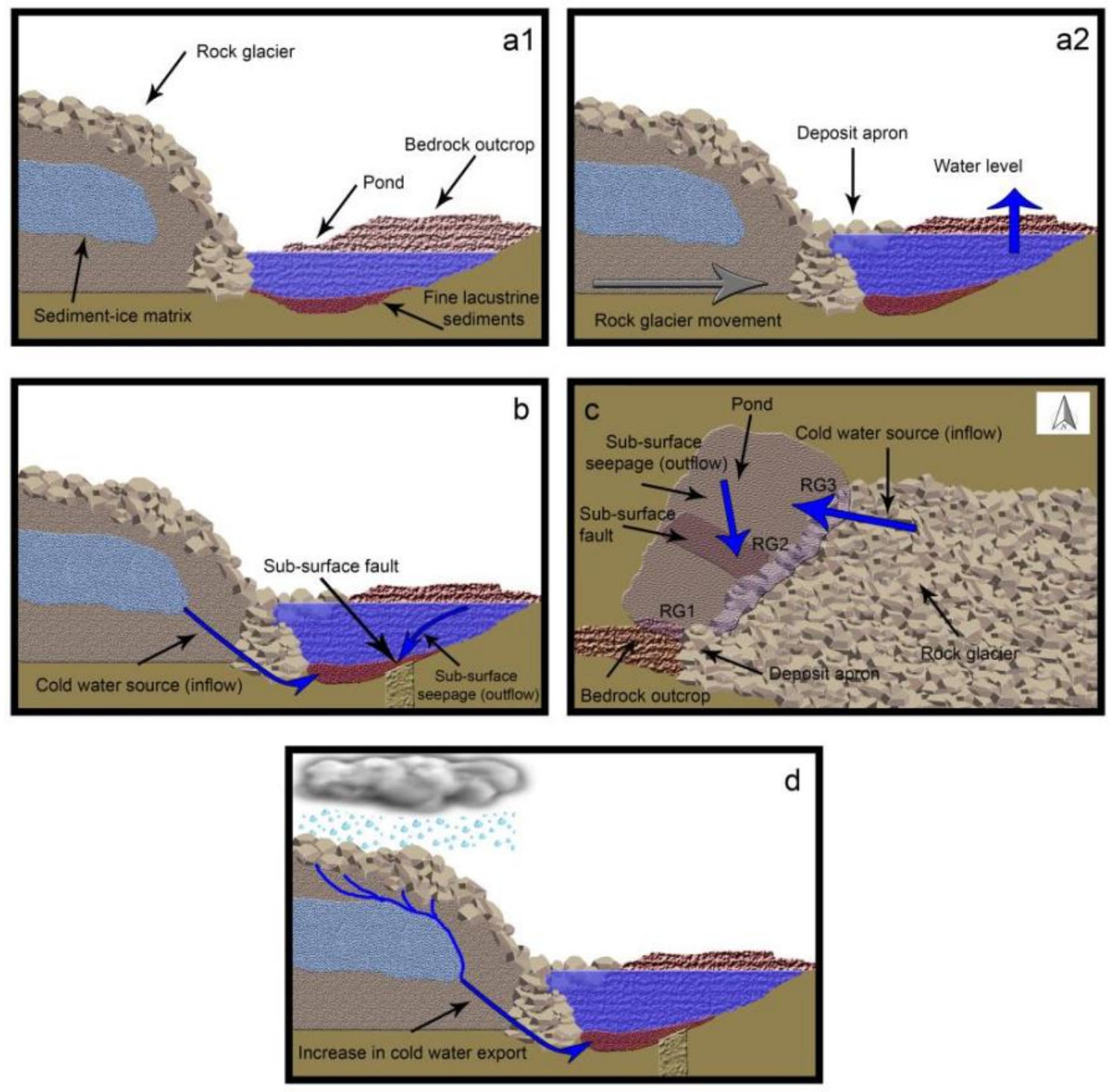

Figure 6.1.1 - (a1-a2) Simplified conceptual model of rock-glacier advance and progressive filling of the small valley depression. Deposit apron display on southern bedrock outcrop and associated potential modification of water level due to dam formation are also represented. (b) Hydrological dynamics of the rock glacier-pond system (profile representation - b) (planimetric representation - c). (d) Increase in cold water export from the rock glacier after rainfall events at RG3 site. 
(Fig. 5.1.1c and 5.1.1d), suggesting that the landform has progressively moved down on the slope and buried the lacustrine sediments (and the material coming from the rock-glacier front) on the eastern side of the pond instead of pushing them during its advance.

The advancing of the rock glacier has also generated a small deposit apron in a flat zone of the southeastern area of the pond (Fig. 6.1.2). Here, the waterborne GPR profiles highlight the presence of surficial coarse diffractions mixed to a generally smooth-reflecting horizon at shallow depths, indicating the potential presence of a boulder-rich fine-grained deposit composed of boulders from the rock glacier and fine-grained lacustrine sediments (Fig. 5.1.1b). ERT surveys show that in this area a body of massive bedrock is present (3000-5000 Ohm•m), and partially outcropping towards the southwestern side (Fig. 6.1.2). Thus, the southern shore is composed of bare bedrock in the western portion, and partially by subsurface bedrock with overlaying rock-glacier deposits in the southeastern corner. Here, the rock-glacier apron at the surface lies on the subsurface bedrock. Thus, it is possible to assume that the advancing of the rock glacier has influenced the evolution of the pond, creating a small dam which could have contributed in increasing the level of water impounded in the valley depression (Fig. 6.1.1a1 and 6.1.1a2). The lacustrine sediments in the northern part of the pond show a rather continuous pattern over the high-resistivity body (Fig. 5.1.2, L1-L4); conversely, in the central and southern part of the pond sediments show some discontinuities (Fig. 5.1.2, L1-L4). This structural setting corresponds to a sharp change in the bedrock properties below pond sediments. 


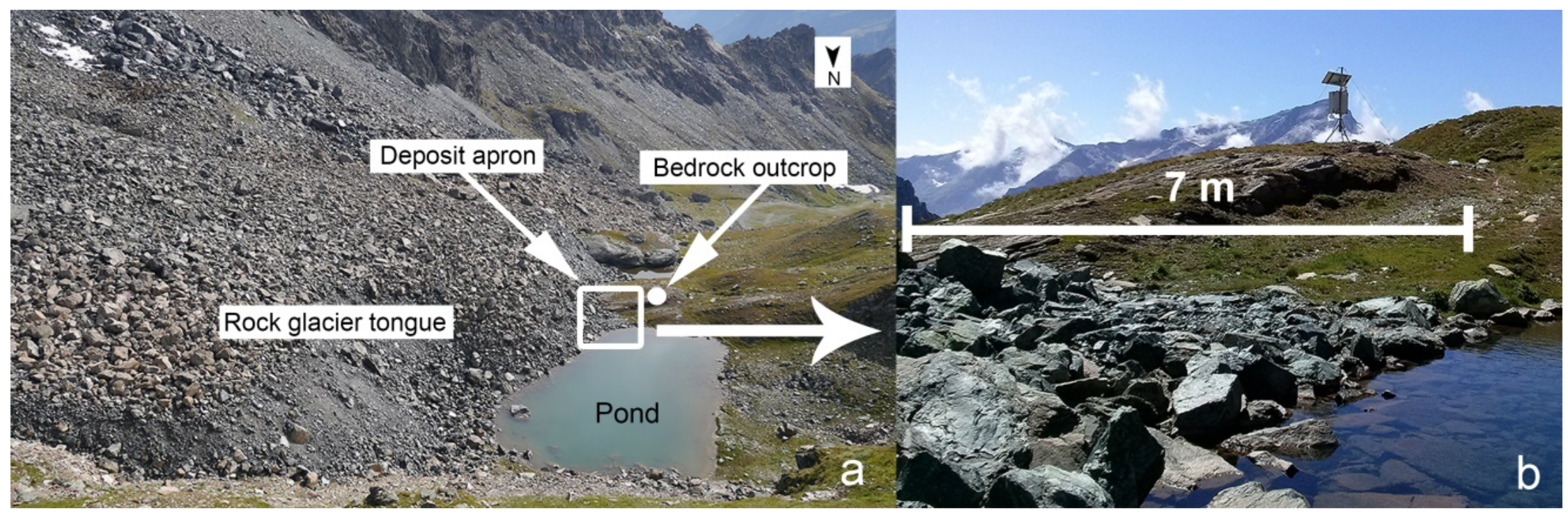

Figure 6.1.2 - (a) Picture of the rock-glacier tongue flowing into the pond and deposit apron in the southern bedrock outcrop zone; (b) details of the deposit apron. 
Sharp vertical contacts between bedrock units are aligned with discontinuities in the lacustrine sediments. Based on observations of litho-structural properties of bedrock units in several outcrops around the Col d'Olen and rock-glacier area (Fig. 6.1.3), these vertical structures likely correspond to a highly-fractured rock mass developed across a shear zone due to a major N100E fault. Evidence of tectonic deformations can be also useful for understanding hydrogeological properties of bedrock, which could constrain inflow and outflow dynamics.

The ERT data show a wide zone with relatively low resistivity (300-600 Ohm.m) truncating two higher resistive areas. This area shows a WNW-ESE elongated orientation in the pond bedrock for a width of about 10-15 m (Fig. 5.1.2, 5.1.3 and 5.1.4b). The orientation of the low resistivity is in accordance with the orientation of distinctive structural association of brittle faults and fractures in the area (Fig. 6.1.3). Considering the sharp morphology of the detected anomaly, the strong resistivity contrast and the orientation of this structure and structural setting of the area, this is interpreted to be related to a minor fault zone affecting the bedrock. Lower resistivity values probably indicate the presence of altered and highly fractured rocks in this band. This area of weakness could also significantly affect the water balance through modification of the water circulation from the pond by seepage.

Remarkably, the main negative SP area was found along the anomaly detected by the ERT analyses (Fig. 5.1.4a), thus a water seepage from the pond can be assumed to occur at this location (Fig. 6.1.1b and 6.1.1c). 


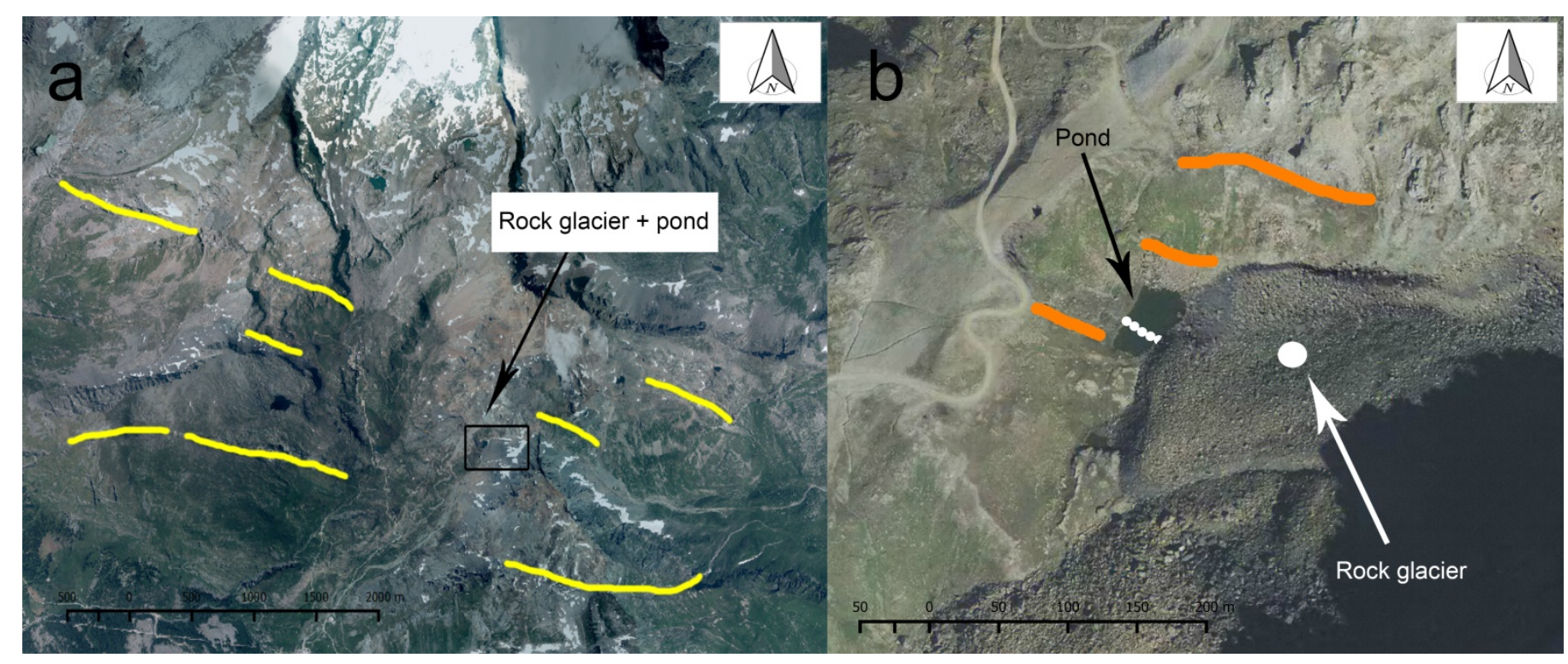

Figure 6.1.3 - (a) Large-scale geological structure of the Col d'Olen area (yellow line: main trench and fault) (digital orthoimage from the year 2012; source: Ministero dell'Ambiente e della Tutela del Territorio e del Mare - Geoportale Nazionale, http://www.pcn.minambiente.it/GN). (b) Fine-scale structure in the rock-glacier area (orange line: minor trench and fault; white dotted line: subsurface minor fault direction) (digital orthoimage from the year 2006; source: Ministero dell'Ambiente e della Tutela del Territorio e del Mare - Geoportale Nazionale, http://www.pcn.minambiente.it/GN). The lower-resolution digital orthoimage 2006 was chosen for showing minor fault directions at fine scale because of the complete absence of snow in the analysed area which partially conceals the structural setting in the higher-resolution digital orthoimage 2012. 
The progressive decrease in water level independent of precipitation amount could indicate the presence of a subsurface seepage. Moreover, a possible explanation about the lack of strong increases in water level after strong precipitation events can be associated with the presence of the rock-glacier dam in the southeastern corner of the pond. Although no surface water or seepage at the foot of the dam were observed in the field, it is possible to assume that when the water level of the pond rises high enough, as shown by the hydrometric station measurements, water starts spilling through the most porous zone (large boulders) of the dam. Thus, in addition to the subsurface water seepage at the pond bottom, a further outflowing mechanism could be present only with higher water level. This mechanism was not assessed by SP measurements likely because they were performed when water level was not high enough to cause seepage at the dam. Moreover, the transition from water-electrodes to groundelectrodes (different salinity in ground water and pond water) on the southern shore might hide the signal of the seepage. Finally, investigation depth for SP was chosen to be around 3 metres in order to analyse the potential presence of a subsurface seepage at the pond bottom, thus, the potential seepage at the dam could be surficial and not assessable from deeper SP investigations. In the future, it might be interesting to improve the analyses performing different SP measurements during the ice-free season (to account for different pond water level conditions) and at different investigation depths (to potentially assess the presence of a more surficial transient seepage at the dam). 


\subsubsection{Subsurface hydrological connection between the rock glacier and the pond via intermittent inflow}

Due to the isothermal conditions of the pond both in July and September 2015, the presence of a conspicuous inflow of cold water coming from the rock glacier and flowing at the pond bottom can be excluded. Indeed, this should result in a strong thermal stratification with cold waters at the pond bottom, which is inconsistent with the observation of a completely mixed pond. Thus, water inflow coming from the rock glacier is assumed to be reduced, as also discussed in the following paragraphs.

The pond water level decreased rather continuously throughout the ice-free seasons 2014 (Fig. 5.1.5c) and 2015 (Fig. 5.1.5d), with limited periods of level increase due to strong precipitation. Even during warm atmospheric periods, such as mid-August to mid-September 2014 and mid-July to the beginning of August 2015, water level in the pond showed decreasing trends. This suggests that the melting of internal ice in the rock glacier did not contribute enough in the hydrological regime of the pond during the investigated ice-free seasons to be easily noticeable based on water level.

The SP results show one main positive anomaly located in the northern part of the pond, close to the rock glacier (Fig. 5.1.4a). The RG3 sensor was placed at this site and recorded much lower water temperatures than in other parts of the pond (RG1 and RG2). The litho-structural setting of the slopes in the rock-glacier area and sedimentology of the pond suggest that high density and persistence of structural discontinuities (N100E and N60E systems) make the rock masses in 
the northern side of the pond permeable, thus preventing surficial flow. The impermeable character of the high resistivity bedrock (Fig. 5.1.4b, zone C) and the absence of vertical discontinuities in pond sediments (Fig. 5.1.2) in its northern side should also impede pond to be fed by underground water, which could be conducted away from the pond area by fractured bedrock along the shear zones. For these reasons, the main SP positive anomaly is interpreted as evidence of cold water flowing from the rock glacier into the pond. Low water temperature from the rock glacier can be attributed to the contact of water with melting ice in the subsurface (e.g., Haeberli, 1975; Krainer and Mostler, 2002; Berger et al., 2004; Williams et al., 2006; Krainer et al., 2007; Krainer et al., 2012; Millar et al., 2013; Carturan et al., 2016). The secondary, weakly positive anomaly on the southern shore of the pond is considered an artefact. Indeed, the SP data were obtained measuring between one electrode in the ground and the other floating in water, thus, a different salinity in ground water and pond water could cause this potential.

Since only RG3 is characterised by cold water, it is reasonable to assume the pond to be well mixed, as also demonstrated by water temperature profiles (Tab. 5.1.1), and that the cold source near RG3 lowers temperature only locally (Fig. 5.1.6a and 5.1.6b). Even if the temperature of the cold source is low $(<=+0.5$ ${ }^{\circ} \mathrm{C}$ ), its small discharge can explain its negligible influence on temperatures at RG2 (and RG1).

Heat-tracer results show that in 2014 , the main inferred contribution of the rock glacier (after winter snowpack depletion) is from mid-September to mid-October 
(period 2 in Fig. 5.1.6e), in 2015 it is one month earlier (mid-August to midSeptember, period 4 in Fig. 5.1.6f). Warmer air in July-August 2015 (mean: +6.4 ${ }^{\circ} \mathrm{C}$ ) in comparison to July-August 2014 (mean: $+3.4{ }^{\circ} \mathrm{C}$ ) could have influenced thawing inside the rock glacier. Moreover, the air temperature in September and during the first ten days of October 2014 was warmer (mean: $+1.8{ }^{\circ} \mathrm{C}$ ) than during the same time-span in 2015 (mean: $-0.2^{\circ} \mathrm{C}$ ) and contributed to extending the thawing season until October 2014. The contribution from the rock glacier reaches minimum values when mean air temperature is negative or close to $0{ }^{\circ} \mathrm{C}$ for some days, as is especially evident in 2015 . This marks the end of the rockglacier cold-water export at the end of the ice-fee season. Increasing hydrological contributions from the rock glacier were found to be associated with precipitation during the ice-free season, which increased the export of cold water from the landform. This resulted in a clear decrease of water temperature at RG3 (Fig. 5.1.6a and 5.1.6b) due to the greater amount of cold water flowing into the pond (Fig. 6.1.1d).

\subsection{Atmospheric forcing of physicochemical fluxes from the Col d'Olen Rock Glacier}

Integrated analyses of water temperatures, inferred rock-glacier discharge, stable water isotopes and solute content showed systematic patterns. In both ice-free seasons (2014 and 2015) RG1 and RG2 generally showed similar patterns, while higher geochemical concentrations were measured at RG3 (Fig. 5.2.1 and 5.2.2). There, increases of inferred rock-glacier discharge after precipitation events (Fig. 
5.2.1e and 5.2.1f) were found to be temporally associated with isotopicallyenriched waters, particularly evident for $d_{\text {excess }}$ (Fig. 5.2.1g and 5.2.1h).

\subsubsection{Export of solutes during rain events}

As discussed in Section 6.1.2, the inferred main hydrological contribution of the rock glacier occurred one month later in 2014 than in 2015. In both ice-free seasons, the main periods of rock-glacier discharge occurred after the melting of the snowpack (Fig. 5.2.1a, 5.2.1b, and appendix, Fig. 1) and thus, the contribution of cold meltwater from snow on rock-glacier discharge can be excluded. A long-lasting winter snowpack in 2014 probably contributed in delaying the onset of active-layer thawing (cf., Hanson and Hoelzle, 2004).

During periods of strong inferred rock-glacier discharge at RG3, $d_{\text {excess }}$ was observed to increase, reaching maximum values at RG3 both in 2014 and 2015 (Fig. 5.2.1). In these periods, $d_{\text {excess }}$ values at RG3 (max.: $16.5 \%$, mean: 14.3 $\%$ ) were observed to be closer to those of rain (max.: $+19.5 \%$, mean: $+15.9 \%$ ) than of snow (max.: $+13.3 \%$, mean: $+11.7 \%$ ). This might indicate that the cold water originated from a combination of isotopically-enriched rainwater and melt of ice subject to multiple melt-freeze cycles (Steig et al., 1998; Williams et al., 2006). However, giving the mixed origin (i.e., rain, icemelt, groundwater) of the water source at RG3 (further mixed with pond water) and the fact that it is not easy to discriminate among these different components, the contribution of ice melt, here considered as a product of melting of ice in a mixture of ice and debris, to the hydrological budget cannot be well constrained (cf., Krainer et al., 2007). Although less evident, $\delta^{18} \mathrm{O}$ and $\delta^{2} \mathrm{H}$ became more enriched at RG3 than 
at $R G 1,2$ during the heterogeneous periods (Tab. 5.2.1). The different isotopic signature between RG3 and RG1,2 was further highlighted by the slope of the $\delta^{2} \mathrm{H}-\delta^{18} \mathrm{O}$ relationship. Indeed, slope at RG3 was higher (9.6) than the slopes at RG1 (8.9) and RG2 (9), which were similar to the slope of the LMWL (8.9): this indicates that the water has a different source at RG3, which is also subjected to different evaporation rates than at RG1 and RG2 (Tab. 5.2.2). Slopes higher than the GMWL slope (8) are not uncommon in Italy, which presents a high slope variability among different sampling sites, ranging from 4.9 to 9.2 (Longinelli and Selmo, 2003; Giustini et al., 2016). The higher slope at RG3 indicates that little if any evaporation is occurring in the water source system: an occurrence consistent with coarse debris setting and very limited vegetation cover producing high infiltration rates in the rock-glacier system (Williams et al., 2006).

At the beginning of the ice-free season 2015 (until mid-August), although relative rock-glacier discharge was estimated to be low to moderate (between 0.1 and 0.4 ), RG3 did not show isotopic behaviour strongly differing from RG1,2. This can be explained with the presence of cold and rather isotopically-depleted snowmelt coming from the rock glacier, although snow was estimated to be absent in the catchment and on the rock glacier (Fig. 5.2.1a, 5.2.1b, and Appendix, Fig. 1). Thus, it might be possible that, even if investigated at finescale with a grid of surficial ground thermal sensors, the potential effects of "hidden" long-lasting snow patches melting among the boulders require an improvement of measurement setting. Snow melting could have led to an inflow of cold and rather isotopically-depleted water from the rock glacier without strong 
heterogeneous behaviour among sampling points due to its reduced discharge and because of the presence of isotopically-depleted snowmelt water at the beginning of the ice-free season in the pond (cf., Krainer et al., 2007; Jeelani et al., 2010; Penna et al., 2014). Moreover, ice might have accumulated by refreezing of snowmelt after percolating into the active layer (Hinkel et al., 2001; Rist and Phillips, 2005; Woo, 2012). This surficial ice might have quickly melted during the warm period July-August 2015, resulting in a combination of snowmelt (isotopically depleted), surficial icemelt (isotopic signature similar to snowmelt), and potential minor internal icemelt (isotopically enriched) resulting in a rather depleted isotopic signature.

Increases in $\mathrm{EC}$ and major ions $\left(\mathrm{SO}_{4}{ }^{2-}, \mathrm{Mg}^{2+}, \mathrm{Ca}^{2+}\right)$ were also found in late summer and early fall after the melting of the winter snowpack, associated with higher rock-glacier discharge after liquid precipitation events. Thus, it is possible to assume that these resulted from of the export of geochemically-concentrated icemelt (Williams et al., 2006), although mixed with low geochemicallyconcentrated precipitation. Icemelt from rock glaciers has been assumed to be enriched in $\mathrm{SO}_{4}{ }^{2-}$ (Thies et al., 2007; Thies et al., 2013; llyashuk et al., 2014) due to enhanced chemical weathering of freshly-exposed mineral surfaces in an environment (in this case composed of fine-grain serpentinite sediments with potential presence of sulphide minerals such as pyrite) with high availability of moisture (Williams et al., 2006). Thus, sulphate increases at RG3 are supposed to derive from icemelt export. This is also corroborated by the fact that this chemical species does not have a direct weathering source in pond area and 
peaty soils, that could generate $\mathrm{SO}_{4}{ }^{2-}$ by the mineralisation of organic matter (Blodau et al., 2007), are absent. $\mathrm{Mg}^{2+}$ was also found to increase at RG3 during higher rock-glacier discharge periods (Fig. 5.2.2a, 5.2.2b, and Tab. 5.2.3); its source can be serpentinites, which are usually enriched in $\mathrm{Mg}^{2+}$ (Vithanage et al., 2014; Baumeister et al., 2015), and constitute the fine-grained sediment rockglacier body. Also $\mathrm{Ca}^{2+}$ increased at RG3 contextually with higher rock-glacier discharge, although less strongly than $\mathrm{Mg}^{2+}$ (Fig. 5.2.2c, 5.2.2d, and Tab. 5.2.3). This can be explained with the fact that even though serpentinite rocks are depleted in essential nutrients such as $\mathrm{Ca}^{2+}, \mathrm{K}^{+}$, and $\mathrm{P}$ (Baumeister et al., 2015), the presence of calcschists on the rock-glacier surface might be expected to result in higher concentrations of $\mathrm{Ca}^{2+}$ (Touhari et al., 2014). Thus icemelt is expected to be primarily enriched in $\mathrm{SO}_{4}{ }^{2-}$, and weathering products from serpentinites such as $\mathrm{Mg}^{2+}$ and, secondarily, in $\mathrm{Ca}^{2+}$ from carbonate dissolution deriving from surficial rocks during percolation of snow meltwater and/or from rain in the ground (Baltensperger et al., 1990; Haeberli et al., 1999). Rain flowing through internal sediment-ice matrix during the thawing season after warm atmospheric periods is assumed to be the main driver of solute export from the rock glacier: soluble ions are released by thaw and made available for flushing.

Greater and earlier heterogeneous periods for EC and major ions at RG3 were found in 2015 than in 2014 (Fig. 5.2.1 and 5.2.2). This is consistent with the observation of a shorter lasting snow cover in 2015 (Fig. 5.2.1b) than in 2014 (Fig. 5.2.1a), which could have allowed higher export of solutes from ice melting in 2015. Indeed, the presence of yearly thick and long lasting snow cover, which 
reduces the melting of interior ice during the thawing season, is assumed to result in much lower concentrations of geochemical products exported from rock glaciers. Conversely, thin and short lasting winter snowpack is supposed to enhance ice melt and the export of solutes from rock glaciers (Williams et al., 2006). In turn, a thin non-insulating snow cover is capable to make the ground thermal regime colder (Luetschg et al., 2008), thus, this might contrast the effect of a short lasting snow cover in the summer on the export of solutes from a rock glacier.

$\mathrm{NO}_{3}{ }^{-}$was also found to strongly increase at $\mathrm{RG} 3$ during higher periods of rockglacier contribution both in 2014 (Fig. 5.2.10) and 2015 (Fig. 5.2.1p). Microbial communities adapted to the extreme environment of the interior of rock glaciers have been indicated as potential sources of the elevated nitrate in the rockglacier outflows (Williams et al. 2007). Additional research in the Rocky Mountains suggested the observed increase in nitrate in surface waters may also be a result of melt water flushing microbially active sediments during permafrost degradation (Barnes et al., 2014) and active microbial populations in sediment pockets within talus deposits (Ley et al., 2004). Nitrate leaching is also possible from organic soil horizons during higher flow (Walling and Webb, 1986), but these are absent on the rock glacier: thus nitrate increase at RG3 during higher rock-glacier discharge cannot be attributed to leaching from soil.

Trace elements associated with serpentinite weathering ( $\mathrm{Ni}, \mathrm{Mn}, \mathrm{Co})$ strongly increased at RG3 during periods of main rock-glacier discharge both in 2014 and 2015 (Fig. 5.2.2 and Tab. 5.2.3). Interestingly, trace elements increases at RG3 
were found to be somehow temporally anticipated with respect to major ions (Fig. 5.2.2), showing a different behaviour (Fig. 5.2.3 and Tab. 5.2.4). This fact is particularly evident in 2015, when increases in trace elements at RG3 were measured not only during main rock-glacier discharge periods (mid-August - midSeptember), but also in July when rock-glacier relative discharge was calculated to be between 0.1 and 0.4 (ratio Qrock/Qtot), especially after a liquid precipitation period (mid-July) (Fig. 5.2.1f). Thus, it is possible that these elements are more easily exported from a matrix of ice and sediment composed of ultramafic rocks like serpentinites. Moreover, an initial peak in trace-element concentrations was found at the beginning of the ice-free season 2015 (Fig. 5.2.2). Ilyashuk et al. (2014), investigating a lake downstream a rock glacier in the Central Eastern European Alps, speculated that chemically highly-concentrated meltwaters might seep from the landform into the lake during the cold season. This might be the case, although it is unclear why this is not evident for other analysed solutes in the present study (Fig. 5.2.2 and 5.2.3). Another explanation might be the mobilisation of trace elements to the pond before the onset of the ice-free season due to snowmelt when precipitation that has accumulated during winter is released (McNamara et al., 1997; Pokrovsky et al., 2010). Trace elements might also be potentially incorporated into snowmelt from upper soil horizons in the catchment (Rember and Trefry, 2004; Bagard et al., 2011).

Based on the information derived from the integrated analyses performed in this study and the conceptual model of source waters and flowpaths in a rock glacier proposed by Williams et al. (2006) and further supported by Leopold et al. 
(2011), I speculate on the main processes driving the export of physicochemical fluxes from the Col d'Olen Rock Glacier through a simplified conceptual model. Differently from what was proposed by Williams et al. (2006) and Leopold et al. (2011), fine sediments and soils at the surface of the rock glaciers are not in the presented conceptual model, since they were not observed on the Col d'Olen Rock Glacier. A coarse, blocky material with air-filled interstices is found at the surface of the rock glacier. These large void spaces can enhance water infiltration in the rock glacier during the summer months. Fine-grained material is assumed to gradually become abundant with increasing depth, and close to the permafrost table, fines are predominant, typical of "bouldery" rock glaciers (Haeberli et al., 2006). A frozen core is hypothesised in this talus-derived rock glacier, and it is expected to be composed of a mixture of sediment and ice (Wahrhaftig and Cox, 1959; Barsch, 1996; Haeberli et al., 2006), as in most rock glaciers discussed in the literature (Haeberli, 1985; Barsch, 1988).

At the beginning of the ice-free season, snow melt runoff is the dominant water source, depleted in isotopes and with low solute concentration, and the $0{ }^{\circ} \mathrm{C}$ isotherm is near the surface (Fig. 6.2.1a). Higher concentrations of trace elements are present in the pond potentially due to meltwater seep from the rock glacier during the cold season or due to mobilised trace elements in snowmelt before the onset of the ice-free season. 

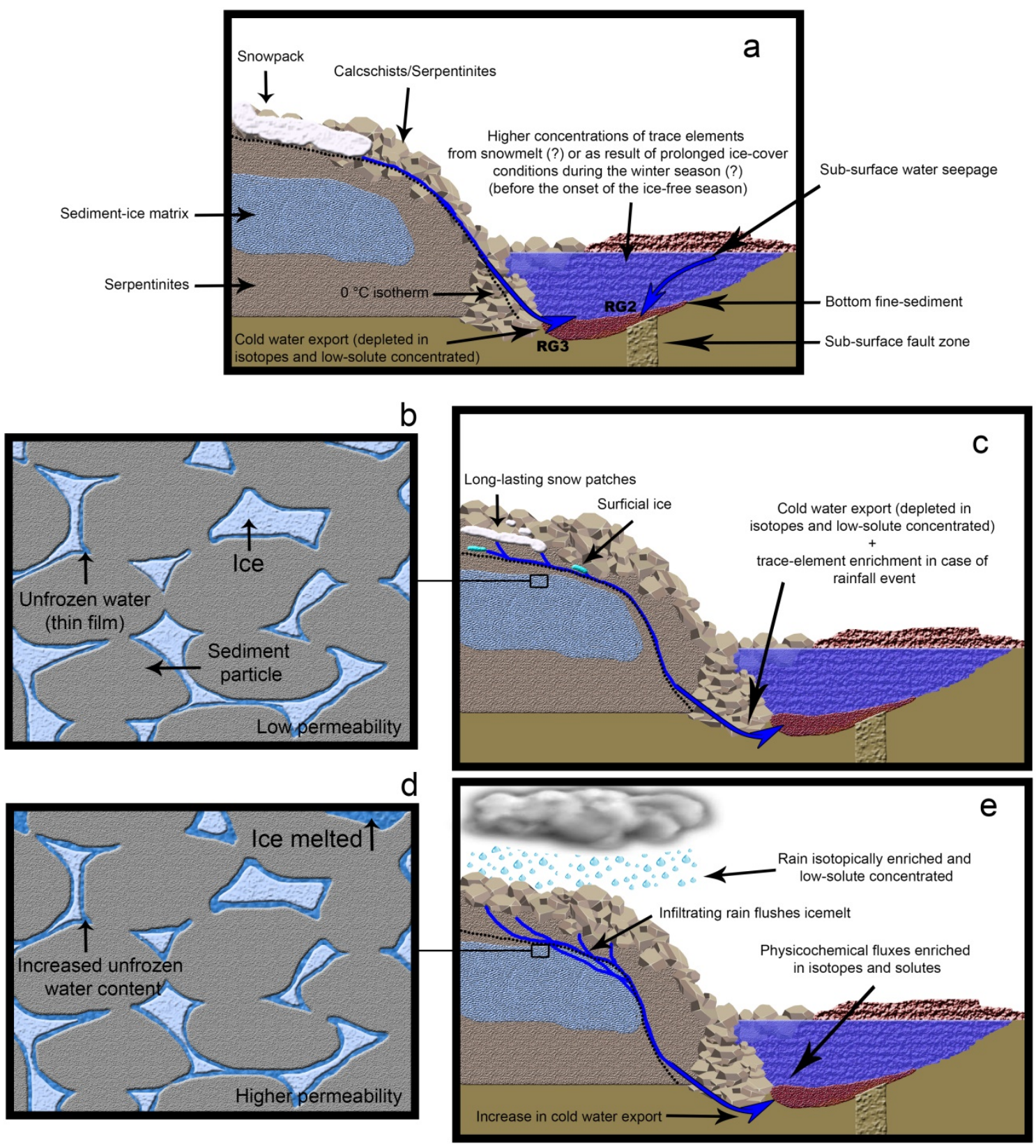

Figure 6.2.1 - Conceptual scheme of hypothesised internal structure of the rock glacier and main processes driving the export of physicochemical fluxes into the adjacent pond. Heterogeneity in the rock-glacier interior might be present, however, it has not been considered in this conceptual model. Refer to the text for details on this figure. 
Later in the ice-free season, the active layer is partially, or completely, thawed and the remaining snowmelt (from long-lasting snow patches in hollows between and underneath boulders) flows in it. The frozen core is below $0{ }^{\circ} \mathrm{C}$ but significant quantities of unfrozen water can exist in capillaries and as films on the surfaces of soil particles (Williams and Smith, 1989; Rempel, 2012) (Fig. 6.2.1b). This unfrozen water is geochemically concentrated due to solute expulsion during ice growth in soil pores (Konrad and McCammon, 1990). At low temperatures, the permeability of the sediment-ice matrix is low due to freezing of capillary water and the decrease of water film thickness around soil grains (Burt and Williams, 1976). Snow meltwater at this time may percolate through the rock glacier in the void spaces created by the larger clast material, and infiltrating water most likely flows near and around the frozen core. The $0{ }^{\circ} \mathrm{C}$ isotherm extends into the rock glacier (Fig. 6.2.1c). Minor amounts of internal meltwater can be exported after rainfall periods (e.g., July 2015), which might be able to modify the thermal properties of the active layer (lijima et al., 2010), enhancing water percolation and ice melting. This association of source waters leads to a rather depleted isotopic signature and similar solute concentrations at all sampling points in the pond, with single concentration increase discrepancies at RG3 for easily exportable trace elements from the sediment-ice matrix after rainfall periods.

After the snowmelt depletion and with the progression of the thawing season, the ground temperature increases and the temperature of the uppermost zone of the internal sediment-ice matrix increases as well. This leads to an increase in its permeability and in the amount of contained unfrozen water (Fig. 6.2.1d), even if 
still below $0{ }^{\circ} \mathrm{C}$ (Williams and Smith, 1989; Kurylyk and Watanabe, 2013). The 0 ${ }^{\circ} \mathrm{C}$ isotherm might also extend into the frozen core, thickening the active layer and melting some of the ice-debris mixture below. The internal ice is then in contact with significant amount of liquid water and undergoes isotopic fractionation. Further isotopic enrichment might be also caused by melt/freeze episodes (Steig et al., 1998; Williams et al. 2006), with isotopic fractionation between infiltrating liquid water and ice that preferentially removes the lighter isotopes, leaving the heavier isotopes behind as the liquid water drains (Williams et al., 2006). Water in contact with newly-eroded mineral surfaces causes chemical weathering, further increasing geochemical products in the liquid water. Then, isotopically-enriched and geochemically-depleted subsurface flow of infiltrated rain water flushes this isotopically- and geochemically-enriched icemelt, with the resulting physicochemical fluxes entering into the pond at RG3 (Fig. 6.2.1e). Higher permeability of the sediment-ice matrix further allows a higher proportion of percolating rain to infiltrate in it (Haeberli et al. (2006) suggest that precipitation can infiltrate up to $0.5 \mathrm{~m}$ into rock glacier ice), enhancing the export of the available stored solutes. Moreover, infiltrating water into the frozen core might be further enhanced by dilatancy and melting ice in the creeping rock glacier (Arenson et al., 2002; Arenson and Palmer, 2005). Rainfall periods earlier in the ice-free season might also enhance the solute flushing during rainfall events later in the ice-free season by solubilising ions in the upper zone of the sediment-ice matrix and reducing moisture storage in the active layer (Lamhonwah et al., 2017). Thus, differently from the model proposed by Williams 
et al. (2006), snowpack duration and air temperature during the summer are not the only atmospheric forcing determining the export of solutes from a rock glacier, but rain is also a fundamental component to be considered in this process. Finally, nitrate export from the rock glacier increases too, likely due to the flushing of microbially active sediments. 


\section{Discussion}

The inferred transport of coarse material towards and down the rock-glacier front and subsequent incorporation at the bottom of the advancing permafrost body is in agreement with previous observations and conceptual models (Kääb and Reichmuth, 2005). At the bottom of the pond, a thick layer of silty material is present, characterised by low resistivity, as also reported in other water-cover environments (Mitchell et al., 2008; Nyquist et al., 2008; Colombero et al., 2014). Below this fine-sediment layer, a minor fault zone in the bedrock might allow a subsurface seepage. This weakness area has a WNW-ESE elongated orientation in accordance with the orientation of distinctive structural association of brittle faults and fractures in the area. This is in agreement with the findings of Bistacchi and Massironi (2000) and Bistacchi et al. (2000) who reported that the geological context of the study area is highly affected by WNW-ESE Miocene-toPresent fault lineaments. The regional character of the fault zone (Bistacchi and Massironi, 2000; Bistacchi et al., 2000) indicates a possible deep extension of its shear zone. Deep-seated fractured bedrock below the pond could deeply conduct outflowing water from the pond, thus preventing local superficial evidence of outflow patterns, which in fact were not observed downstream the pond.

The continuously decreasing water level throughout the ice-free seasons, even during warm periods, suggests a limited contribution of the rock glacier to the hydrological dynamics of the pond. High air temperature can result in increasing meltwater export into the pond due to enhanced ice melting, leading to 
increasing water level (Langston et al., 2013). Conversely, the pattern observed in this thesis agrees with results of previous studies on rock-glacier hydrology (Krainer and Mostler, 2002; Berger et al., 2004; Krainer et al., 2007; Geiger et al., 2014). These reported a gradual decline in rock-glacier discharge throughout the summer (with the progressive depletion of the snowpack), except during storms, with a minimal contribution of rock-glacier meltwater to the total discharge on a seasonal basis. This also agrees with previous observations of rock-glacier outflows, which are characterised by small discharge because coarse debris on rock glaciers strongly retards heat transfer and melt at depth (Potter, 1972; Gardner and Bajewsky, 1987; Krainer and Mostler, 2002; Millar et al., 2013). An inflow area in the pond was found along the rock-glacier front, were low water temperatures were measured and attributed to cold water coming from the rock glacier (cf., Haeberli, 1975; Krainer et al., 2012; Carturan et al., 2016). Rainfall periods can cause great variations in groundwater circulation in rock glaciers; furthermore, dry springs can reactivate after heavy and/or repeated rainfall events (Kummert et al., 2017). Furthermore, intense summer rainfall events have been reported to cause peaks in the discharge of rock glaciers without deeply modifying water temperature, which usually remains constantly low around the freezing point (Krainer and Mostler, 2002; Berger et al., 2004; Krainer et al., 2007; Geiger et al., 2014). This is in agreement with the pattern found in the pond, with increasing inferred hydrological contributions from the rock glacier often associated with summer liquid precipitation due to a greater amount of cold water flowing from the rock glacier into the pond. Towards the end of the ice-free 
season, the inferred hydrological contribution of the rock glacier reaches minimum values; in this case, the cold-water source could be frozen or have negligible discharge (Krainer and Mostler, 2002; Krainer et al., 2012; Millar et al., 2013).

Isotopically-enriched waters and increases in $\mathrm{EC}$, major ions $\left(\mathrm{SO}_{4}{ }^{2-}, \mathrm{Mg}^{2+}\right.$, $\left(a^{2+}\right)$, and trace elements were found in concomitance of high inferred rockglacier discharge. Isotopic enrichment trends were observed in the outflows of other rock glaciers (Williams et al., 2006; Krainer et al., 2007) and there, were attributed primarily to the progressive decrease of isotopically-depleted snowmelt and secondarily to higher contribution of isotopically-enriched rain (short-time release, quickflow pulses, time-scale: hours) (Johnson, 1981; Tenthorey, 1993; Krainer and Mostler, 2002) and icemelt plus groundwater (average/long-time release, baseflow reservoir behaviour, time-scale: days-months-years) (Tenthorey, 1992; Harris et al., 1994; Burger et al., 1999). Regarding the $d_{\text {excess, }}$ a mean $d_{\text {excess }}$ value for snow of about $+11 \%$ was reported by Williams et al. (2006) in their study on the Green Lake 5 rock glacier, similar to the base value for the ice core of the Galena rock glacier (Steig et al., 1998). Williams et al. (2006) found increasing $d_{\text {excess }}$ values in the rock-glacier outflow during the summer season, with a maximum value of $+17.5 \%$ in the fall. An enrichment of $+6 \%$ compared to snow is similar to the values for sections of the ice core from the Galena rock glacier that had undergone multiple melt-freeze cycles (Steig et al., 1998). In the present study, a smaller enrichment was found at RG3, but it is worth noting that the mixing with more depleted pond water is likely to smooth 
the enriched isotopic signal coming from the rock-glacier into the pond. Williams et al. (2006) attributed the $d_{\text {excess }}$ enrichment in the rock-glacier outflow to icemelt subject to multiple melt-freeze cycles. The authors also reported that some combination of isotopically-enriched rain water and icemelt could have potentially provided the same isotopic values in the outflow of the rock glacier. However, the effect of rain was considered minimal due to its small contribution to annual precipitation.

In the present study, although increases in $\mathrm{EC}$ and major ions $\left(\mathrm{SO}_{4}{ }^{2-}, \mathrm{Mg}^{2+}\right.$, $\mathrm{Ca}^{2+}$ ) were found in late summer and early fall, in agreement with previous studies in rock glaciers (Krainer and Mostler, 2002; Berger et al., 2004; Williams et al., 2006; Krainer et al., 2007; Thies et al., 2013), they were also associated with higher rock-glacier discharge after liquid precipitation events. This association, at the best of my knowledge, has been observed here for the first time. Indeed, some of the previously cited researches reported dilution of rockglacier outflows after rainfall due to its low solute content (Krainer and Mostler, 2002; Berger et al., 2004; Krainer et al., 2007). Thus, flowing of rain on or/and in the internal sediment-ice matrix during the thawing season after warm atmospheric periods is assumed to be the main driver of solute export from the rock glacier as it was firstly comprehensively described by Lamhonwah et al. (2017) in a High Arctic catchment in Canada (Melville Island). Here, the authors found rainfall events to act as a hydrological flushing mechanism, mobilising solutes from the subsurface (upper permafrost) to surface waters. 
The effect of rainwater alone on causing isotopic and solute differences between RG3 and RG1,2 can be excluded since different rain events occurred during the investigated ice-free seasons but main isotopic enrichments and solute increases at RG3 were associated with higher rock-glacier discharge in mid-summer or at the end, after warm atmospheric periods and strong rainfall events. Regarding solutes, this excludes the possibility of a simple flushing process from micropores during higher flows or other reactions in the rock-glacier fine-grained sediment interior (cf., Clow and Drever, 1996). However, variations of solute concentrations in response to changes in discharge are usually modest (Clow and Drever, 1996), generally evidencing relatively small declines to great discharge increases through the "chemostatic" behaviour (Godsey et al., 2009). Additionally, rainfall events are usually reported to lower solute concentrations in mountain surface waters, showing strong concentration-flow relationships, especially for weathering-related ions (Froehlich et al., 2008; Goulsbra et al., 2014; Blumstock et al., 2015). Finally, main heterogeneous periods for isotopes and solutes were systematically found at RG3, which is inconsistent with the assumption of some effect of rain flowing from the catchment and/or directly falling into the pond, which should influence all the sampling sites.

Also $\mathrm{NO}_{3}{ }^{-}$was found to strongly increase at $\mathrm{RG} 3$ during higher periods of rock-glacier contribution. These finding is in agreement with other researches performed in mountain permafrost areas, where increases in nitrate concentrations in surface waters were attributed to melting ice in permafrost and rock glaciers (Williams et al. 2007; Baron et al., 2009; Fegel et al., 2016). 
Trace elements associated with serpentinites weathering ( $\mathrm{Ni}, \mathrm{Mn}, \mathrm{Co})$ strongly increased at RG3 during periods of main inferred rock-glacier discharge both in 2014 and 2015. Also this pattern is in agreement with previous observations of higher metal concentrations in rock-glacier ponds (Thies et al., 2007) and rockglacier outflows (Thies et al., 2013) in comparison to reference surface waters not influenced by rock glaciers, even though these studies did not investigate intra-seasonal trends. Ilyashuk et al. (2014) found higher trace-element (and major-ion) concentrations in a rock-glacier lake in the Italian Alps at the beginning of the summer season 2012 (the investigated lake was $\sim 70 \%$ ice covered), and the authors attributed this pattern to highly-concentrated salt solutions seeping from the rock glacier into the lake through the cold season, although no direct evidence of this process was provided. Physical and chemical stratification of the water column, which reduces water circulation and aeration of deep-water layers, developing during periods of prolonged ice cover (8-9 months) was attributed to a solute-rich inflow sinking down the water column due to its high density.

Generally, EC and solute content in the Col d'Olen Rock Glacier Pond were comparable to values measured in rock-glacier outflows in catchments composed of metamorphic rocks (Krainer and Mostler, 2001a,b, 2002; Berger et al., 2004; Krainer et al., 2007), but lower than values measured in other rock glacier outflows (Williams et al., 2006; Thies et al., 2013) and lakes (Thies et al., 2007; Ilyashuk et al., 2014). $\mathrm{NO}_{3}{ }^{-}$concentrations in the pond, except during high rock-glacier discharge periods at RG3, were comparable to those measured in a 
rock-glacier lake in the Central Eastern European Alps (llyashuk et al., 2014) and other high elevations surface waters (Balestrini et al., 2014; Magnani et al., 2017), but lower than those measured in rock-glacier outflows in the Colorado Front Range (Williams et al., 2007). Trace-element concentrations in this study were lower than ones measured in other rock-glacier outflows (Thies et al., 2013) and rock-glacier lakes (llyashuk et al., 2014). During periods of high rock-glacier discharge Ni concentrations at RG3 exceeded the European guideline values for drinking water by a factor of two (Council of the European Union, 1998).

As demonstrated in this work, after winter snowmelt depletion, rainfall events facilitate the export of solutes previously stored in a rock glacier. In the Northern Hemisphere, snow cover extent in spring (March, April) has undergone significant reduction over the period 1922-2010 (Brown and Robinson, 2011). Contextually, a significant air temperature increase $\left(1.26{ }^{\circ} \mathrm{C}\right)$ at hemispheric scale has been found at mid-latitudinal land areas $\left(40^{\circ}-60^{\circ} \mathrm{N}\right)$ (Brutel-Vuilmet et al., 2016). In the North-Western Italian Alps between 1961 and 2010 the weather stations located above $1600 \mathrm{~m}$ a.s.l. presented an increase in air temperature (Acquaotta et al., 2014). Moreover, Terzago et al. (2012, 2013) outlined a significant decrease of snow depth over seasonal (November-May) time scale, and Fratianni et al. (2015) reported significant decreases in fresh snow, causing a shift of the snowmelt in spring as also reported for the Swiss Alps (Klein et al., 2016). As global climate models generally predict a continuous increase in air temperature during the coming decades, suggesting that moisture availability under warmer scenarios is likely to increase summer rainfall (IPCC, 2013), an 
increase in solute flushing from rock glaciers is likely. Potential impacts might be relevant considering that extremely high elemental concentrations have been reported in rock-glacier ice (Krainer et al., 2011). However, the impacts of this process on surface-water characteristics will likely be dependent on the ratio of rock-glacier size to catchment area, and frozen core characteristics and dimensions. Finally, this study presents for the first time the effects of rain on solute flushing from rock glaciers, although a similar process has been already described for permafrost terrains in the Arctic. 


\section{Conclusions and future research directions}

\subsection{Conclusions}

On the basis of the performed surveys it is hypothesised that the advancing movement of the rock glacier has modified the configuration of the valley depression, where the pond is located, which has been progressively filled by the rock glacier. Rock-glacier advance is also assumed to have modified the level of water impounded in the depression, through the creation of a dam. The hydrological connection between the rock glacier and the pond is represented by a subsurface inflow of cold water from the rock glacier. Greater discharge from the rock glacier occurred following intense precipitation during the ice-free season. The influence of the rock-glacier subsurface inflow on the hydrological regime and thermal behaviour of the pond during the ice-free season was limited due to a small discharge. An outflowing mechanism of the pond is hypothesised and might be associated with the presence of a subsurface seepage.

Although the rock-glacier discharge was small, the physicochemical analyses captured an intra-seasonal pattern of solute export from the Col d'Olen Rock Glacier into the pond during the ice-free season. A temporal correlation between higher rock-glacier discharge and greater export of solutes was shown. Rainfall was found to be the primary driver of solute export during the ice-free season, with the flushing of stored solutes as a likely mechanism.

This thesis provides insight into the mechanisms linking active rock glaciers and adjacent impounded surface waters in high-mountain areas, where stable and surficial outflowing streams are absent, through the application of 
geophysical and hydrological techniques. Moreover, this study proposes an approach to characterise the hydrological dynamics of a rock glacier-pond system. For this, waterborne geophysical methods and their integration with the heat-tracer approach can be considered as a valuable tool. Finally, this thesis offers improvements on previous efforts of studying the causes of rock glacier export of physicochemical fluxes and provides a methodological baseline for future monitoring.

\subsection{Future research directions}

This thesis suggests potential future research directions:

- With projected reductions in snow cover thickness and duration, and increases in air temperature and summer rainfall in the northern hemisphere and in the Alps, an increase in solute flushing from rock glaciers is likely. Considering the limited number of studies on the effects of rock-glacier thawing on downstream water quality, the establishment of frequent monitoring for key chemical analytes in surface water is recommended. In turn, this will provide greater statistical power to detect changes in solute levels, especially considering elements that are dangerous for drinking water and ecosystem health. In this context, what duration will the effects of the increased geochemical contribution of rock glaciers have? Will these effects subside after a few decades when rock glaciers become inactive or relict, or will the sediment bodies continue to supply high solute levels? Melting of ice in active rock glaciers could 
increase their storage capacity. Chemical composition of outflowing water might be affected by this process. Moreover, fresh water stored in rock glaciers can be important for local water management only during the melt season (summer) since during the cold season (winter) discharge is extremely low or absent. Future studies on water quality originating from rock glaciers should also focus on relict rock glaciers due to their higher storage capacity and residence time for fresh water which can also be released during winter.

- Other debris cover features can be interested by the presence of permafrost containing significant amount of ground ice such as talus slopes (Lambiel and Pieracci, 2008; Gruber and Haeberli, 2009; Scapozza et al., 2011), which are omnipresent in mountain landscapes (Sass, 2006). Should we expect the same behaviour evidenced in rock glaciers (flushing of solutes) for these typical mountain features? 


\section{References}

ACGR (Associate Committee On Geotechnical Research), (1988). Glossary of Permafrost and Related Ground Ice Terms. Permafrost Subcommittee, National Research Council of Canada, Technical Memorandum 142.

Acquaotta, F., Fratianni, S., Garzena, D. (2014). Temperature changes in the North-Western Italian Alps from 1961 to 2010. Theoretical and Applied Climatology, 122: 619-634.

Adrian, R., Reilly, C.M.O., Zagarese, H., Baines, S.B., Hessen, D.O., Keller, W., Livingstone, D.M., Sommaruga, R., Straile, D., Van Donk, E., Weyhenmeyer, G.A., Winder, M. (2009). Lakes as sentinels of climate change. Limnology and Oceanography, 54(6): 2283-2297.

Allen, C.R., O'Brien, R.M.G., Sheppard, S.M.F. (1976). The chemical and isotopic characteristics of some northeast Greenland surface and pingo waters. Arctic and Alpine Research, 8: 297-317.

Anderson, M.P. (2005). Heat as a ground water tracer. Ground Water, 43(6): 951-968.

Angillieri, E., Yanina, M. (2009). A preliminary inventory of rock glaciers at $30^{\circ} \mathrm{S}$ latitude, cordillera frontal of San Juan, Argentina. Quaternary International, 195: $151-157$.

Anisimov, O., Reneva, S. (2006). Permafrost and changing climate: The Russian perspective. Ambio 35(4): 169-175. 
Anisimova, N.P. (1975). Cryogenic metamorphism of underground water. Proceedings of the 2nd International Conference on Permafrost.

Arcone, S., Finnegan, D., Boitnott, G. (2010). GPR characterization of a lacustrine UXO site. Geophysics, 75(4): 221-239.

Arenson, L.U., Hoelzle, M., Springman, S. (2002). Borehole deformation measurements and internal structure of some rock glaciers in Switzerland. Permafrost and Periglacial Processes, 13: 117-135.

Arenson, L.U., Jakob, M. (2010). The significance of rock glaciers in the dry Andes - A discussion of Azócar and Brenning (2010) and Brenning and Azócar (2010). Permafrost and Periglacial Processes, 21: 286-288.

Arenson, L.U., Johansen, M.M., Springman, S. (2004). Effects of volumetric ice content and strain rate on shear strength under triaxial conditions for frozen soil samples. Permafrost and Periglacial Processes 15: 261-271.

Arenson, L.U., Palmer, A.C. (2005). Rock glaciers, fault gouge and asphalt. Hard particles in a nonlinear creeping matrix. Cold Regions Science and Technology, 43: 117-127.

Azócar, G.F., Brenning, A. (2010). Hydrological and geomorphological significance of rock glaciers in the dry Andes, Chile $\left(27^{\circ}-33^{\circ} \mathrm{S}\right)$. Permafrost and Periglacial Processes, 21: 42-53.

Bagard, M.L., Chabaux, F., Pokrovsky, O.S., Viers, J., Prokushkin, A.S., Stille, P., Rihs, S., Schmit, A.D., Dupre, B. (2011). Seasonal variability of element 
fluxes in two Central Siberian rivers draining high latitude permafrost dominated areas. Geochimica et Cosmochimica Acta, 75: 3335-3357.

Bajewski, I., Gardner, J.S. (1989). Discharge and sediment-load characteristics of the Hilda rock-glacier stream, Canadian Rocky Mountains, Alberta. Physical Geography, 10: 295-306.

Balch, E.S. (1990). Glaciers or Freezing Caverns. Lane and Scott, Philadelphia.

Balduff, D.M. (2007). Pedogenesis, inventory, and utilization of subaqueous soils in Chincoteague Bay. University of Maryland, Maryland.

Balestrini, R., Polesello, S., Sacchi, E. (2014). Chemistry and isotopic composition of precipitation and surface waters in Khumbu valley (Nepal Himalaya): $\mathrm{N}$ dynamics of high elevation basins. Science of the Total Environment, 485-486: 681-692.

Baltensperger, U., Gaggeler, H., Gloor, M., Hoehn, E., Keil, R. (1990). Chemical composition. Pilot Analyses of Permfrost Cores from the Active Rock Glacier Murtèl, Piz Corvatsch, Eastern Swiss Alps. Workshop Report, Arbeitsheft VAW/ETHZ 9: 24-26.

Banin, A., Anderson, D.M. (1974). Effects of salt concentration changes during freezing on the unfrozen water content of porous materials. Water Resources research, 10(1): 124-128.

Barnes, R.T., Williams, M.W., Parman, J.N., Hill, K., Caine, N. (2014). Thawing glacial and permafrost features contribute to nitrogen export from Green Lakes Valley, Colorado Front Range, USA. Biogeochemistry, 117: 413-430. 
Baron, J.S., Schmidt, T.M., Harman, M.D. (2009). Climate-induced changes in high-elevation stream nitrate dynamics. Global Change Biology, 15(7): 17771789 .

Barone, F.S., Yanful, E.K., Quigley, R.M., Rowe, R.K. (1989). Effect of multiple contaminant migration on diffusion and adsorption of some domestic waste contaminants in a natural clayey soil. Canadian Geotechnical Journal, 26: 189198.

Barsch, D. (1977). Nature and importance of mass-wasting by rock glaciers in alpine permafrost environments. Earth Surface Processes, 2: 231-245.

Barsch, D. (1978). Active rock glaciers as indicators for discontinuous alpine permafrost. an example from the Swiss Alps. Proceedings of the 3rd International Conference on Permafrost.

Barsch, D. (1988). Rockglaciers. [Ed.] Clark, M.J, Advances in Periglacial Geomorphology. Wiley, New York, 69-90.

Barsch, D. (1996). Rockglaciers: Indicators for the Present and Former Geoecology in High Mountain Environments. Springer-Verlag: BerlinHeidelberg.

Barsch, D., Fierz, H., Haeberli, W. (1979). Shallow core drilling and borehole measurements in permafrost of an active rock glacier near the Grubengletscher, Wallis, Swiss Alps. Arctic and Alpine Research, 11(2): 215228. 
Baumeister, J.L., Hausrath, E.M., Olsen, A.A., Tschauner, O., Adcock, C.T., Metcalf, R.V. (2015). Biogeochemical weathering of serpentinites: An examination of incipient dissolution affecting serpentine soil formation. Applied Geochemistry, 54: 74-84.

Befus, K.M., Cardenas, M.B., Ong, J.B., Zlotnik, V.A. (2012). Classification and delineation of groundwater-lake interactions in the Nebraska Sand Hills (USA) using electrical resistivity patterns. Hydrogeology Journal, 20: 1483-1495.

Beniston, M. (2006). Mountain weather and climate: A general overview and a focus on climatic change in the Alps. Hydrobiologia, 562(1): 3-16.

Berger, J., Krainer, K., Mostler, W. (2004). Dynamics of an active rockglacier (Ötztal Alps, Austria). Quaternary Research, 62: 233-242.

Berthling, I. (2011). Beyond confusion: Rock glaciers as cryo-conditioned landforms. Geomorphology, 131: 98-106.

Birchak, J.R., Gardner, C.G., Hipp, J.E., Victor, J.M. (1974). High dielectric microwave probes for sensing soil moisture. Proceedings of the IEEE, 62: 9398.

Bistacchi, A., Massironi, M. (2000). Post-nappe brittle tectonics and kinematic evolution of the north-western Alps: an integrated approach. Tectonophysics, 327: $267-292$.

Bistacchi, A., Eva, E., Massironi, M., Solarino, S. (2000). Miocene to present kinematics of the NW-Alps: evidences from remote sensing, structural 
analysis, seismotectonics and thermochronology. Journal of Geodynamics, 30: 205-228.

Blodau, C., Mayer, B., Peiffer, S., Moore, T.R. (2007). Support for an anaerobic sulfur cycle in two Canadian peatland soils. Journal of Geophysical Research, 112(G2): G02004, doi:org/10.1029/2006JG000364.

Blumstock, M., Tetzlaff, D., Malcolm, I.A., Nuetzmann, G., Soulsby, C. (2015). Baseflow dynamics: Multi-tracer surveys to assess variable groundwater contributions to montane streams under low flows. Journal of Hydrology, 527: 1021-1033.

Bodin, X., Thibert, E., Fabre, D., Ribolini, A., Schoeneich, P., Francou, B., Reynaud, L., Fort, M. (2009). Two decades of responses (1986-2006) to climate by the Laurichard rock glacier, French Alps. Permafrost and Periglacial Processes, 20(4): 331-344.

Boeckli, L., Brenning, A., Gruber, S., Noetzli, J. (2012). Permafrost distribution in the European Alps: calculation and evaluation of an index map and summary statistics, The Cryosphere, 6: 807-820.

Bolch., T., Marchenko, S. (2006). Significance of glaciers, rockglaciers, and icerich permafrost in the Northern Tien Shan as water towers under climate change conditions. Proceedings of the workshop "Assessment of SnowGlacier and Water Resources in Asia".

Bollmann, E., Girstmair, A., Mitterer, S., Krainer, K., Sailer, R., Stotter, J. (2015). A rock glacier activity index based on rock glacier thickness changes and 
displacement rates derived from airborne laser scanning. Permafrost and Periglacial Processes, 26: 347-359.

Bowden, W.B., Gooseff, M.N., Malser, A., Green, A., Peterson, B.J., Bradford, J. (2008). Sediment and nutrient delivery from thermokarst features in the foothills of the North Slope, Alaska: Potential impacts on headwater stream ecosystems. Journal of Geophysical Research, 113: G02026, doi:10.1029/2007JG000470.

Bradley, M.P., Stolt, M.H. (2003). Subaqueous soil-landscape relationships in a Rhode Island Estuary. Soil Science Society of America Journal, 67: 14871495.

Brenning, A. (2005). Geomorphological, hydrological, and climatic significance of rock glaciers in the Andes of Central Chile (33-35 S). Permafrost and Periglacial Processes, 16: 231-240.

Brenning, A. (2010). The significance of rock glaciers in the Dry Andes - reply to Arenson L.U. and Jakob M. Permafrost and Periglacial Processes, 21(3): 286288.

Brenning, A., Trombotto, D. (2006). Logistic regression modeling of rock glacier and glacier distribution: Topographic and climatic controls in the semi-arid Andes. Geomorphology, 81: 141-154.

Brooks, R.R. (1987). Serpentine and Its Vegetation. Dioscorides Press, Portland. 
Brouchkov, A. (2000). Salt and water transfer in frozen soils induced by gradients of temperature and salt content. Permafrost and Periglacial Processes, 11: 153-160.

Brown, R.D., Robinson, D.A. (2011). Northern Hemisphere spring snow cover variability and change over 1922-2010 including an assessment of uncertainty. The Cryosphere, 5: 219-229.

Brutel-Vuilmet, C., Ménégoz, M., Krinner, G. (2013). An analysis of present and future seasonal Northern Hemisphere land snow cover simulated by CMIP5 coupled climate models. The Cryosphere, 7: 67-80.

Buchli, T., Merz, K., Zhou, X., Kinzelbach, W., Springman, S. (2013). Characterization and monitoring of the Furggwanghorn rock glacier, Turtmann Valley, Switzerland: results from 2010 to 2012. Vadose zone journal, 12(1), doi:10.2136/vzj2012.0067.

Buraschi, E., Salerno, F., Monguzzi, C., Barbiero, G., Tartari, G. (2005). Characterization of the Italian lake-types and identification of their reference sites using anthropogenic pressure factors. Journal of Limnology, 64(1): 7584.

Burger, K.C., Degenhardt, J.J., Giardino, J.R. (1999). Engineering geomorphology of rock glaciers. Geomorphology, 31: 93-132.

Burn, C.R. (1988). The development of near-surface ground ice during the Holocene at sites near Mayo, Yukon Territory, Canada. Journal of Quaternary Science, 3: 31-38. 
Burn, C.R., Michel, F.A. (1988). Evidence for recent temperature-induced water migration into permafrost from tritium content of ground ice near Mayo, Yukon Territory, Canada. Canadian Journal of Earth Sciences, 25: 909-915.

Burt, T.P., Williams, P.J. (1976). Hydraulic conductivity in frozen soils. Earth Surface Processes, 1(3): 349-360.

Caine, N. (1974). The geomorphic processes of the alpine environment. [Eds.] Ives, J.D., Barry, R.G., Arctic and Alpine Environments, Methuen, London, 721-748.

Carpenter, S.R., Benson, B.J., Biggs, R., Chipman, J.W., Foley., J.A., Golding, S.A., Hammer, R.B., Hanson, P.C., Johnson, P.T.J., Kamarainen, A.M., Kratz, TK., Lathrop, R.G., McMahon, K.D., Provencher, B., Rusak, J.A., Solomon, C.T., Stanley, E.H., Turner, M.G., Vander Zanden, J.M., Wu, C-H., Yuan, H. (2007). Understanding regional change: A comparison of two lake districts. Bioscience, 57: 323-335.

Carturan, L., Zuecco, G., Seppi, R., Zanoner, T., Borga, M., Carton, A., Dalla Fontana, G. (2016). Catchment-scale permafrost mapping using spring water characteristics. Permafrost and Periglacial Processes, 27(3): 253-270.

Cary, J.W., Mayland, H.F. (1972). Salt and water movement in unsaturated frozen soil. Proceedings of the Soil Science Society of America, 36: 549-555.

Catalan, J., Camarero, L., Felip, M., Pla, S., Ventura, M., Buchaca, T., Bartumeus, F., de Mendoza, G., Miró, A., Casamayor, E.O., Medina-Sánchez, J.M., Bacardit, M., Altuna, M., Bartrons, M., De Quijano, D.D. (2006). High 
mountain lakes: Extreme habitats and witnesses of environmental changes. Limnetica, 25(1-2): 551-584.

Catalan, J., Curtis, C.J., Kernan, M. (2009). Remote European mountain lake ecosystems: Regionalisation and ecological status. Freshwater Biology, 54(12): 2419-2432.

Cecil, L.D., Green, J.R., Vogt, S., Michel, R., Cottrell, G. (1998). Isotopic composition of ice cores and meltwater from upper Freemont Glacier and Galena Creek Rock Glacier, Wyoming. Geografiska Annaler, 80A(3-4): 287292.

Chagué-Goff, C., Fyfe, W.S. (1997). Effect of permafrost on geochemistry in a Canadian peat plateau bog. Applied Geochemistry, 12(4): 465-472.

Cheng, G. (1983). The mechanism of repeated-segregation for the formation of thick layered ground ice. Cold Regions Science and Technology, 8: 57-66.

Chuvilin, E.M., Ershov, E.D., Smirnova, O.G. (1998). Ionic migration in frozen soils and ice. Proceedings of the 7th International Conference on Permafrost.

Clark, D.H., Steig, E.J., Potter, N.J., Fitzpatrick, J., Updike, A.B., Clark, G.M. (1996). Old ice in rock glaciers may provide long-term climate records. EOS, Transactions American Geophysical Union, 77: 217-222.

Clow, D.W., Schrott, L., Webb, R., Campbell, D.H., Torizzo, A., Dornblaser, M. (2003). Ground water occurrence and contributions to streamflow in an alpine catchment, Colorado Front Range. Ground Water, 41(7): 937-950. 
Colombero, C., Comina, C., Gianotti, F., Sambuelli, L. (2014). Waterborne and on-land electrical surveys to suggest the geological evolution of a glacial lake in NW Italy. Journal of Applied Geophysics, 105: 191-202.

Constantz, J. (2008). Heat as a tracer to determine streambed water exchanges. Water Resources Research, 44(4): DOI:10.1029/2008WR006996/full.

Corte, A. (1976). The hydrological significance of rock glaciers. Journal of Glaciology, 17: 157-158.

Corte, A. (1978). Rock glaciers as permafrost bodies with debris cover as an active layer. A hydrological approach. Andes of Mendoza, Argentina. Proceedings of the 3rd International Conference on Permafrost.

Council of the European Union (1998). Directive on the Quality of Water Intended for Human Consumption, 98/83/CE, Official Journal of the European Communities. European Union, Brussels.

Craig, H. (1961). Isotopic variations in meteoric waters. Science, 133: 17021703.

Cremonese, E., Gruber, S., Phillips, M., Pogliotti, P., Boeckli, L., Noetzli, J., Suter, C., Bodin, X., Crepaz, A., Kellerer-Pirklbauer, A., Lang, K., Letey, S., Mair, V., Morra di Cella, U., Ravanel, L., Scapozza, C., Seppi, R., Zischg, A. (2011). Brief Communication: "An inventory of permafrost evidence for the European Alps". The Cryosphere, 5: 651-657. 
Croce, F.A., Milana, J.P. (2002). Internal structure and behaviour of a rock glacier in the Arid Andes of Argentina. Permafrost and Periglacial Processes, 13(4): 289-299.

Dal Piaz, G.V. (2001). Geology of the Monte Rosa Massif: historical review and personal comments. Schweizerische Mineralogische und Petrographische Mitteilungen, 81: 275-303.

Dansgaard, W. (1964). Stable isotopes in precipitation. Tellus, 16: 436-468.

Das, B. (2008). Advanced Soil Mechanics. Third Edition, Taylor \& Francis: London \& New York.

Davis, N. (2001). Permafrost: a guide to frozen ground in transition. University of Alaska Press, Fairbanks.

Delaloye, R., Lambiel, C. (2005). Evidence of winter ascending air circulation throughout talus slopes and rock glaciers situation in the lower belt of alpine discontinuous permafrost (Swiss Alps). Norsk Geografisk Tidsskrift, 59: 194203.

Delaloye, R., Perruchoud, E., Avian, M., Kaufmann, V., Bodin, X., Hausmann, H., Ikeda, A., Kääb, A., Kellerer-Pirklbauer, A., Krainer, K., Lambiel, C., Mihajlovic, D., Staub, B., Roer, I., Thibert, E. (2008). Recent interannual variations of rock glacier creep in the European Alps. Proceedings of the 9th International Conference on Permafrost.

Devyatkin, V.N. (1993). Heat Flow of Siberian Cryolithozone. VO Nauka, Novosibirsk. 
Dugan, H.A., Lamoureux, S.F., Lafrenière, M.J., and Lewis, T. (2009). Hydrological and sediment yield response to summer rainfall in a small high Arctic watershed. Hydrological Processes, 23: 1514-1526.

Duguay, M.A., Edmunds, A., Arenson, L.U., Wainstein, P.A. (2015). Quantifying the significance of the hydrological contribution of a rock glacier - A review. GEOQuébec 2015, Challenges from North to South.

Elconin, R.F., LaChapelle, E.R. (1997). Flow and internal structure of a rock glacier. Journal of Glaciology, 43(144): 238-244.

Everett, K.R., Marion, G.M., Kane, D.L. (1989). Seasonal geochemistry of an arctic tundra drainage basin. Ecography, 12: 279-289.

Evin, M., Assier, A. (1983). Relations hydrologiques entre glacier et glaciers rocheux: l'exemple du cirque de Marinet (Haute-Ubaye, Alpes du Sud). Communication, Section de Glaciologie de la Societe hydrotechnique de France.

Fanning, D.S., Fanning, M.C.B. (1989). Soil: Morphology, Genesis, and Classification. John Wiley \& Sons, New York.

Fanning, D.S., Rabenhorst, M.C., Burch, S.N., Islam, K.R., Tangren, S.A. (2002). Soil Mineralogy with Environmental Applications. SSSA, Madison, WI.

Fegel, T.S., Baron, J.S., Fountain, A.G., Johnson, G.F., Hall, E.K. (2016). The differing biogeochemical and microbial signatures of glaciers and rock glaciers. Journal of Geophysical Research, 121(3): 919-932. 
Ferronato, C., Falsone, G., Natale, M., Zannoni, D., Buscaroli, A., Vianello, G., Vittori Antisari, L. (2016). Chemical and pedological features of subaqueous and hydromorphic soils along a hydrosequence within a coastal system (San Vitale Park, Northern Italy). Geoderma, 265: 141-151.

Fratianni, S., Terzago, S., Acquaotta, F., Faletto, M., Garzena, D., Prola, M.C., Barbero, S. (2015). How snow and its physical properties change in a changing climate alpine context? Engineering Geology for society and territory, Springer, 1(11): 57-60.

French, H.M. (1974). Active thermokarst processes, eastern Banks Island, western Canadian Arctic. Canadian Journal of Earth Science, 11: 785-794.

French, H.M. (2007). The Periglacial Environment. Third edition, John Wiley \& Sons, Chichester.

Frey, K.E., McClelland, J.W. (2009). Impacts of permafrost degradation on arctic river biogeochemistry. Hydrological Processes, 23: 169-182.

Fritz, M., Opel, T., Tanski, G., Herzschuh, U., Meyer, H., Eulenburg, A., Lantuit, H. (2015). Dissolved organic carbon (DOC) in Arctic ground ice. The Cryosphere, 9: 737-752.

Fritz, M., Wetterich, S., Meyer, H., Schirmeister, L., Lantuit, H., Pollard, W.H. (2011). Origin and characteristics of massive ground ice on Hershel Island (western Canadian Arctic) as revealed by stable water isotope and hydrochemical signatures. Permafrost and Periglacial Processes. 22: 26-38. 
Froehlich, H.L., Breuer, L., Frede, H., Huisman, J.A., Vach, K.B. (2008). Water source characterization through spatiotemporal patterns of major, minor and trace element stream concentrations in a complex, mesoscale German. Hydrological Processes, 2043(2007): 2028-2043.

Fuchs, M., Campbell, G., Papendick, R. (1978). An analysis of sensible and latent heat flow in a partially frozen unsaturated soil. Soil Science Society of America Journal, 42(3): 379-385.

Gadek, B., Leszkiewicz, J. (2010). Influence of snow cover on ground surface temperature in the zone of sporadic permafrost, Tatra Mountains, Poland and Slovakia. Cold Regions Science and Technology, 60(3): 205-211.

Gardaz, J.M. (1998). Permafrost prospecting, periglacial and rock glacier hydrology in mountain areas. Case studies in the Valais Alps, Switzerland. PhD Thesis, University of Fribourg, Switzerland.

Gardner, J.S., Bajewsky, I. (1987). Hilda rock glacier stream discharge and sediment load characteristics, Sunwapta Pass area, Canadian Rocky Mountains. [Eds.] Giardino, J.R., Shroder, J.F., Vitek, J.D., Rock Glaciers. Allen and Unwin, London, 161-174.

Gasco, I., Borghi, A., Gattiglio, M. (2011). P-T Alpine metamorphic evolution of the Monte Rosa nappe along the Piedmont Zone boundary (Gressoney Valley, NW Italy). Lithos, 127(1-2): 336-353. 
Gee, G.W., Bauder, J.W. (1986). Methods of soil analysis: part 1 - physical and mineralogical methods, SSSA book series. Soil Science Society of America, American Society of Agronomy.

Geiger, S.T., Daniels, J.M., Miller, S.N., Nicholas, J.W. (2014). Influence of rock glaciers on stream hydrology in the La Sal Mountains, Utah. Arctic, Antarctic, and Alpine Research, 46(3): 645-658.

Giardino, J.R., Shroder, J.F., Vitek, J.D. (1987). Rock Glaciers. Allen and Unwin, London.

Giardino, J.R., Vitek, J.D., Demorett, J.L. (1992). A model of water movement in rock glaciers and associated water characteristics. [Eds.] Dixon, J.C., Abrahams, A.D., Periglacial Geomorphology, Wiley, Chichester, 159-184.

Giesler, R., Lyon, S.W., Mörth, C.-M., Karlsson, J., Karlsson, E.M., Jantze, E.J., Destouni, G., Humborg, C. (2014). Catchmentscale dissolved carbon concentrations and export estimates across six subarctic streams in northern Sweden, Biogeosciences, 11: 525-537.

Giustini, F., Brillia, M., Patera, A. (2016). Mapping oxygen stable isotopes of precipitation in Italy. Journal of Hydrology: Regional Studies, 8: 162-181.

Godone, D., Garnero, G., Filippa, G., Freppaz, M., Terzago, S., Rivella, E., Salandin, A., Barbero, S. (2011). Snow cover extent and duration in MODIS time series: A comparison with in-situ measurements (Provincia Verbano Cusio Ossola, NW Italy). 2011 International Conference on Multimedia Technology, IEEE, doi:10.1109/ICMT.2011.6002893. 
Goodrich, L. (1982). The influence of snow cover on the ground thermal regime. Canadian Geotechnical Journal, 19(4): 421-432.

Gooseff, M.N., Van Horn, D., Sudman, Z., McKnight, D.M., Welch, K.A., Lyons, W.B. (2016). Stream biogeochemical and suspended sediment responses to permafrost degradation in stream banks in Taylor Valley, Antarctica. Biogeosciences, 13: 1723-1732.

Gorbunov, A.P., Marchenko, S.S., Seversky, E.V. (2004). Short communication: The thermal environment of blocky materials in the mountains of Central Asia. Permafrost and Periglacial Processes, 15: 95-98.

Goto, T., Kondo, K.K., Ito, R., Esaki, K., Oouchi, Y., Abe, Y., Tsujimura, M. (2012). Implications of self-potential distribution for groundwater flow system in a nonvolcanic mountain slope. International Journal of Geophysics, doi:10.1155/2012/640250.

Goulsbra, C., Evans, M., Lindsay, J. (2014). Temporary streams in a peatland catchment: pattern, timing, and controls on stream network expansion and contraction. Earth Surface Processes and Landforms, 39(6): 790-803.

Grangeia, C., Matias, M. (2012). Shallow water integrated geophysical survey - a case study with geological and hydrological consequences. Proceeding of Near Surface Geoscience - 18th European Meeting of Environmental and Engineering Geophysics, doi:10.3997/2214-4609.20143407. 
Gruber, S. (2005). Mountain permafrost: transient spatial modelling, model verification and the use of remote sensing. Ph.D. thesis, Department of Geography, University of Zürich, Switzerland.

Gruber, S. (2012). Derivation and analysis of a high-resolution estimate of global permafrost zonation. The Cryosphere, 6: 221-233.

Gruber, S., Fleiner, R., Guegan, E., Panday, P., Schmid, M.-O., Stumm, D., Wester, P., Zhang, Y., Zhao, L. (2017). Review article: Inferring permafrost and permafrost thaw in the mountains of the Hindu Kush Himalaya region. The Cryosphere, 11: 81-99.

Gruber, S., Haeberli, W. (2007). Permafrost in steep bedrock slopes and its temperature-related destabilization following climate change. Journal of Geophysical Research, 112, doi/10.1029/2006JF000547.

Gruber, S., Haeberli, W. (2009). Mountain Permafrost. [Ed.] Margesin, R., Permafrost soils, Springer-Verlag Berlin Heidelberg, 33-44.

Gruber, S., Hoelzle, M. (2008). The cooling effect of coarse blocks revisited. Proceedings of the $9^{\text {th }}$ International Conference on Permafrost.

Gruber, S., Peter, M., Hoelzle, M., Woodhatch, I., Haeberli, W. (2003). Surface temperatures in steep alpine rock faces - a strategy for regional-scale measurement and modelling. Proceedings of the 8th International Conference on Permafrost. 
Gruber, S., Hoelzle, M., Haeberli, W., (2004). Rock-wall temperatures in the alps: Modelling their topographic distribution and regional differences. Permafrost and Periglacial Processes, 15: 299-307.

Gubler, S. (2013). Measurement variability and model uncertainty in mountain permafrost research. Ph.D. thesis, Department of Geography, University of Zürich, Switzerland.

Gubler, S., Fiddes, J., Keller, M., Gruber, S., (2011). Scale-dependent measurement and analysis of ground surface temperature variability in alpine terrain. The Cryosphere, 5: 431-443.

Guglielmin, M., Camusso, M., Polesello, S., Valsecchi, S. (2004). An old relict glacier body preserved in permafrost environment: The Foscagno Rock Glacier. Arctic, Antarctic, and Alpine Research, 36(1): 108-116.

Gurney, S.D. (1998). Aspects of the genesis and geomorphology of pingos: perennial permafrost mounds. Progress in Physical Geography, 22: 307-324.

Haeberli W. (1975). Untersuchungen zur Verbreitung von Permafrost zwischen Flüelapass und Piz Grialetsch (Graubünden). Mitt. ETH Zurich 17.

Haeberli, W. (1985). Creep of mountain permafrost: internal structure and flow of alpine rock glaciers. Mitt. ETH Zurich 77.

Haeberli, W. (1992). Construction, environmental problems and natural hazards in periglacial mountain belts. Permafrost and Periglacial Processes, 3: 111124. 
Haeberli, W. (1996). On the morphodynamics of ice/debris-transport systems in cold mountain areas. Norsk Geografisk Tidsskrift, 50: 3-9.

Haeberli, W., Hallet, B., Arenson, L.U., Elconin, R., Humlum, O., Kääb, A., Kaufmann, V., Ladanyi, B., Matsuoka, N., Springman, S., Vonder Mühll, D. (2006). Permafrost creep and rock glacier dynamics. Permafrost and Periglacial Processes, 17: 189-214.

Haeberli, W., Kääb, A., Wagner, S., Geissler, P., Haas, J.N., Glatzel-Mattheier, H., Wagenbach, D., Vonder Mühll, D. (1999). Pollen analysis and ${ }^{14} \mathrm{C}$-age of moss remains recovered from a permafrost core of the active rock glacier Murtèl/Corvatsch (Swiss Alps): geomorphological and glaciological implications. Journal of Glaciology, 45(149): 1-8.

Haeberli, W., Vonder Mühll, D. (1996). On the characteristic and possible origin of ice in the rock glacier permafrost. Zeitschrift für Geomorphologie N.F., Suppl.-Bd., 104: 43-57.

Hallet, B. (1978). Solute redistribution in freezing ground. Proceedings of the 3rd International Conference on Permafrost.

Hamerlík, L., Svitok, M., Novikmec, M., Očadlík, M., Bitušík, P. (2014). Local, among-site, and regional diversity patterns of benthic macroinvertebrates in high altitude waterbodies: Do ponds differ from lakes? Hydrobiologia, 723(1): $41-52$.

Handy, M.R., Schmid, S.M., Bousquet, R., Kissling, E., Bernoulli, D. (2010). Reconciling plate-tectonic reconstructions of Alpine Tethys with the geological- 
geophysical record of spreading and subduction in the Alps. Earth-Science Reviews, 102(3-4): 121-158.

Hansen, J., Sato M. (2016). Regional climate change and national responsibilities. Environmental Research Letters, 11: 034009, doi:10.1088/1748-9326/11/3/034009.

Hanson, S., Hoelzle, M. (2004). The thermal regime of the active layer at the Murtèl Rock Glacier based on data from 2002. Permafrost and Periglacial Processes, 15: 273-282.

Harms, T.K., Jones Jr., J.B. (2012). Thaw depth determines reaction and transport of inorganic nitrogen in valley bottom permafrost soils. Global Change Biology, 18: 2958-2968.

Harris, H., Arenson, L.U., Christiansen, H.H., Etzelmüller, B., Frauenfelder, R., Gruber, S., Haeberli, W., Hauck, C., Hoelzle, M., Humlum, O., Isaksen, K., Kääb, A., Kern-Lütschg, M.A., Lehning, M., Matsuoka, N., Murton, J., Noetzli, J., Phillips, M., Ross, N., Seppälä, M., Springman, S., Vonder Mühll, D. (2009). Permafrost and climate in Europe: Monitoring and modelling thermal, geomorphological and geotechnical responses. Earth-Science Reviews, 92: 117-171.

Harris, K.J., Carey, A.E., Lyons, W.B., Welch, K.A., Fountain, A.G. (2007). Solute and isotope geochemistry of subsurface ice melt seeps in Taylor Valley, Antarctica. Geological Society of America Bulletin, 119(5-6): 548-555. 
Harris, R.N., Davies, M.C.R., Etzelmüller, B. (2001). The assessment of potential geotechnical hazards associated with mountain permafrost in a warming global climate. Permafrost and Periglacial Processes, 12: 145-156.

Harris, S., Pedersen, D. (1998). Thermal regimes beneath coarse blocky materials. Permafrost and Periglacial Processes, 9(2): 107-120.

Harris, S.A., Wayne, K., Blumenstengel, D., Cook, H., Krouse, R., Whitley, G. (1994). Comparison of the water drainage from an active near-slope rock glacier and a glacier, St. Elias Mountains, Yukon Territory. Erdkunde, 48: 8191.

Hauer, F.R., Baron, J.S., Campbell, D.H., Fausch, K.D., Hostetler, S.W., Leavesley, G.H., Leavitt, P.R., McKnight, D.M., Stanford, J.A. (1997). Assessment of Climate Change and Freshwater Ecosystems of the Rocky Mountains, Usa and Canada. Hydrological Processes, 11: 903-924.

Hausmann, H., Krainer, K., Brückl, E., Mostler, W. (2007). Internal structure and ice content of Reichenkar rock glacier (Stubai Alps, Austria) assessed by geophysical investigations. Permafrost and Periglacial Processes, 18: 351367.

Heginbottom, J.A., Dubreuil, M.A., Harker, P.A. (1995). Canada-Permafrost. National Atlas of Canada, 5th Edition. National Atlas Information Service, Natural Resources Canada, Ottawa, Plate 2.1 MCR 4177.

Hermann, A., Lehrer, M., Stichler, W. (1981). Isotope input into runoff systems from melting snow covers. Nordic Hydrology, 12: 309-318. 
Himes, R., Miller, S., Mink, W. (1959). Zone freezing in demineralizing saline waters. Industrial \& Engineering Chemistry, 51: 1345-1348.

Hinkel, K.M., Paetzold, F., Nelson, F.E., Bockheim, J.G. (2001). Patterns of soil temperature and moisture in the active layer and upper permafrost at Barrow, Alaska: 1993-1999. Global and Planetary Change, 29: 293-309.

Hughes, O.L. (1974). Geology and permafrost in relation to hydrology and geophysics. Permafrost Hydrology, Proceedings of a Workshop Seminar, Environment Canada, 21-28.

Humlum, O. (1997). Active layer thermal regime at three rock glaciers in Greenland. Permafrost and Periglacial Processes, 8: 383-408.

Humlum, O. (1998). The climatic significance of rock glaciers. Permafrost and Periglacial Processes, 9: 375.395.

Humlum, O. (2000). The geomorphic significance of rock glaciers: estimates of rock glacier debris volumes and headwall recession rates in West Greenland. Geomorphology, 35(1-2): 41-67.

Humlum, O., Christiansen, H.H., Juliussen, H. (2007). Avalanche-derived rock glaciers in Svalbard. Permafrost and Periglacial Processes, 18: 75-88.

lijima, Y., Fedorov, A.N., Park, H., Suzuki, K., Yabuki, H., Maximov, T.C., Ohata, T. (2010). Abrupt increases in soil temperatures following increased precipitation in a permafrost region, Central Lena River Basin, Russia. Permafrost and Periglacial Processes, 21: 30-41. 
llyashuk, B.P., Ilyashuk, E.A., Psenner, R., Tessadri, R., Koinig, K.A. (2014). Rock glacier outflows may adversely affect lakes: Lessons from the past and present of two neighboring water bodies in a crystalline-rock watershed. Environmental Science and Technology, 48(11): 6192-6200.

Ikeda, A., Matsuoka, N. (2006). Pebbly versus bouldery rock glaciers: Morphology, structure and processes. Geomorphology, 73(3-4): 279-296.

Ikeda, A., Matsuoka, N., Kääb, A. (2008). Fast deformation of perennially frozen debris in a warm rock-glacier in the Swiss Alps: an effect of liquid water. Journal of Geophysical Research, 113: F01021, doi:10.1029/2007JF000859.

IPCC (2013). Climate Change 2013: The Physical Science Basis. Contribution of Working Group I to the Fifth Assessment Report of the Intergovernmental Panel on Climate Change. Cambridge University Press, Cambridge, United Kingdom and New York, NY, USA.

Isaksen, K., Ødegard, R.S., Eiken, T., Sollid, J.L. (2000). Composition, flow and development of two tongue-shaped rock glaciers in the permafrost of Svalbard. Permafrost and Periglacial Processes, 11: 241-257.

Ishido, T., Pritchett, J.W. (1999). Numerical simulation of electrokinetic potentials associated with subsurface fluid flow. Journal of Geophysical Research, 104: 247-259.

Janke, J.R., Bellisario, A.C., Ferrando, F.A. (2015). Classification of debriscovered glaciers and rock glaciers in the Andes of central Chile. Geomorphology, 241: 98-121. 
Jeelani, Gh., Bhat, N.A., Shivanna, K. (2010). Use of $\delta^{18} \mathrm{O}$ tracer to identify stream and spring origins of a mountainous catchment: A case study from Liddar watershed, Western Himalaya, India. Journal of Hydrology, 393: 257264.

Jessen, S., Holmslykke, H.D., Rasmussen, K., Richardt, N., Holm, P.E (2014). Hydrology and pore water chemistry in a permafrost wetland, llulissat, Greenland. Water Resources Research, 50(6): 4760-4774.

Johnson, P.G. (1981). The structure of a talus-derived rock glacier deduced from its hydrology. Canadian Journal of Earth Sciences, 18: 1422-1430.

Jorgenson, M.T., Racine, C.H., Walters, J.C., Osterkamp, T.E. (2001). Permafrost degradation and ecological changes associated with a warming climate in Central Alaska. Climatic Change, 48: 551-579.

Juliussen, H., Humlum, O. (2008). Thermal regime of openwork block fields on the mountains Elgåhogna and Sølen, central-eastern Norway. Permafrost and Periglacial Processes, 19(1): 1-18.

Kammerer, P., Lee, G. (1969). Freeze concentration of organic compounds in dilute aqueous solutions. Water Research, 3: 276-278.

Kääb, A., Frauenfelder, R., Roer, I. (2007). On the response of rockglacier creep to surface temperature increase. Global and Planetary Change, 56: 172-187.

Kääb, A., Kaufmann, V., Ladstadter, R., Eiken, T. (2003). Rock glacier dynamics: implications from high-resolution measurements of surface velocity fields. Proceedings of the 8th International Conference on Permafrost. 
Kääb, A., Reichmuth, T. (2005). Advance mechanisms of rock glaciers. Permafrost and Periglacial Processes, 16: 187-193.

Keller, F., Gubler, H.U. (1993). Interaction between snow cover and high mountain permafrost at Murtél Corvatsch, Swiss Alps. Proceedings of the 6th International Conference on Permafrost.

Keller, K., Blum, J.D., Kling, G.W. (2007). Geochemistry of soils and streams on surfaces of varying ages in Arctic Alaska. Arctic, Antarctic, and Alpine Research, 39: 84-98.

Keller, K., Blum, J.D., Kling, G.W. (2010). Stream geochemistry as an indicator of increasing permafrost thaw depth in an arctic watershed. Chemical Geology, 273(1-2): 76-81.

Killawee, J.A., Fairchild, I.J., Tison, J.L., Janssens, L., Lorrain, L. (1998). Segregation of solutes and gases in experimental freezing of dilute solutions: Implications for natural glacial systems. Geochimica et Cosmochimica Acta, 62(23/24): 3637-3655.

Klaminder, J., Yoo, K., Rydberg, J., Giesler, R. (2008). An explorative study of mercury export from a thawing palsa mire. Journal of Geophysical research, 113: G04034, doi:10.1029/2008JG000776.

Klein, G., Vitasse, Y , Rixen, C., Marty, C. Rebetez, M. (2016). Shorter snow cover duration since 1970 in the Swiss alps due to earlier snowmelt more than to later snow onset. Climatic Change, 139(3): 637-649. 
Kokelj, S.V., Burn, C.R. (2003). Ground ice and soluble cations in near-surface permafrost, Inuvik, Northwest Territories, Canada. Permafrost and Periglacial Processes, 143: 275-289.

Kokelj, S.V., Burn, C.R. (2005). Geochemistry of the active layer and nearsurface permafrost, Mackenzie delta region, Northwest Territories, Canada. Canadian Journal of Earth Sciences, 42: 37-48.

Kokelj, S.V., Jenkins, R.E., Milburn, D., Burn, C.R., Snow, N. (2005). The influence of thermokarst disturbance on the water quality of small upland lakes, Mackenzie Delta region, Northwest Territories, Canada. Permafrost and Periglacial Processes, 16: 343-353.

Kokelj, S.V., Lacelle, D., Lantz, T.C., Tunnicliffe, J., Malone, L., Clark, I.D., Chin, K.S. (2013). Thawing of massive ground ice in mega slumps drives increases in stream sediment and solute flux across a range of watershed scales. Journal of Geophysical Research, 118: 681-692.

Kokelj, S.V., Lewkowicz, A.G. (1999), Salinization of permafrost terrain due to natural geomorphic disturbance, Fosheim Peninsula, Ellesmere Island. Arctic, 52: $372-385$.

Kokelj, S.V., Smith, C.A.S., Burn, C.R. (2002). Physical and chemical characteristics of the active layer and permafrost, Herschel Island, western Arctic coast, Canada. Permafrost and Periglacial Processes, 13: 171-185.

Kokelj, S.V., Zajdlik, B., Thompson, M.S. (2009). The impacts of thawing permafrost on the chemistry of lakes across the subarctic boreal tundra 
transition, Mackenzie Delta region, Canada. Permafrost and Periglacial Processes, 20: 185-200.

Konrad, J.M., McCammon, A.W. (1990). Solute portioning in freezing soils. Canadian Geotechnical Journal, 27(6): 726-736.

Konrad, S.K., Humphrey, N.F., Steig, E.J., Clark, D.H., Potter Jr, N., Pfeffer, W.T. (1999). Rock glacier dynamics and paleoclimatic implications. Geology, 27(12): 1131-1134.

Krainer, K. (2014). Permafrost and Climate Change in North and South Tyrol. permAfrost, Austrian Permafrost Research Initiative, Final Report, 51-67.

Krainer, K., Bressan, D., Dietre, B., Haas, J.N., Hajdas, I., Lang, K., Mair, V., Nickus, U., Reidl, D., Thies, H., Tonidandel, D. (2015). A 10,300-year-old permafrost core from the active rock glacier Lazaun, southern Ötztal Alps (South Tyrol, northern Italy). Quaternary Research, 83(2): 324-335.

Krainer, K., Mostler, W. (2001a). Aktive Blockgletscher als Transportsysteme für Schuttmassen im Hochgebirge: Der Reichenkar Blockgletscher in den westlichen Stubaier Alpen. Geoforum Umhausen, 1: 28-43.

Krainer, K., Mostler, W. (2001b). Der aktive Blockgletscher im Hinteren Langtal Kar, Gößnitz Tal (Schober Gruppe, Nationalpark Hohe Tauern). Wissenschaftliche Mitteilungen aus dem Nationalpark Hohe Tauern, 6: 139168.

Krainer, K., Mostler, W. (2002). Hydrology of Active Rock Glaciers: Examples from the Austrian Alps. Arctic, Antarctic, and Alpine Research, 34(2): 142-149. 
Krainer, K., Mostler, W., Spötl, C. (2007). Discharge from active rock glaciers, Austrian Alps: A stable isotope approach. Austrian Journal of Earth Sciences, 100: $102-112$.

Krainer, K., Mussner, L., Behm, M., Hausmann, H. (2012). Multi-disciplinary investigation of an active rock glacier in the Sella Group (Dolomites; Northern Italy). Austrian Journal of Earth Sciences, 105(2): 48-62.

Krainer, K., Nickus, U., Thies, H., Tessadri, R. (2011). Geochemical analyses of permafrost ice and of permafrost water springs. PermaNET Project report, WP7.

Kummert, M., Delaloye, R., Braillard, L. (2017) Erosion and sediment transfer processes at the front of rapidly moving rock glaciers: Systematic observations with automatic cameras in the western Swiss Alps. Permafrost and Periglacial Processeses, doi.org/10.1002/ppp.1960.

Kurylyk, B.L., Watanabe, K. (2013). The mathematical representation of freezing and thawing processes in variably-saturated, non-deformable soils. Advances in Water Resources, 60: 160-177.

Lacelle, D., Doucet, A., Clark, I.D., Lauriol, B. (2007). Acid drainage generation and seasonal recycling in disturbed permafrost near Eagle Plains, northern Yukon Territory, Canada. Chemical Geology, 243: 157-177.

Lacelle, D., Fontaine, M., Forest, A.P., Kokelj, S.V. (2014). High-resolution stable water isotopes as tracers of thaw unconformities in permafrost: A case study from western Arctic Canada. Chemical Geology, 368: 85-96. 
Lacelle, D., Juneau, V., Pellerin, A., Lauriol, B., Clark, I.D. (2008). Weathering regime and geochemical conditions in a polar desert environment, Haughton impact structure region, Devon Island, Canada. Canadian Journal of Earth Sciences, 45: 1139-1157.

Lacelle, D., Vasil'chuk, Y.K. (2013). Recent progress (2007-2012) in permafrost isotope geochemistry. Permafrost and Periglacial Processes, 24: 138-145.

Lachhab, A., Booterbaugh, A., Beren, M. (2014). Bathymetry and sediment accumulation of Walker Lake, PA using two GPR antennas in a new integrated method. Journal of Environmental Engineering Geophysics, 20(3): 245-255.

Lafrenière, M.J., Lamoureux, S.F. (2013). Thermal perturbation and rainfall runoff have greater impact on seasonal solute. Permafrost and Periglacial Processes, 24: 241-251.

Lambiel, C., Delaloye, R. (2004). Contribution of real-time kinematic GPS in the study of creeping mountain permafrost: examples from the Western Swiss Alps. Permafrost and Periglacial Processes, 15: 229-241.

Lambiel, C., Pieracci, K. (2008). Permafrost distribution in talus slopes located within the alpine periglacial belt, Swiss Alps. Permafrost and Periglacial Processes, 19: 293-304.

Lamhonwah, D., Lafrenière, M.J., Lamoureux, S.F., Wolfe, B.B. (2017). Evaluating the hydrological and hydrochemical responses of a High Arctic catchment during an exceptionally warm summer. Hydrological Processes, doi:10.1002/hyp.11191. 
Lami, A., Marchetto, A., Musazzi, S., Salerno, F., Tartari, G., Guilizzoni, P., Rogora, M., Tartari, G.A. (2010). Chemical and biological response of two small lakes in the Khumbu Valley, Himalayas (Nepal) to short-term variability and climatic change as detected by long-term monitoring and paleolimnological methods. Hydrobiologia, 648: 189-205.

Langston, G., Hayashi, M., Roy, J.W. (2013). Quantifying groundwater-surface water interactions in a proglacial moraine using heat and solute tracers. Water Resources Research, 49(9): 5411-5426.

Leibman, M.O. (1996). Results of chemical testing for various types of water and ice, Yamal Peninsula, Russia. Permafrost and Periglacial Processes, 7: 287296.

Leibman, M.O., Streletskaya, I.D. (1997). Landslide induced changes in the chemical composition of active-layer soils and surface-water runoff, Yamal Peninsula, Russia. Proceedings of the International Symposium on Physics, Chemistry and Ecology of Seasonally Frozen Soils, 120-126.

Leopold, M., Voelkel, J., Dethier, D., Williams, M.W., Caine, N. (2010). Mountain Permafrost - a valid archive to study climate change? Examples from the Rocky Mountains Front Range of Colorado, USA. Nova acta Leopoldina, 112: 281-289.

Leopold, M., Williams, M.W., Caine, N., Völkel, J., Dethier, D. (2011). Internal structure of the Green Lake 5 rock glacier, Colorado Front Range, USA. Permafrost and Periglacial Processes, 22(2): 107-119. 
Ley, R.E., Williams, M.W., Schmidt, S.K. (2004). Microbial population dynamics in an extreme environment: controlling factors in talus soils at $3,750 \mathrm{~m}$ in the Colorado Rocky Mountains. Biogeochemistry, 68(3): 313-335.

Lewkowicz, A.G. (2007). Dynamics of active-layer detachment failures, Fosheim Peninsula, Ellesmere Island, Nunavut, Canada. Permafrost and Periglacial Processes, 18: 89-103.

Levy, J.S., Fountain, A.G., Welch, K.A., Berry Lyons, W. (2012). Hypersaline "wet patches" in Taylor Valley, Antarctica. Geophysical Research Letters, 39: L05402.

Libohova, Z., Doolittle, J., Villars, T., West, LT. (2015). Mapping the subaqueous soils of Lake Champlain's Missisquoi Bay using ground-penetrating radar, digital soil mapping and field measurements. Photogrammetric Engineering \& Remote Sensing, 80(4): 323-332.

Loke, M.H., Lane, J.W. (2004). Inversion of data from electrical resistivity imaging surveys in water-covered areas. Exploration Geophysics, 35(4): 266-271.

Longinelli A., Selmo, E. (2003). Isotopic composition of precipitation in Italy: a first overall map. Journal of Hydrology, 270: 75-88.

Luethi, M., Funk, M. (2001). Modelling heat flow in a cold, high-altitude glacier: interpretation of measurements from Colle Gnifetti, Swiss Alps. Journal of Glaciology, 47: 314-324.

Luetschg, M., Lehning, M., Haeberli, W. (2008). A sensitivity study of influencing warm/thin permafrost in the Swiss Alps. Journal of Glaciology, 54: 696-704. 
Mackay, J.R. (1972). The world of underground ice. Annals of the Association of American Geographers, 62: 1-22.

Mackay, J.R. (1977). Pulsating pingos, Tuktoyaktuk Peninsula, NWT. Canadian Journal of Earth Sciences, 14: 209-222.

Mackay, J.R. (1978). Sub-pingo water lenses, Tuktoyaktuk Peninsula, Northwest Territories. Canadian Journal of Earth Sciences, 15: 1219-1227.

Mackay, J.R. (1983). Downward water movement into frozen ground, western arctic coast, Canada. Canadian Journal of Earth Sciences, 20: 120-134.

Mackay, J. R. (1985). Pingo ice of the western Arctic coast, Canada. Canadian Journal of Earth Sciences, 22: 1452-1464.

Mackay, J.R. (1990a). Some observations on the growth and deformation of epigenetic, syngenetic, and antisyngenetic ice wedges. Permafrost and Periglacial Processes, 1: 15-29.

Mackay, J.R. (1990b). Seasonal growth bands in pingo ice. Canadian Journal of Earth Science, 27: 1115-1125.

Mackay, J.R. (1994). Pingos and pingo ice of the western Arctic coast, Canada. Terra, 106: 1-11.

Mackay, J.R. (1995). Active layer changes (1968 to 1993) following the foresttundra fire near Inuvik, NWT, Canada. Arctic and Alpine Research, 27: 323336. 
Mackay, J.R. (2000). Thermally induced movements in ice-wedge polygons, western Arctic coast: a long-term study. Géographie physique et Quaternaire, 54: 41-68.

Mackay, J.R., Burn, C.R. (2002). The first 20 years (1978-1979 to 1998-1999) of active-layer development, Illisarvik experimental drained lake site, western Arctic coast, Canada. Canadian Journal of Earth Sciences, 39: 1657-1674.

Mackay, J.R., Dallimore, S.R. (1992). Massive ice of the Tuktoyaktuk area, western Arctic coast, Canada. Canadian Journal of Earth Sciences, 29: 12351249.

Mackay, J.R., Slaymaker, O. (1989). The Horton River breakthrough and resulting geomorphic changes in a permafrost environment, western Arctic Coast, Canada. Geografiska Annaler, 71(A): 171-184.

Magnani, A., Viglietti, D., Balestrini, R., Williams, M.W., Freppaz, M. (2017). Contribution of deeper soil horizons to $\mathrm{N}$ and $\mathrm{C}$ cycling during the snow-free season in alpine tundra, NW Italy. Catena, 155: 75-85.

Malone, L., Lacelle, D., Kokelj, S., Clark, I.D. (2013). Impacts of hillslope thaw slumps on the geochemistry of permafrost catchments (Stony Creek watershed, NWT, Canada). Chemical Geology, 356: 38-49.

Manasypov, R.M., Pokrovsky, O.S., Kirpotin, S.N., Shirokova, L.S. (2014). Thermokarst lake waters across the permafrost zones of western Siberia. The Cryosphere, 8: 1177-1193. 
Mari, S., Scapozza, C., Pera, S., Delaloye, R. (2013). Prove di multitracciamento di ghiacciai rocciosi e ambienti periglaciali nel Vallon de Réchy (VS) e nella Valle di Sceru (TI). Bollettino della Società ticinese di Scienze naturali, 101: 13-20.

Mast, M.A., Turk, J.T., Clow, D.W., Campbell, D.H. (2011). Response of lake chemistry to changes in atmospheric deposition and climate in three highelevation wilderness areas of Colorado. Biogeochemistry, 103(1-3): 27-43.

McNamara, J.P., Kane, D.L., Hinzman, L.D., 1997. Hydrograph separations in an Arctic watershed using mixing model and graphical techniques. Water Resources Research, 33 (7): 1707-1719.

McVey, S., Schoeneberger, P.J., Turenne, J., Payne, M., Wysocki, D.A. (2012). Subaqueous soils (SAS) description. Field Book for Describing and Sampling Soils. National Soil Survey Center Natural Resources Conservation Service U.S. Department of Agriculture.

Millar, C.I., Westfall, R.D. (2008). Rock glaciers and related periglacial landforms in the Sierra Nevada, CA, USA: inventory, distribution, and climatic relationships. Quaternary International, 188: 90-104.

Millar, C.I., Westfall, R.D., Delany, D.L. (2013). Thermal and hydrologic attributes of rock glaciers and periglacial talus landforms: Sierra Nevada, California, USA. Quaternary International, 310: 169-180.

Millar, C.I., Westfall, R.D., Evenden, A., Holmquist, J.G., Schmidt-Gengenbach, J., Franklin, R.S., Nachlinger, J., Delany, D.L. (2015). Potential climatic refugia 
in semi-arid, temperate mountains: Plant and arthropod assemblages associated with rock glaciers, talus slopes, and their forefield wetlands, Sierra Nevada, California, USA. Quaternary International, 387: 106-121.

Minora, U., Godone, D., Lorenzini, S., D'agata, C., Bocchiola, D., Sepulveda Barcaza, G., Smiraglia, C., Diolaiuti, G.A. (2015). 2008-2011 Snow Covered Area (SCA) variability over 18 watersheds of the central Chile through MODIS data. Geografia Fisica e Dinamica Quaternaria, 38(2): 169-174.

Mitchell, N., Nyquist, J.E., Toran, L., Rosenberry, D.O., Mikochik, J.S. (2008). Electrical resistivity as a tool for identifying geologic heterogeneities which control seepage at Mirror Lake. 21st Symposium on the Application of Geophysics to Engineering and Environmental Problems.

Mladenov, N., López-Ramos, J., McKnight, D.M., Reche, I. (2009). Alpine lake optical properties as sentinels of dust deposition and global change. Limnology and Oceanography, 54: 2386-2400.

Muller, S.W. (1943). Permafrost or permanently frozen ground and related engineering problems. U.S. Engineers Office, Strategic Engineering Study, Special Report No. 62.

Murrman, R.P. (1973). Ionic mobility in permafrost. Proceedings 2nd International Conference on Permafrost.

Nechaev, E.A., Romanov, V.P. (1981). Adsorption of anions on ice and freezing potentials. Russian Journal of Physical Chemistry, 55(7): 1027-1028. 
Necsoiu, M., Onaca, A., Wigginton, S., Urdea, P. (2016). Rock glacier dynamics in Southern Carpathian Mountains from high-resolution optical and multitemporal SAR satellite imagery. Remote Sensing of Environment, 177: 21-36.

Nelson, F.E., Anisimov, O.A., Shiklomanov, N.I. (2002). Climate change and hazard zonation in the circum-Arctic permafrost regions. Natural Hazards, 26: 203-225.

Nogués-Bravo, D., Araújoc, M.B. , Erread, M.P., Martínez-Ricad, J.P. (2007). Exposure of global mountain systems to climate warming during the $21 \mathrm{st}$ Century. Global Environmental Change, 17: 420-428.

Nyquist, J.E., Freyer, P.A., Toran, L. (2008). Stream bottom resistivity tomography to map ground water discharge. Ground Water, 46(4): 561-569.

O'Brien, R. (1971). Observations on pingos and permafrost hydrology in Schuchert Dal, N.E. Greenland. Meddelelser om Gronland, 195(1): 1-20.

Opel, T., Dereviagin, A.Y., Meyer, H., Schirrmeister, L., Wetterich, S. (2011). Palaeoclimatic information from stable water isotopes of Holocene ice wedges on the Dmitrii Laptev Strait, northeast Siberia, Russia. Permafrost and Periglacial Processes, 22: 84-100.

Ostroumov, V., Hoover, R., Ostroumova, N., Van Vliet-Lanoë, B., Siegert, C., Sorokovikov, V. (2001). Redistribution of soluble components during ice segregation in freezing ground. Cold Regions Science and Technology, 32: 175-182. 
Otto, J.C., Schrott, L., Jaboyedo, M., Dikau, R. (2009). Quantifying sediment storage in a high Alpine valley (Turtmanntal, Switzerland). Earth Surface Processes and Landforms, 34: 1726-1742.

Outcalt, S.I. (1982). Massive near-surface ground ice in arctic Alaska: description and modelling analysis. Physical Geography, 3: 123-147.

Parker, P., Collins, G. (1999). Ultra-rapid freezing of water treatment residuals. Water Research, 33: 2239-2246.

Penna, D., Engel, M., Mao, L., Dell'Agnese, A., Bertoldi, G., Comiti, F. (2014). Tracer-based analysis of spatial and temporal variations of water sources in a glacierized catchment. Hydrology and Earth System Sciences, 18: 5271-5288.

PERMOS (2007). Permafrost in Switzerland, 2002/2003 and 2003/2004. Glaciological Report (Permafrost) No. 4/5 of the Cryospheric Commission of the Swiss Academy of Sciences, [Ed.] Vonder Mühll, D., Noetzli, J., Roer, I., Makowski, K., Delaloye, R.

Pham, S.V., Leavitt, P.R., McGowan, S., Peres-Nato, P. (2008). Spatial variability of climate and land-use effects on lakes of the northern Great Plains. Limnology and Oceanography, 53: 728-742.

Pogliotti, P. (2011). Influence of snow cover on MAGST over complex morphologies in mountain permafrost regions. Ph.D. thesis, Department of Earth Sciences, University of Turin, Italy.

Pokrovsky, O.S., Viers, J., Shirokova, L.S., Shevchenko, V.P., Filipov, A.S., Dupré, B., 2010. Dissolved, suspended, and colloidal fluxes of organic carbon, 
major and trace elements in the Severnaya Dvina River and its tributary. Chemical Geology, 273: 136-149.

Potter, N. Jr. (1972). Ice-cored rock glacier, Galena Creek, northern Absaroka Mountains, Wyoming. Geological Society of America Bulletin, 83(10): 30253057.

Qui, G., Chamberlain, E.J., Iskandar, I.K. (1986). Ion and moisture migration and frost heave in freezing Morin clay. Journal of Glaciology and Geocryology, 8(1): 1014 .

Qui, G., Sheng, W., Huang, C., Zheng, K. (1988). Direction of ion migration during cooling and freezing processes. Proceedings of the 5th International Conference on Permafrost.

R Development Core Team, R. (2011). R: A Language and Environment for Statistical Computing. (R. D. C. Team, Ed.) R Foundation for Statistical Computing, doi:10.1007/978-3-540-74686-7.

Rangecroft, S., Harrison, S., Anderson, K. (2015). Rock glaciers as water stores in the Bolivian Andes: an assessment of their hydrological importance. Arctic, Antarctic, and Alpine Research, 47(1): 89-98.

Rangecroft, S., Harrison, S., Anderson, K., Magrath, J., Castel, A.P., Pacheco, P. (2013). Climate change and water resources in arid mountains: An Example from the Bolivian Andes. Ambio, 42: 852-863. 
Rember, R., Trefry, J. (2004). Increased concentrations of dissolved trace metals and organic carbon during snowmelt in rivers of the Alaskan arctic. Geochimica et Cosmochimica Acta, 68: 477-489.

Rempel, A.W. (2012). Hydromechanical processes in freezing soils. Vadose Zone Journal, 11, doi:10.2136/vzj2012.0045.

Ribolini, A., Guglielmin, M., Fabre, D., Bodin, X., Marchisio, M., Sartini, S., Spagnolo, M., Schoeneich, P. (2010). The internal structure of rock glaciers and recently deglaciated slopes as revealed by geoelectrical tomography: insights on permafrost and recent glacial evolution in the Central and Western Alps (Italy-France). Quaternary Science Reviews, 29: 507-521.

Riggs, G.A., Hall, D.K., Salomonson, V.V. (1994). A snow index for the Landsat Thematic Mapper and Moderate Resolution Imaging Spectroradiometer. Proceedings of IGARSS '94 - 1994 IEEE International Geoscience and Remote Sensing Symposium.

Rist, A., Phillips, M. (2005). First results of investigations on hydrothermal processes within the active layer above alpine permafrost in steep terrain. Norsk Geografisk Tidsskrift-Norwegian Journal of Geography, 59: 177-183.

Rode, M., Kellerer-Pirklbauer, A. (2012). Schmidt-hammer exposure-age dating (SHD) of rock glaciers in the Schoderkogel-Eisenhut area, Schladminger Tauern Range, Austria. Holocene, 22: 761-771. 
Roer, I., Kääb, A., Dikau, R. (2005). Rock glacier acceleration in the Turtmann valley (Swiss Alps): Probable controls. Norsk Geografisk Tidsskrift, 59: 157163.

Rucker, D.F., Noonan, G.E., Greenwood, W.J. (2011). Electrical resistivity in support of geological mapping along the Panama Canal. Engineering Geology, 117(1-2): 121-133.

Salerno, F., Gambelli, S., Viviano, G., Thakuri, S., Guyennon, N., D'Agata, C., Diolaiuti, G., Smiraglia, C., Stefani, F., Bocchiola, D., Tartari, G. (2014). High alpine ponds shift upwards as average temperatures increase: A case study of the Ortles-Cevedale mountain group (Southern Alps, Italy) over the last 50 years. Global and Planetary Change, 120: 81-91.

Salerno, F., Rogora, M., Balestrini, R., Lami, A., Tartari, G. A., Thakuri, S., Tartari, G. (2016). Glacier melting increases the solute concentrations of Himalayan glacial lakes. Environmental Science \& Technology, 50(17): 91509160.

Sambuelli, L., Bava, S. (2012). Case study: A GPR survey on a morainic lake in northern Italy for bathymetry, water volume and sediment characterization. Journal of Applied Geophysics, 81: 48-56.

Sambuelli, L., Colombo, N., Giardino, M., Godone, D. (2015). A waterborne GPR survey to estimate fine sediments volume and find optimum core location in a rockglacier lake. Proceeding of Near Surface Geoscience - 21st European Meeting of Environmental and Engineering Geophysics. 
Sass, O. (2006). Determination of the internal structure of alpine talus deposits using different geophysical methods (Lechtaler Alps, Austria). Geomorphology, 80: 45-58.

Scapozza, C., Lambiel, C., Baron, L, Marescot, L., Reynard, E. (2011). Internal structure and permafrost distribution in two alpine periglacial talus slopes, Valais, Swiss Alps. Geomorphology, 132(34): 208-221.

Scapozza, C., Lambiel, C., Bozzini, C., Mari, S., Conedera, M. (2014). Assessing the rock glacier kinematics on three different timescales: a case study from the southern Swiss Alps. Earth Surface Processes \& Landforms, 39: 2056-2069.

Schmid, M.O., Gubler, S., Fiddes, J., Gruber, S. (2012). Inferring snowpack ripening and melt-out from distributed measurements of near-surface ground temperatures. The Cryosphere, 6(5): 1127-1139.

Schmid, S.M., Fügenschuh, B., Kissling, E., Schuster, R. (2004). Tectonic map and overall architecture of the Alpine orogen. Eclogae Geologicae Helvetiae, 97: 93-117.

Schmidt, C., Conant, Jr. B., Bayer-Raich, M., Schirmer, M. (2007). Evaluation and field-scale application of an analytical method to quantify groundwater discharge using mapped streambed temperatures. Journal of Hydrology, 347: 292-307.

Schreier, H., Omueti, J.A., and Lavkulich, L.M. (1987). Weathering processes of asbestos-rich serpentinitic sediments. Soil Science Society of America Journal, 51: 993-999. 
Schrott, L. (1996). Some geomorphological-hydrological aspects of rock glaciers in the Andes San Juan, Argentina. Zeitschrift fur Geomorphologie Supplement, 104: $161-173$.

Schuur, E.A.G., McGuire, A.D., Schädel, C., Grosse, G., Harden, J.W., Hayes, D.J., Hugelius, G., Koven, C.D., Kuhry, P., Lawrence, D.M., Natali, S.M., Olefeldt, D., Romanovsky, V.E., Schaefer, K., Turetsky, M.R., Treat, C.C., Vonk, J.E. (2015). Climate change and the permafrost carbon feedback. Nature, 520: 171-179.

Scotti, R. Crosta, G.B., Villa, A. (2017). Destabilisation of creeping permafrost: the Plator rock glacier case study (Central Italian Alps). Permafrost and Periglacial Processes, 28(1): 224-236.

Seppi, R. (2006). I rock glaciers delle Alpi Centrali come indicatori ambientali (Gruppo Adamello-Presanella e settore orientale del Gruppo Ortles-Cevedale). PhD thesis, Department of Earth and Environmental Sciences, University of Pavia, Italy.

Seppi, R., Zanoner, T., Carton, A., Bondesan, A., Francese, R., Carturan, L., Zumiani, M., Giorgi, M., Ninfo, A. (2015). Current transition from glacial to periglacial processes in the Dolomites (South-Eastern Alps). Geomorphology, 228: $71-86$.

Shafique, U., Anwar, J., Munawar, M.A., Zaman, W., Rehman, R., Dar, A., Salman, M., Saleem, M., Shahid, N., Akram, M., Naseer, A., Jamil, N. (2011). 
Chemistry of ice: Migration of ions and gases by directional freezing of water. Arabian Journal of Chemistry, 45: doi:10.1016/j.arabjc.2011.02.019.

Shur, Y., Hinkel, K.M., Nelson, F.E. (2005). The transient layer: implications for geocryology and climate-change science. Permafrost and Periglacial Processes, 16: 5-17.

Siegel, D. (2008). Reductionist hydrogeology: ten fundamental principles. Hydrological Processes, 22: 4967-4970.

Slagoda, E.A., Opokina, O.L., Kurchatova, A.N., Rogov, V.V. (2012). Structure and composition of complex massive ice bodies in Late Pleistocene-Holocene sediments of the Marre-Sale Cape, West Yamal. Proceedings of the 10th International Conference on Permafrost.

Staub, B., Delaloye, R. (2016). Using near-surface ground temperature data to derive snow insulation and melt indices for mountain permafrost applications. Permafrost and Periglacial Processes, 28(1): 237-248.

Stauffer, B., Wagenbach, D. (1990). Stable isotopes. Pilot Analyses of Permfrost Cores from the Active Rock Glacier Murtèl, Piz Corvatsch, Eastern Swiss Alps. Workshop Report, Arbeitsheft VAW/ETHZ 9: 22-23.

Steck, A., Masson, H., Robyr, M. (2015). Tectonics of the Monte Rosa and surrounding nappes (Switzerland and Italy): Tertiary phases of subduction, thrusting and folding in the Pennine Alps. Swiss Journal of Geosciences, 108: 3-34. 
Steig, E.J., Fitzpatrick, J., Potter, N.J., Clark, D.H. (1998). The geochemical record in rock glaciers. Geografiska Annaler, 80: 277-286.

Stenni, B., Genoni, L., Flora, O., Guglielmin, M. (2007). An oxygen isotope record from the Foscagno rock-glacier ice core, Upper Valtellina, Italian Central Alps. The Holocene, 17(7): 1033-1039.

St-Jean, M., Lauriol, B., Clark, I.D., Lacelle, D., Zdanowicz, C. (2011). Investigation of ice-wedge infilling processes using stable oxygen and hydrogen isotopes, crystallography and occluded gases (O2, N2, Ar). Permafrost and Periglacial Processes, 22: 49-64.

Storey, J., Choate, M., Lee, K. (2014). Landsat 8 operational land imager on-orbit geometric calibration and performance. Remote Sensing, 6(11): 11127-11152.

Strozzi, T., Kääb, A., Frauenfelder, R. (2004). Detecting and quantifying mountain permafrost creep from in situ inventory, space-borne radar interferometry and airborne digital photogrammetry. International Journal of Remote Sensing, 25: 2919-2931.

Taylor, S., Feng, X., Kirchner, J.W., Osterhuber, R., Klaue, B., Renshaw, C. (2001). Isotopic evolution of a seasonal snowpack and its melt. Water Resources Research, 37(3): 759-769.

Tenthorey, G. (1992). Short communication: Perennial névés and the hydrology of rock glaciers. Permafrost and Periglacial Processes, 3: 247-252. 
Tenthorey, G. (1993). Paysage géomorphologique du Haut-Val de Réchy (Valais, Suisse) et hydrologie liée aux glaciers rocheux. PhD thesis, University of Fribourg, Switzerland.

Terzago, S., Cremonini, R., Cassardo, C., Fratianni, S. (2012). Analysis of snow cover precipitation during the period 2000-09 and evaluation of a MSG/SEVIRI snow cover algorithm in SW Italian Alps. Geografia Fisica \& Dinamica Quaternaria, 35: 91-99.

Terzago, S., Fratianni, S., Cremonini, R. (2013). Winter precipitation in Western Italian Alps (1926-2010): trends and connections with the North Atlantic/Arctic Oscillation. Meteorology and Atmospheric Physics, 704: 125-136.

Thies, H., Nickus, U., Tessadri, R., Psenner, R. (2007). Unexpected response of high Alpine Lake waters to climate warming. Environmental Science \& Technology, 41, 7424-7429.

Thies, H., Nickus, U., Tolotti, M., Tessadri, R., Krainer, K. (2013). Evidence of rock glacier melt impacts on water chemistry and diatoms in high mountain streams. Cold Regions Science and Technology, 96: 77-85.

Tolotti, M., Forsstrom, L., Morabito, G., Thaler, B., Stoyneva, M., Cantonati, M., Šiško, M., Lotter, A. (2009). Biogeographical characterisation of phytoplankton assemblages in high altitude, and high latitude European lakes. Advances in Limnology, 62: 55-75. 
Touhari, F., Meddi, M., Mehaiguene, M., Razack, M. (2014). Hydrogeochemical assessment of the Upper Cheliff groundwater (North West Algeria). Environmental Earth Sciences, 73: 3043, doi:10.1007/s12665-014-3598-6.

Ukraintseva, N.G., Streletskaya, K.A., Ermokhina, K.A., Yermakov, S.Y. (2003). Chemical properties of plant-soil permafrost system on landslide slopes, Yamal, Russia. Proceedings of the 8th International Conference on Permafrost.

Unnikrishna, P.V., Kendall, C., McDonnell, J.J. (2002). Isotope variations in a Sierra Nevada snowpack and their relation to meltwater. Journal of Hydrology, 260: 38-57.

Vaccaneo, D., Sambuelli, L., Marini, P., Tascone, R., Orta, R. (2004). Measurement system of complex permittivity of ornamental rocks in $\mathrm{L}$ frequency band. IEEE transaction on geoscience and remote sensing, 42: 2490-2498.

Vasil'chuk, Y.K., Vasil'chuk, A.C. (1998). ${ }^{14} \mathrm{C}$ and ${ }^{18} \mathrm{O}$ in Siberian syngenetic icewedge complexes. Proceedings of the 16 th International ${ }^{14} \mathrm{C}$ Conference, 40(2): 883-893.

Venables, W.N., Ripley, B.D. (2002). Modern Applied Statistics with S. Springer, New York.

Vieira, G., Bockheim, J., Guglielmin, M., Balks, M., Abramov, A.A., Boelhouwers, J., Cannone, N., Ganzert, L., Gilichinsky, D., Goryachkin, S., López-Martínez, J., Meiklejohn, I., Raffi, R., Ramos, M., Schaefer, C., Serrano, E., Simas, F., 
Sletten, R., Wagner, D. (2010). Thermal state of permafrost and active-layer monitoring in the Antarctic: advances during the International Polar Year 20072008. Permafrost and Periglacial Processes, 21: 182-197.

Vithanage, M., Rajapaksha, A.U., Oze, C., Rajakaruna, N., Dissanayake, C.B. (2014). Metal release from serpentine soils in Sri Lanka. Environmental Monitoring and Assessment, 186(6): 3415-3429.

Vittori Antisari, L., Carbone, S., Ferronato, C., Simoni, A., Vianello, G. (2011). Characterization of heavy metals atmospheric deposition for assessment of urban environmental quality in the Bologna city (Italy). EQA - International Journal of Environmental Quality, 7(7): 49-63.

Vonder Mühll, D. (1996). Drilling in alpine permafrost. Norsk Geografisk Tidsskrift, 50: 17-24.

Vonk, J.E., Tank, S.E., Bowden, W.B., Laurion, I., Vincent, W.F., Alekseychik, P., Amyot, M., Billet, M.F., Canário, J., Cory, R.M., Deshpande, B.N., Helbig, M., Jammet, M., Karlsson, J., Larouche, J., MacMillan, G., Rautio, M., Walter Anthony, K.M., Wickland, K.P. (2015). Reviews and syntheses: Effects of permafrost thaw on Arctic aquatic ecosystems. Biogeosciences, 12: 71297167.

Wagner, S. (1990). Ice fabrics and air bubbles. Pilot Analyses of Permfrost Cores from the Active Rock Glacier Murtèl, Piz Corvatsch, Eastern Swiss Alps. Workshop Report, Arbeitsheft VAW/ETHZ 9: 16-22. 
Wagner, S. (1996). DC resistivity and seismic refraction soundings on rock glacier permafrost in northwestern Svalbard. Norsk Geografisk Tidsskrift, 50: 25-36.

Wahrhaftig, C., Cox, A. (1959). Rock glaciers in the Alaska Range. Geological Society of America Bulletin, 70: 383-436.

Walling, D.E., Webb, B.W. (1986). Solutes in river systems. [Ed.] Trudgill, S.T., Solute Processes, John Wiley \& Sons, Chichester, 251-327.

Walter Anthony, K.M., Zimov, S.A., Chanton, J.P., Verbyla, D., Chapin, F.S. (2006). Methane bubbling from Siberian thaw lakes as a positive feedback to climate warming. Nature, 443: 71-75.

Williams, M.W., Knauf, M., Caine, N., Liu, F., Verplanck, P.L. (2006). Geochemistry and source waters of rock glacier outflow, Colorado Front Range. Permafrost and Periglacial Processes, 17(1): 13-33.

Williams, M.W., Knauf, M., Cory, R., Caine, N., Liu, N. (2007). Nitrate content and potential microbial signature of rock glacier outflow, Colorado Front Range. Earth Surface Processes and Landforms, 32: 1032-1047.

Williams, P.J., Smith, M.W. (1989). The frozen earth. Fundamentals of geocryology. Cambridge University Press, Cambridge.

Williamson, C.E., Dodds, W., Kratz, T.K., Palmer, M.A. (2008). Lakes and streams as sentinels of environmental change in terrestrial and atmospheric processes. Frontiers in Ecology and the Environment, 6(5): 247-254.

Woo, M. (2012). Permafrost hydrology. Springer-Verlag Berlin Heidelberg. 
Woo, M., Lewkowicz, A.G., Rouse, W.R. (1992). Response of the Canadian permafrost environment to climatic change. Physical geography: 13, 287-317.

Yershov, E.D., Lebedenko, Y.P. (1991). Water and ion migration of frozen soils in open system. Proceedings of 6th International Symposium on Ground Freezing, 11-15.

Yoshikawa, K. (1998). The groundwater hydraulics of open system pingos. Proceedings of the 7th International Conference on Permafrost.

Yoshikawa, K., Natsagdorj, S., Sharkhuu, A. (2013). Groundwater hydrology and stable isotope analysis of an open-system pingo in Northwestern Mongolia. Permafrost and Periglacial Processes, 24: 175-183.

Yoshikawa, K., White, D., Hinzman, L., Goering, D., Petrone, K., Bolton, W., Ishikawa, N. (2003). Water in permafrost: case study of aufeis and pingo hydrology in discontinuous permafrost. Proceedings of the 8th International Conference on Permafrost.

Zhang, T., Barry, R.G., Knowles, K., Heginbottom, J.A., Brown, J. (1999). Statistics and characteristics of permafrost and ground-ice distribution in the Northern Hemisphere. Polar Geography, 23: 132-154.

Zhang, T., Barry, R.G., Knowles, K., Ling, F., Armstrong, R.L. (2003). Distribution of seasonally and perennially frozen ground in the Northern Hemisphere. Proceedings of the 8th International Conference on Permafrost. 
Zomer, R., Sharma, E. (2009). A need for mountain perspectives: impacts of climate change on ecosystem services in the greater Hindu Kush - Himalaya region. IOP Conference Series: Earth and Environmental Science. 


\section{Appendix}

\section{Additional figures}

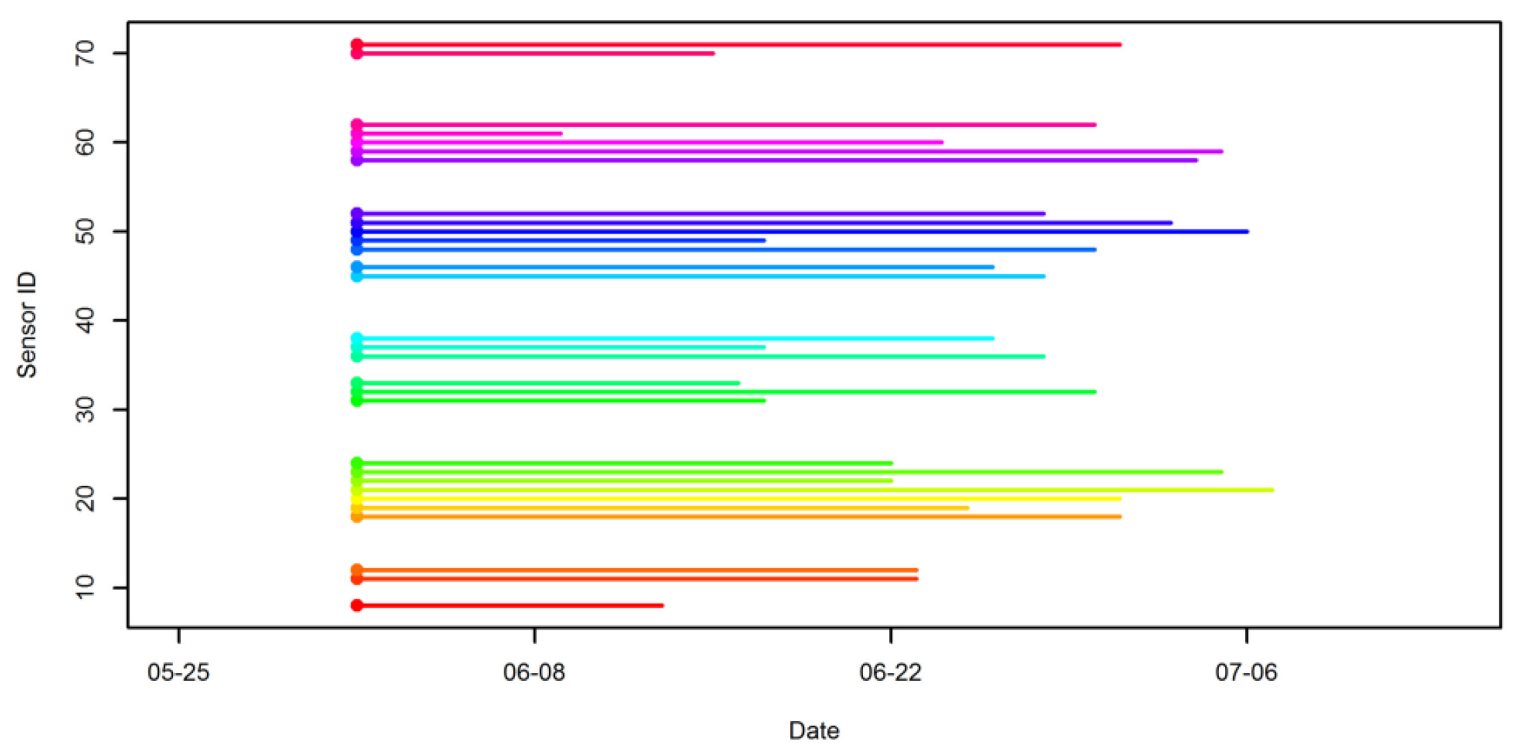

Figure 1 - Snow melt-out date (MD) series. 31 out of 32 available data series (Fig. 4.6.1) were used for the calculation of the snow MD (sensor $n^{\circ} 34$ was not used because of not thermally insulated by snow, which allowed air flowing through the snowpack, preventing the application of the algorithm created by Schmid et al. (2012)). All MD series start from 1 June 2015 when all sensors evidenced snowmelting. 

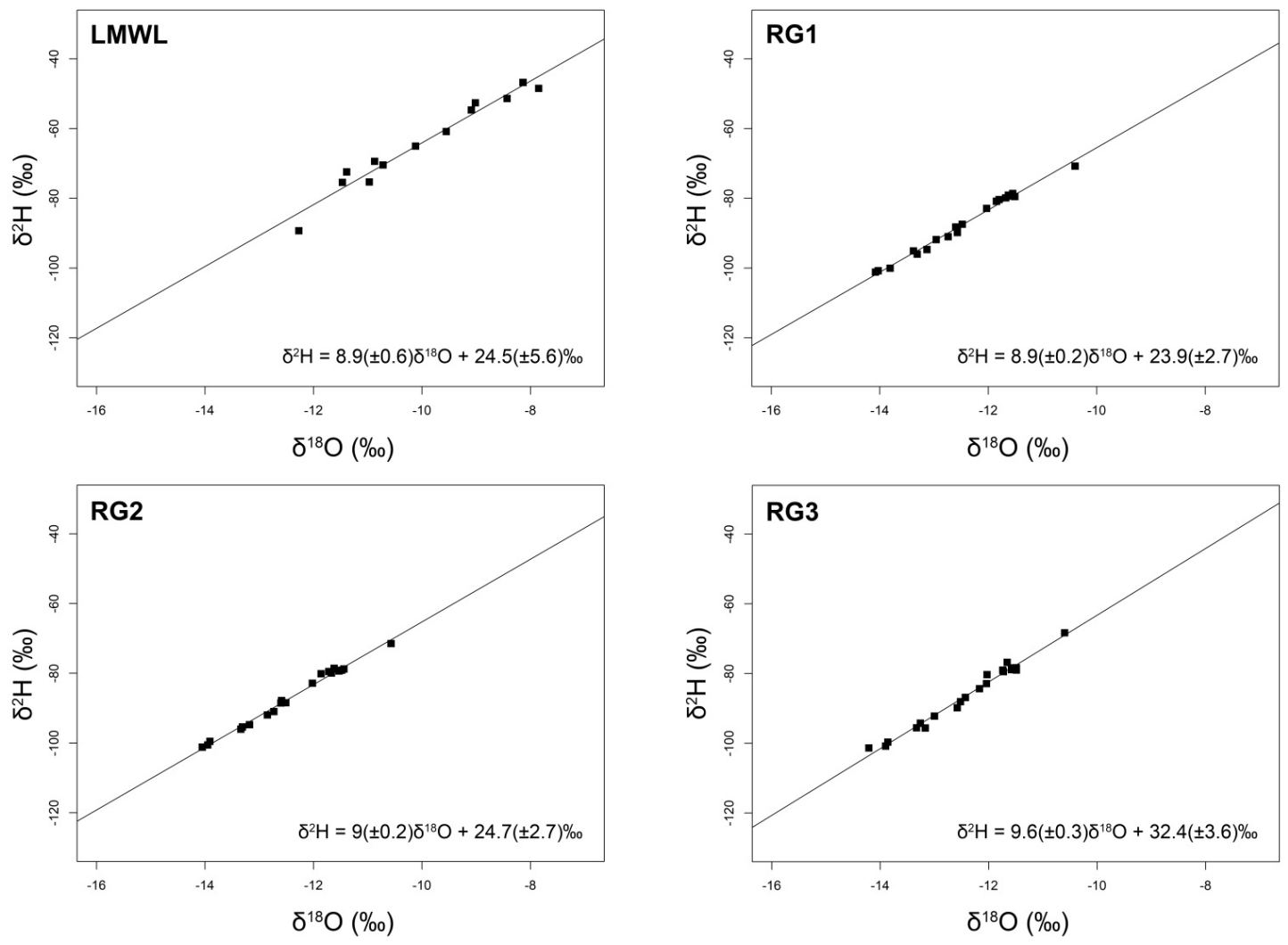

Figure $2-\delta^{2} H-\delta^{18} O$ relationship for the Local Meteoric Water Line (LMWL) and the 3 sampling points in the pond. 


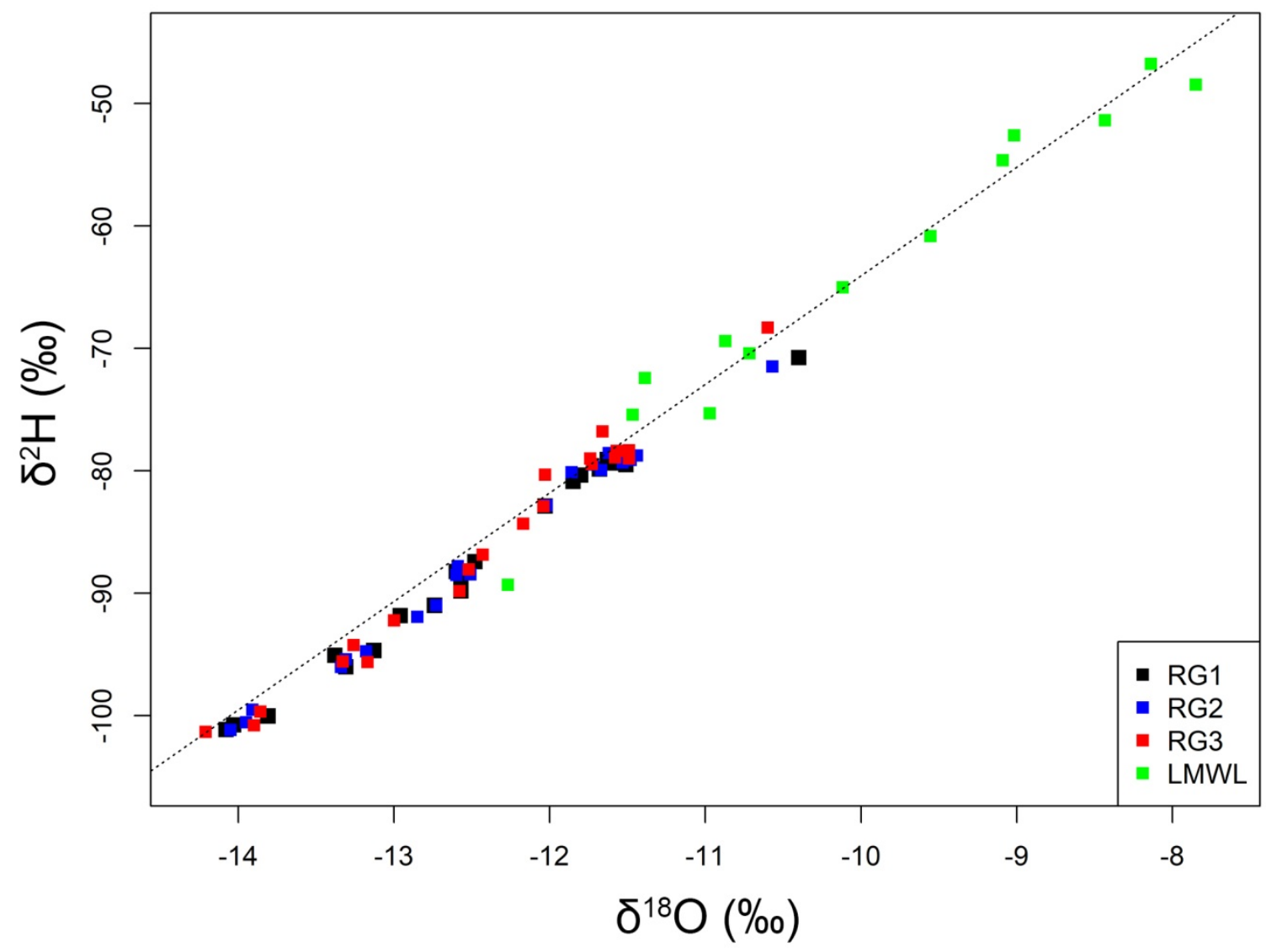

Figure $3-\delta^{2} H$ versus $\delta^{18} \mathrm{O}$ of $L M W L$ (the regression line of the LMWL is reported) and sampling sites in the pond. 